\title{
2 ar.
}

This is an informal report intended primarily for internal or limited external distribution. The opinions and conclusions stated are those of the author and may or may not be those of the laboratory.

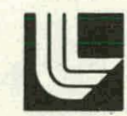

\section{LAWRENCE I.JVERMORE LABORATORY}

University of California/Livermore, California

EXPERIMENTS ON THE BOMBARDMENT

OF METALLIC SURFACES WITH 15-keV DEUTERONS

Angus L. Hunt

Charles C. Damm

Ronald K. Goodman

MS. date: December 4, 1973

NOTICE

This report was prepared as an account of work sponsored by the United States Government. Neither the United States nor the United States Atomic Energy Commission, nor any of their employees, nor any of their subcontractors, or their employees, their contractors, subcontres or implied, or assumes any makes a resility for the accuracy, comlegal liabilty or pleteness or usefulness of any inferents that its use would not infringe privately owned rights. 


\section{DISCLAIMER}

This report was prepared as an account of work sponsored by an agency of the United States Government. Neither the United States Government nor any agency Thereof, nor any of their employees, makes any warranty, express or implied, or assumes any legal liability or responsibility for the accuracy, completeness, or usefulness of any information, apparatus, product, or process disclosed, or represents that its use would not infringe privately owned rights. Reference herein to any specific commercial product, process, or service by trade name, trademark, manufacturer, or otherwise does not necessarily constitute or imply its endorsement, recommendation, or favoring by the United States Government or any agency thereof. The views and opinions of authors expressed herein do not necessarily state or reflect those of the United States Government or any agency thereof. 


\section{DISCLAIMER}

Portions of this document may be illegible in electronic image products. Images are produced from the best available original document. 


\section{THIS PAGE}

\section{WAS INTENTIONALLY LEFT BLANK}




\section{PREFACE}

These data were taken in the period 1962-1964 in support of the high-energy plasma experiments in the Livermore controlled thermonuclear program. The distribution of this work at this late date (1973) certainly requires some explanation.

This report was assembled from experimental data at the request of A. E. Ruark, Director of Controlled Thermonuclear Research, AEC, and transmitted to him in rough draft form in 1964. This draft was passed to A. S. Bishop when he assumed directorship and through the directorship of Roy Gould to the hands of B. J. Eastlund and F. R. Scott of the present DCTR-AEC staff.

The fact that this report did not fall into a circular file during this time is remarkable. It was not issued as a regular Livermore report under the pressure of events and not funded further because of budgetary limitations, but the results were discussed at Plasma Physics Divisional Meetings of the American Physical Society. The results were common knowledge at Livermore, and were incorporated in the design and operation of the mirror and beam experiments. Because of a recent extension of interest in the impurity problem in toroidal systems and the addition of new personnel, the DCTR-AEC has suggested the authors provide for a larger distribution of this information. No attempt to rewrite the material has been made. The reader will find the detailed discussion of mass spectrometric results very difficult to follow at times, but the figures are helpful in these circumstances. 


\section{CONTENTS}

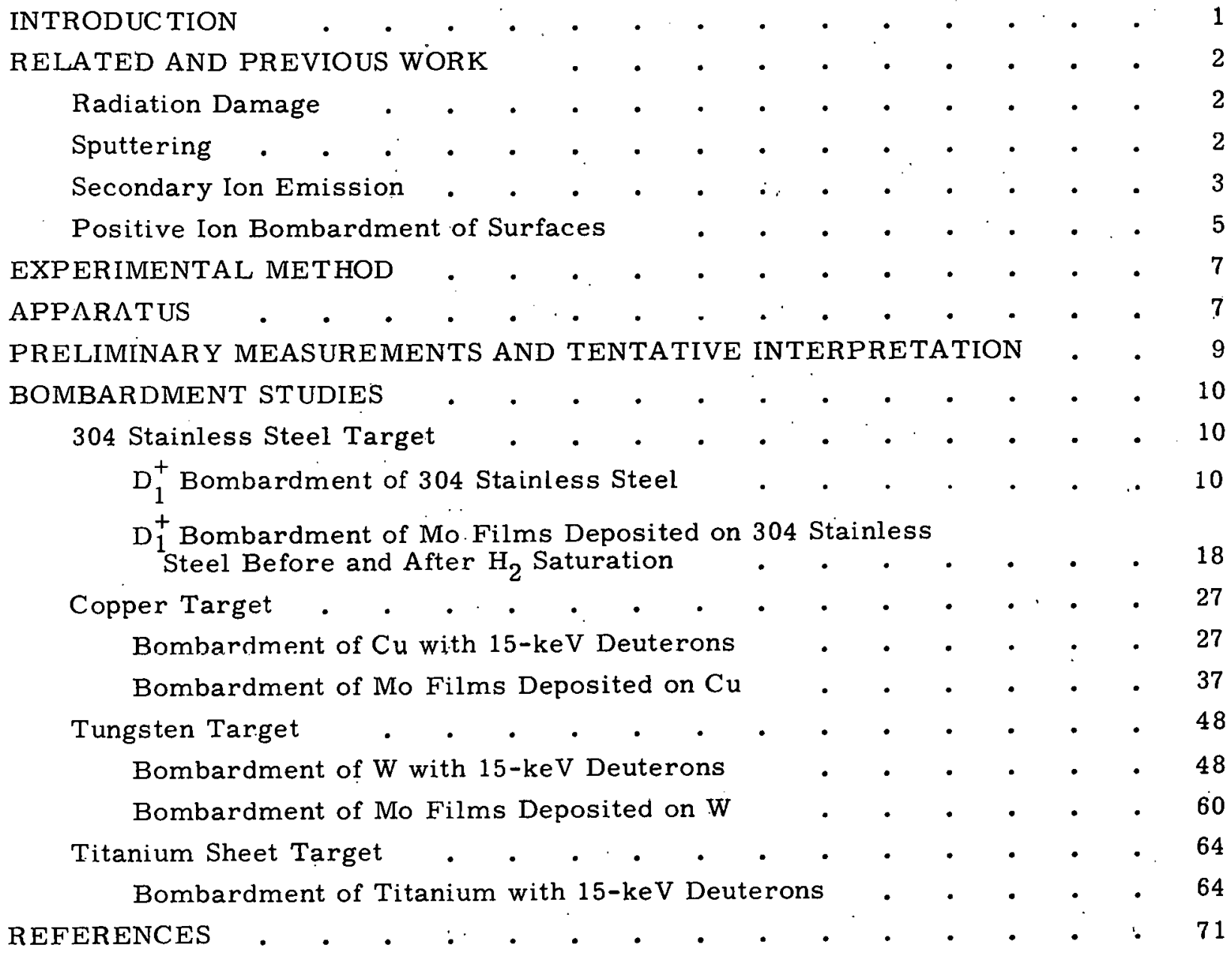




\section{EXPERIMENTS ON THE BOMBARDMENT \\ OF METALLIC SURFACES WITH 15-keV DEUTERONS}

\section{INTRODUCTION}

Current efforts toward the development of controlled thermonuclear energy sources are centralized about attaining high-temperature, high-density deuterium plasmas within various magnetic field configurations. Viewed in a simple way, there are three important parameters which must be controlled or maximized: (1) the energies of the plasma ions and electrons, (2) the density of the plasma, and (3) the period of stable plasma confinement within the magnetic field.

All three factors - temperature, density and containment time-are directly influenced by the plasma purity. A pure plasma will be defined here as consisting of only protons or deuterons and associated electrons." The energy can be radiated as impurity radiation, ${ }^{1}$ and the density as well as the energy can be limited by chargeexchange processes with neutral gas. ${ }^{2}$ The stability of a plasma within one magnetic field configuration has been shown to be directly dependent on plasma purity. ${ }^{3}$ In addition, to attribute plasma density limitations and plasma losses to cooperative phenomena, it has been found experimentally necessary in our plasma experiments to separate such cooperative losses from charge-exchange losses by reducing the residual contamination to a minimum.

It is recognized that energetic neutral atoms impinge upon the vacuum walls after their escape from the magnetic confinement and contaminate the plasma with sputtered material from the wall surfaces. ${ }^{4,5}$ In previous work the sputtered contamination was thought to be only the metallic atoms from the wall. 4,5 It has been shown that the sputtered heavy metal yield from light ionic or atomic bombardment can present a serious problem under adverse conditions but that the sputtering yield is in general small ${ }^{5}$; so this source of contamination has been generally ignored in the design of low-density, energetic plasma experiments.

As will be described in detail later in this paper, it has been found that the gas sputtering, or evolution of nonmetallic surface contamination from the vacuum wall surfaces during bombardment can be much larger in yield. It was the objective of this experimental investigation to ascertain the magnitude and composition of this gaseous evolution under energetic particle bombardment as well as to examine the effect of wall composition, wall temperature, and vacuum technique of the reemission or sorption of the incident particle flux. 


\section{RELATED AND PREVIOUS WORK}

The first part of this paper will be a short review of some of the existing literature on the interaction of energetic particles with solids. Where the relationship of this literature to the problem of plasma purity is not obvious, we will attempt to relate the phenomenon under discussion to plasma experiments by brief interpretive comments. Since each plasma experiment has particular aspects only completely understood by those working directly on the experiments, interpretive comments by these authors may be neither representative nor complete.

The previous work on interaction of energetic particles with solids is extensive and dispersed throughout the literature under the subject headings of sputtering, radiation damage, secondary ion emission, and ultrahigh vacuum. The evolution of gases from surfaces or from the bulk structure of materials may be found in the iiterature on surface physics and chemistry, high-vacuum technique, solubility and diffusion of gases in metals, catalysis, metal physics, and,physical electronics.

\section{Radiation Damage}

The general field of radiation damage has been discussed in some detail by Billington and Crawford, ${ }^{6}$ and more recently in an excellent short review by Seitz, ${ }^{7}$ as well as in a comprehensive set of papers edited by Billington. ${ }^{8}$ Most of the major works on radiation damage have been concerned with the production of defects and dislocations in the solid due to the impingement of electrons, deuterons or protons, and neutrons. Changes in the bulk properties have been of major interest, and so the incident particles have been of very high energy. These studies will be of primary interest when large fluxes of fusion products are encountered. However, some ion sources presently in use inflict radiative damage on targets, collimators, and on source components, thus limiting lifetime and reliability. The degree to which this damage is significant would appear to depend upon the particular source and mode of operation as well as on the lifetime and reliability required. The possibly more important changes in surface properties due to solid defects produced by integrated radiation damage are equally difficult to assess.

\section{Sputtering}

The ejection of the surface atoms of the bulk target structure, known as sputtering, is a gross type of radiation damage which also occurs for low-energy incident particles. The early sputtering work is reviewed by IMassey and Burhop 9 and the later theory by Harrison, ${ }^{10-12}$. while the recent experimental work is largely due to Wehner and coworkers. $13-26$

The theory of sputtering by high-speed ions, that is, above $50 \mathrm{keV}$, has been treated as a simplified case by Goldman and Simon. ${ }^{27}$ The problem of the theoretical 
prediction of the observed sputtering thresholds and an attempt to theoretically define the threshold in terms of sputtering models is considered by Harrison and Magnuson. ${ }^{28}$ Henschke has theoretically treated the phenomena of ejection patterns, sputtering thresholds and periodicity of yield with atomic number. 29

Additional sputtering data obtained by using ion beams are given by $\mathrm{Poppa}^{30}$ and by Yonts et al. ${ }^{31}$ Some interesting results are reported by Pleshivtsev on the sputtering of copper by hydrogen ions with energies to $50 \mathrm{keV}$ as a function of incident angle. ${ }^{32}$ Silver has been sputtered with neutral beams of hydrogen and helium by Weiss et al. ${ }^{33}$ with results that are interpreted as a difference in the sputtering yield for ions and neutrals of the same species. It is possible an undetected surface chemical reaction on silver was responsible for these results, or that the surface had an adsorbed gas layer as suggested by Yonts et al. ${ }^{31}$ It is not now believed that there is a large difference between the simple sputtering yields for ions and neutrals of the same species. ${ }^{34}$ A precise study of the sputtering of silver by light ions with energies from 2-12 keV with a conventional interpretation has been subsequently made by Gronlund and Moore. ${ }^{35}$ The importance of measuring the sputtering yield from only clean surfaces at low pressures has been emphasized by Yonts and Harrison.

Hydrogen and deuterium molecular ions as well as inert gas ions have been used to produce direct structural displacements near the surface of vitreous silica and quartz $^{36}$ and of glass ${ }^{37}$ in the energy range 7.5-59 keV, but no observations on sputtered yields were reported.

For the case of a visionary thermonuclear reactor, the sputtering problems are discussed by Cranston et al. ${ }^{4}$ and by Robson and Hancox. ${ }^{5}$ Additional theoretical considerations by Pease 38 provide a guide for estimating the sputtering yield for highenergy light ions and the effect of sputtered substrate products on the high-temperature plasma.

As generally executed most sputtering experiments do not record the sputtered gas flux, so this phenomenon has not received theoretical attention. However, it seems necessary that a complete sputtering theory include a description of the mechanism of sputtering adsorbed gas films if such a theory is to be considered generally applicable.

\section{Secondary Ion Emission}

The literature on secondary ion emission from surfaces may indicate the expected return flux from light-ion-bombarded plasma boundaries. It should be emphasized that the primary ion emission from the boundary can have no adverse effect on a plasma since the coexistent magnetic field, if parallel to this boundary, will direct such low-energy charged particles to the wall of the plasma chamber. However, these ions may become neutral after they strike the chamber walls, and subsequently may enter the plasma region. It is also possible, under some experimental conditions, for low-energy secondary ions to return to the plasma by moving along the magnetic flux lines if these lines intercept the wall. Secondary ion emission may also be a measure 
of the secondary neutral emission from the surface. One of the few direct observations on the secondary neutral emission was made during experiments designed for secondary ion emission measurements. 39

Bills ${ }^{40}$ found that positive ion currents could be thermally desorbed from Ta, W, and Mo surfaces, even several days after bombardment of the gas covered the surface with low-energy positive nitrogen ions or electrons. No such currents were found if the surface had not been bombarded. The ions were not identified in this work. It was not reported whether a large neutral emission was associated with this positive ion emission. The energy of bombardment was 100-200 eV. This interesting effect has been confirmed by Riddoch and Leck. ${ }^{41}$

With the work of Honig ${ }^{42,43}$ and Bradley ${ }^{39}$ on secondary positive ion emission from metal surfaces, the experimental apparatus reached a degree of sophistication and complexity which made it possible to observe the neutral secondary emission during bombardment with positive inert gas ions of less than $1 \mathrm{keV}$. Because of initial design failure, Bradley ${ }^{30}$ was not able to analyze the neutral emission, although he stated that "these are without doubt much more abundant than the ions." He found the ion yield to be about $0.01 \%$ of the total sputtering yield for platinum, but the relative value of the sputtering and neutral emission in this experiment was not determined.

In a more recent paper, Bradley et al. ${ }^{44}$ improved the experimental technique and were able to measure the ratio of sputtered $\mathrm{Pt}$ ions to sputtered $\mathrm{Pt}$ neutrals and found the ratio to be $1: 1000$. Bulk impurities in the form of the alkali metal ions, Li, $\mathrm{Na}, \mathrm{K}$, and $\mathrm{Ca}$ were detected as ions, but not as neutrals. Their activation energies for volume diffusion and desorption were reported in a separate paper. ${ }^{45}$

Bradley et al. ${ }^{44^{\circ}}$ found $\mathrm{H}_{2} \mathrm{O}, \mathrm{O}_{2}$, and $\mathrm{CO}_{2}$ sputtered from the $\mathrm{Pt}$ surface as neutrals only, while $\mathrm{C}, \mathrm{N}, \mathrm{O}, \mathrm{CO}, \mathrm{N}_{2}, \mathrm{Pt}, \mathrm{A}$ or Xe were sputtered from the surface as ions and neutrals during bombardment with $\mathrm{A}$ or Xe ions. Because the gas evolved under bombardment had the same mass spectrometric composition as the background gaș, they concluded that these gases were surface rather than bulk impurities. The bulk impurities ( $\mathrm{Pb}$ and $\mathrm{Zn}$ ) known to be present in concentrations to $0.02 \%$ could not be detected. However, alkali metal impurities $(0.001 \%)$ were sputtered. Following inert ion bombardment, inert gas was released from the surface by heating to $1300^{\circ} \mathrm{C}$. The activation energy for this release was found to be $1.6 \pm 0.2 \mathrm{eV}$.

Ruedl and Bradley ${ }^{46}$ have recently made a study of particles sputtered and/or evaporated from the (221) plane of a high-purity, single-crystal copper surface. Although they were able to thermally desorb neutral $\mathrm{CO}$ from the $\mathrm{Cu}$ surface, they were not able to find $\mathrm{CO}$ neutrals desorbed during bombardment. However, the $\mathrm{CO}^{+}$ ion was desorbed during the bombardment with $\mathrm{A}^{+}$ions. This is difficult to explain on the basis of the Saha-Langmuir equation, for if the ionization potential were less than the work function of the surface, thermal evaporation of $\mathrm{CO}^{+}$would be expected. It is possible that the absence of $\mathrm{CO}$ neutrals from the surface during bombardment is simply indicative of a reduced sensitivity of the mass spectrometer due to the large argon peak or some other causc. 
An unusual statement appears in the publication of Ruedl and Bradley 47 "No gases, either neutral or charged, could be detected by heating the copper sample to $650^{\circ} \mathrm{C}$ except after periods of ion bombardment." This apparently means that the $\mathrm{Cu}$ surface and the $\mathrm{Cu}$ block on which it was mounted were exceptionally free of desorbable gas and that the sputtered gas $\left(\mathrm{CO}^{+}\right)$was adsorbed on the surface during the sputtering process or because of the bombardment.

It is possible that the results were due to $\mathrm{CO}^{+}$ions driven into surface with $\mathrm{A}^{+}$ ions or $\mathrm{CO}$ adsorbed on the clean, highly damaged sputtered $\mathrm{Cu}$ surface, but not on an annealed and perhaps somewhat contaminated surface.

\section{Positive Ion Bombardment of Surfaces}

In a pioneer work (1056), Leck bombarded surfaces of $\mathrm{Ni}, \mathrm{W}, \Lambda \mathrm{l}$, and Mo with positive ions of $\mathrm{He}, \mathrm{Ne}, \mathrm{A}, \mathrm{Kr}, \mathrm{H}_{2}, \mathrm{~N}_{2}, \mathrm{O}_{2}$, and $\mathrm{CO}_{2} \cdot{ }^{48,49}$ The ions were driven into the surfaces by a Penning-type discharge, so only the maximum energies of the ions were reported. Leck found that at energies over a few $100 \mathrm{eV}$, all ions were "adsorbed" and found no difference between ions of $\mathrm{N}_{2}, \mathrm{Ne}$, and $\mathrm{O}_{2}$, so concluded that a physical process was involved. Leck also found that the gases were held in the lattice at room temperature, but moved at $700-800^{\circ} \mathrm{K}$ to the surface and desorbed quickly. It was also shown that ions lost in the surface by one bombardment can be removed by bombardment with another ion.

This early work may be viewed critically as there was no mass separation and no known eharge state for incident particles, as well as no mass separation of the released gas until the gas had impinged upon the walls of the manifold. The phenomenon was interpreted as "adsorption" when burial in the surface or solid solution in the target possibly would have been the more appropriate term.

The emission of neutrals as well as positive and negative ions from $\mathrm{Ag}, \mathrm{Ge}$, and a Ge-Si alloy has been reported by Honig. ${ }^{42,43}$. The bombarding energies for the heavy inert ions $\left(\mathrm{Xe}^{+}, \mathrm{Kr}^{+}, \mathrm{A}^{+}\right)$were known with some precision in the energy range 30 to $400 \mathrm{eV}$. Honig was able to analyze by mass spectrometry the impurity evolution from the surface. He found $\mathrm{H}_{2} \mathrm{O}, \mathrm{CO}, \mathrm{CO}_{2}$, hydrociarbons and $\mathrm{Hg}$ in large concentrations relative to the ions produced. Ailthough at that time (1958) he was unable to report on the results for clean surfaces or surfaces in ultrahigh vacuum, the neutral gas evolved was very similar in composition to that found in the present work under hopefully better conditions.

The evolution of neutral gases from surfaces under ionic or atomic impact may be viewed as a subcase of the sputtering or impact evaporation problem. The experimental conditions required for quantitative study of the cathode sputtering or impact evaporation mechanism and the conditions for study of neutral gas evolution under ionic or atomic impact are so similar that the following list of experimental conditions is quoted directly from a published review of the cathode sputtering problem. 50 
"1. The energetic particles striking the target should have a uniform known velocity.

2. All particles should strike the target from the same direction.

3. The composition of the beam should be known; preferably it should contain only one species.

4. The target surface should be pure and crystallographically and morphologically well defined.

5. An accurate measurement of incident particle flux and vacuum conditions at the target is essential. The beam diameter should be a minimum.

6. The emitted particles should be unable to return to the target.

7. The direction of particles leaving the target should be measured.

8. The identity and energy distribution of particles leaving the target should be determined.

9. The temperature of the target should be known."

To this list can be added the condition that the charge state of the incident and emitted particles should be known or measured. It is practically impossible, at this time, to meet all these experimental conditions in a single experiment. For example, the reproducibility of target surface conditions must represent a major effort.

A short review on positive ion impact with surfaces has been given by Redhead et al. ${ }^{51}$ from the viewpoint of the effects important to ultrahigh vacuum technique.

Experiments on the range and the related energy loss rate of the incident particle in the target material as well as scattering experiments in very thin foils may give some insight into the mechanism of the desorption process under atomic bombardment in the energy interval from $10^{3}$ to $10^{5} \mathrm{eV}$. Although no experimental data are available concerning the desorbed species from experiments of this type, it is known that the charge state of the transmitted beam depends critically on the surface conditions on the exit side of a metallic foil. ${ }^{52}$. A short review of the literature on hydrogen beams charge-exchanging in metallic foils exists for the energy range of interest here. ${ }^{53}$ Among the early literature cited are the measurements by Warshaw on the stopping power of protons in several metals. ${ }^{54}$ The instrumentation used in the cross-section measurements below $120 \mathrm{keV}$ by Arnold et al. ${ }^{55}$ is of interest. Experimental work on ranges has becn reviewcd by Allison and Warshaw. ${ }^{56}$ The ranges of $5-$ to $27-\mathrm{keV}$ deuterons in $\mathrm{Al}, \mathrm{Cu}$, and $\mathrm{Au}$ have recently been measured by Hines, 57 and interpreted by him in terms of the theoretical work on energy dissipation by ions in the keV energy range by Lindhard and Scharff. 58

Perhaps the most relevant work from the viewpoint of controlled thermonuclear research on the interaction of charged and neutral particles with solid surfaces has been published only in summary form by a group at the Kurchatov Institute of Atomic Energy, Moscow, USSR. ${ }^{59}$ Although much experimental detail are not available, the general result is partially confirmed in the bombardment experiments to be described. The workers at the Kurchatov Institute were able to detect reflected beams of deuterium atoms at energies to several tens of electron volts, but in other respects our 
work confirms their results and extends it to target temperature from room temperature to liquid nitrogen temperatures. In our last work (1964) we detected a small percentage of very high-energy ions (reflected) at energies approaching the beam energy.

\section{EXPERIMENTAL METHOD}

We developed an ultrahigh vacuum apparatus for bombarding a target of representative wall material with beams of hydrogen or deuterium atoms. The mass spectra and pressure histories of the gases evolved from the target surface were observed as functions of target temperature, the energy and flux density of the bombarding particles, and the composition of the residual gases surrounding the target.

The beam of hydrogen or deuterium atoms entered a target chamber of known volume through an orifice, striking a target of known temperature. The target chamber contained a mass spectrometer and two ionization gauges. During bombardment, the target chamber was evacuated at a known rate so the pressure rise would be a measure of the total gas evolved from the target surface while the mass spectrometer determined the gas composition.

To differentiate the pressure rise due to the bombarding particles from that due to hydrogen contamination, we used a deuteron beam rather than a proton beam. The mass spectromeler could then monitor the partial prcssure of the deuterium in the target chamber as a function of time to distinguish the beam-associated gas from the hydrogen evolved from the surface due to impingement of the beam.

\section{APPARATUS}

The apparatus, as schematically shown in Fig. 1, consisted of a small von Ardenne source, followed by a $30^{\circ}$ bending magnet for mass separation and an electrostatic lens system. The bcam then entered a water-vapor neutralizer. After leaving the neutralizer, the beam passed through three stages of differential pumping (Mo-1, Mo-2, Mo-3), with collimating orifices between each stage, before entering the target chamber which included a pressure gauge (P) and a mass spectrometer (M-S). A beam of charged particles could be used if the water vapor was removed from the neutralizer. The source and electrostatic. lens system were pumped by sublimed titanium deposits. The water vapor neutralizer was pumped by a liquid nitrogen trapping system, and the three stages of differential pumping were provided by water-cooled and liquid-nitrogencooled evaporated molybdenum films. The target was pumped by the third stage of differential pumping through the beam input orifice. In spite of this very limited conductance to the pumps, it was found to be possible to obtain pressures in the target chamber as low as $10^{-9} \mathrm{~mm} \mathrm{Hg}$ by baking only the target chamber. 


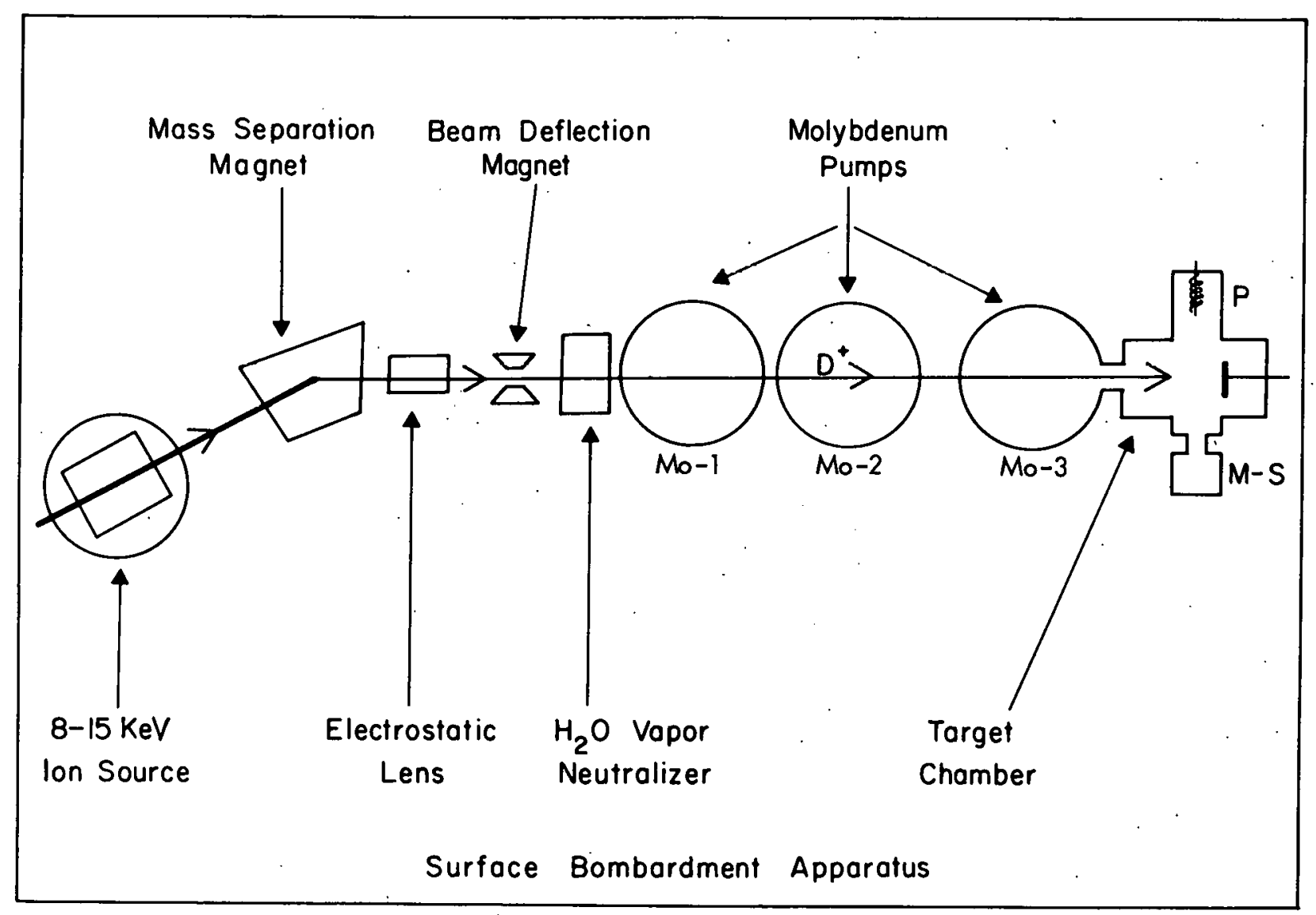

Fig. 1. Schematic of experimental apparatus. 
In the first experiments, proton beams of energies 7.5 to $16 \mathrm{keV}$ and current densities of from 1 to $5 \mu \mathrm{A} / \mathrm{cm}^{2}$ were directed normally on a 304 stainless steel target which had been previously baked under vacuum to $400{ }^{\circ} \mathrm{C}$ as in the usual bakeout procedure. The ratio of the number of desorbed particles to the number of incident particles measured in terms of a total pressure increase due solely to $H$ was highly variable and depended on the duration of the bombardment period, but it was not unusual to observe ratios of five. If only the target was heated to about $200^{\circ} \mathrm{C}$, the ratio could be reduced to less than unity; but after this target had cooled, the ratio of emitted particles to incident particles slowly increased with time. For an unbaked surface, the ratio of emitted particle to incident particle exceeded 10. It was evident from these preliminary results that the interaction of energetic particles with the vacuum chamber surface could be a dominant factor in maintaining plasma purity in controlled thermonuclear research.

Because of the implications of this result, additional experiments were performed to ascertain the nature of the interaction of the 304 stainless steel surface with a $\mathrm{D}^{+}$beam. The use of a charged beam eliminated uncertainties in measuring the total beam current by calorimetry or the secondary electron emission method. It is true. that the geometry of the experiment allowed a small fraction of the charged beam to become neutral in the relatively high-pressure beam-focusing section. This neutral component is incident on the target, and is not measurable by this method.

The data are consistent with the following qualitative model for energetic protons or deuterons normally incident on a stainless steel surface. The incident particle is not reflected from the surface, but is buried within the surface. The thermal spike associated with the loss of kinetic energy within a few thousand angstroms of the surface ${ }^{60}$ desorbs loosely bound surface contamination. Under continued bombardment, the increase in the concentration of buried particles will result in diffusion of these particles to the surface of the stainless steel where they desorb as molecular hydrogen or deuterium. The general observations which support this interpretation are as follows:

Initially, the target retains all of the incident $\mathrm{D}^{+}$beam, with the $\mathrm{D}_{2}$ in the gas phase increasing only slowly with continued bombardment. The concentration of $\mathrm{D}_{2}$ in the gas phase increases with target temperature and with beam current. $\mathrm{D}_{2}$ is desorbed from the stainless steel target jetween $65^{\circ} \mathrm{C}$ and $150^{\circ} \mathrm{C}$ as the target is rapidly heated after a period of bombardment. The pressure rise which occurs in times less than $10 \mathrm{sec}$, as measured from the time the $\mathrm{D}^{+}$beam initially strikes the target, is due to desorbed contamination and not to $\mathrm{D}_{2}$.

The $\mathrm{D}_{2}$ is accumulated in the bulk of the target, for the cold target surfaces rave been saturated with a high residual partial pressure of $\mathrm{H}_{2}$ which would interfere with $\mathrm{D}_{2}$ adsorption on the surface. Further, more than monolayer amounts of $\mathrm{D}_{2}$ could ie accumulated on a room-temperature target, if it is assumed that $10^{15}$ molecules $/ \mathrm{cm}^{2}$ 
constitutes a monolayer surface density. Supporting evidence for the accumulation of $\mathrm{D}$ or $\mathrm{D}_{2}$ in the bulk.structure and not on the surface was obtained by measuring the secondary electron emission coefficient as a function of the duration of bombardment. The secondary electron emission coefficient was independent of the duration of bombardment but not independent of surface contamination, as a higher coefficient was obtained for an aged, cold target.

These studies indicated that the best vacuum wall condition for a plasma experiment might be an atomically clean metallic surface at very low temperature. Such a wall would trap the buried hydrogen or deuterium atoms because of their low diffusion rate at low temperatures, and it would not have a loosely bound gas layer to be desorbed by the energy loss of the incident particle in the metallic structure.

\section{BOMBARDMENT STUDIES}

\section{Stainless Steel Target}

$\underline{D}_{1}^{+}$Bombardment of 304 Stainless Steel

A new target was constructed as shown in Figs. 2, 3, and 4 which could be cooled with liquid nitrogen. With this assembly it was possible to evaporate films of molybdenum onto the target, although it did not prove possible to confine the evaporated film solely to the target surface.

As part of the bakeout procedure for the target chamber, the internal tungsten target heaters were operated and the target was then cooled to $22^{\circ} \mathrm{C}$ and bombarded for 10 min by a beam of deuterons. The deuterium concentration in the gas phase was monitored as a function of bombardment time. After the bombardment, the target was again heated with the tungsten heaters and the rate of deuterium evolution was recorded as a function of time and temperature. The target was again cooled to about the same temperature $\left(30^{\circ} \mathrm{C}\right)$ and the procedure was repeated. After again desorbing the deuterium by heating, the target was cooled to liquid nitrogen temperature and bombarded for 10 min during which time the deuterium evolved was monitored. After bombardment, the target was again heated and the deuterium evolved was recorded.

The following procedure was used to determine the effect of cooling on the bombardment-induced changes in the magnitudes of the other mass numbers $(2,12,14$ and 28): The target was heated to remove the residual deuterium. After cooling to room temperature, it was bombarded with the beam and the increase in a selected mass number was recorded as a function of time. The target was then cooled with liquid nitrogen, and the increase in the same component or mass peak was recorded during bombardment. The target was then heated to remove the residual deuterium and the procedure was repeated for another mass number. It was found that the rate 


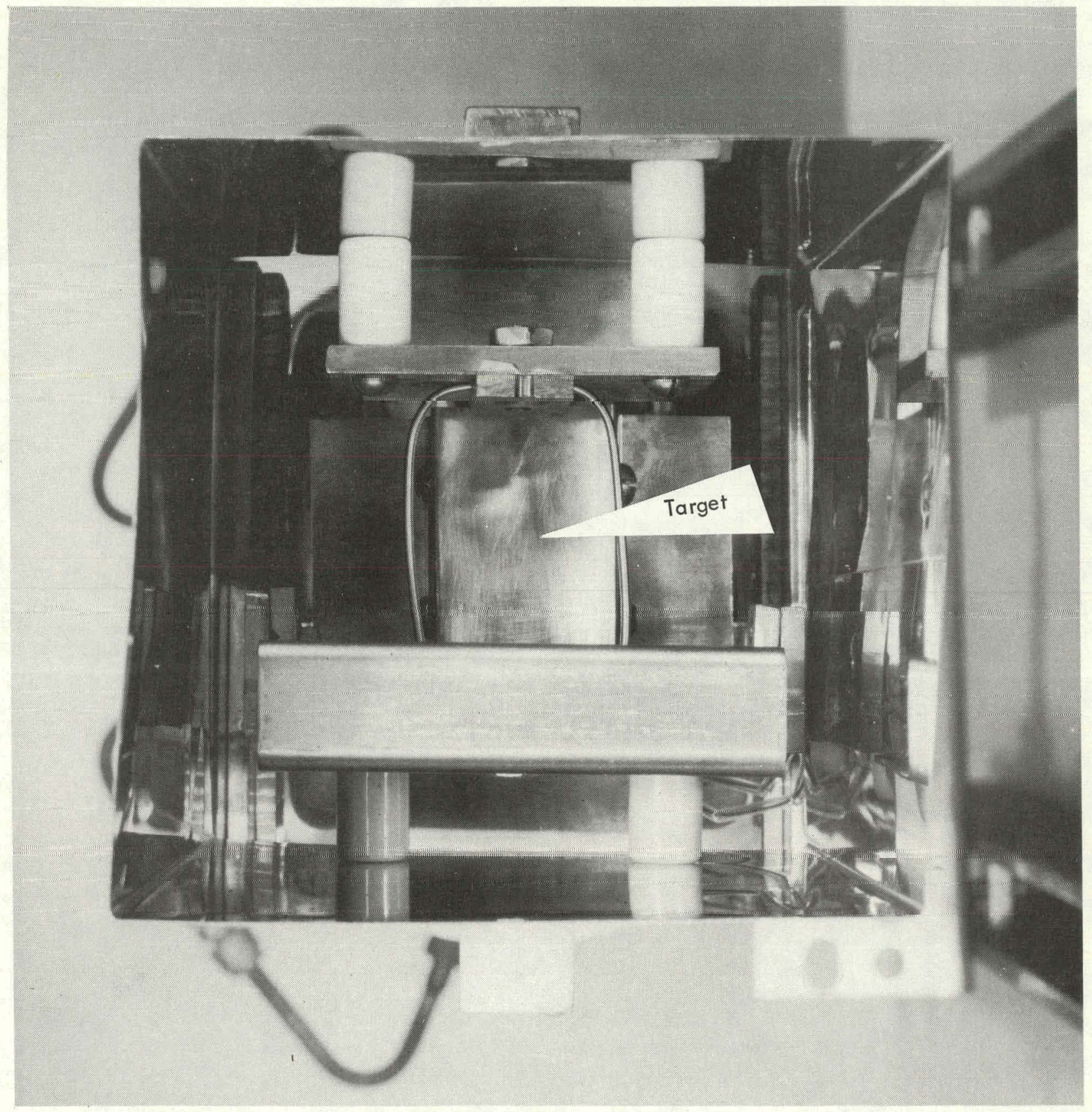

Fig. 2. Target construction. 


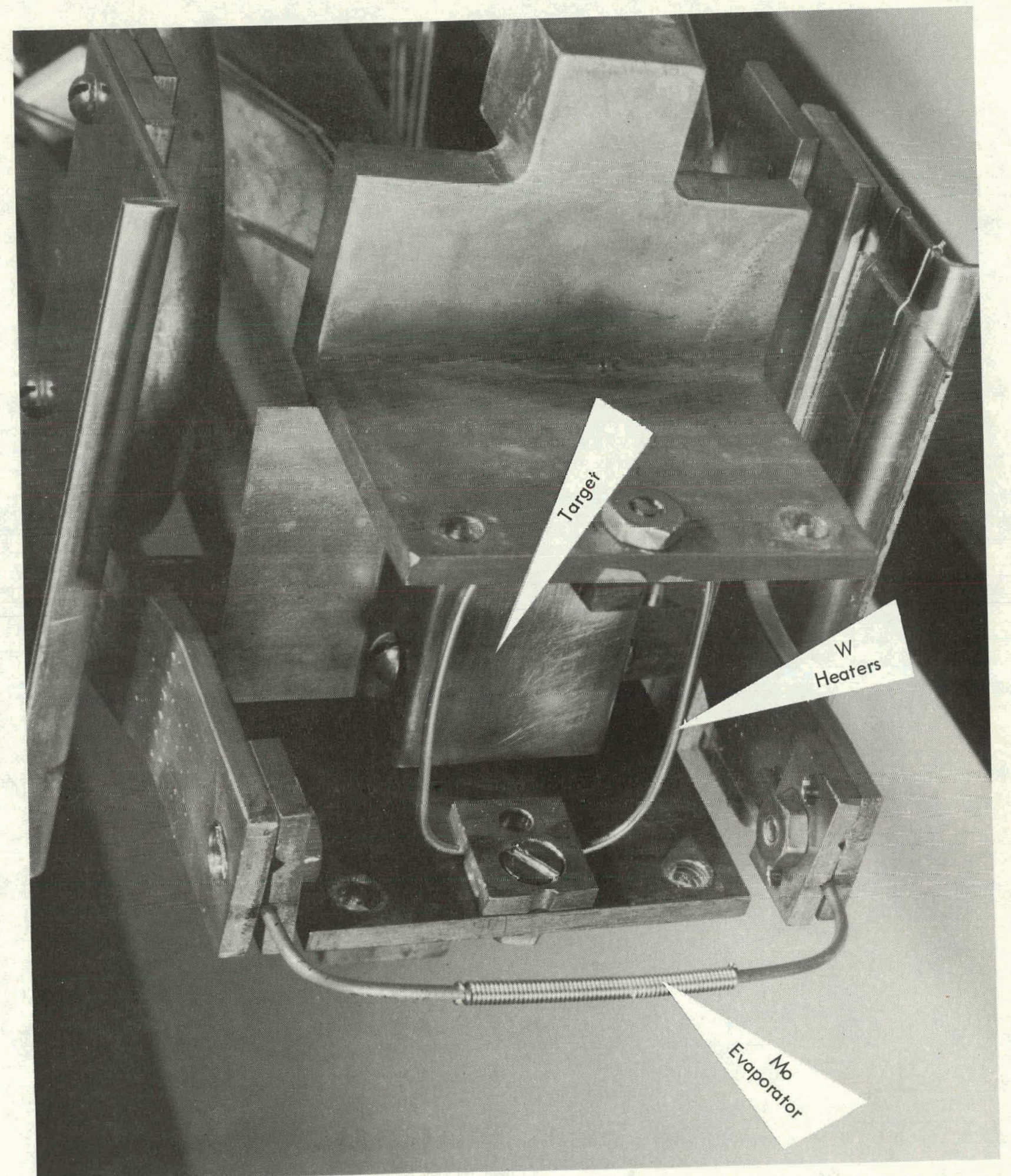

Fig. 3. Target construction. 


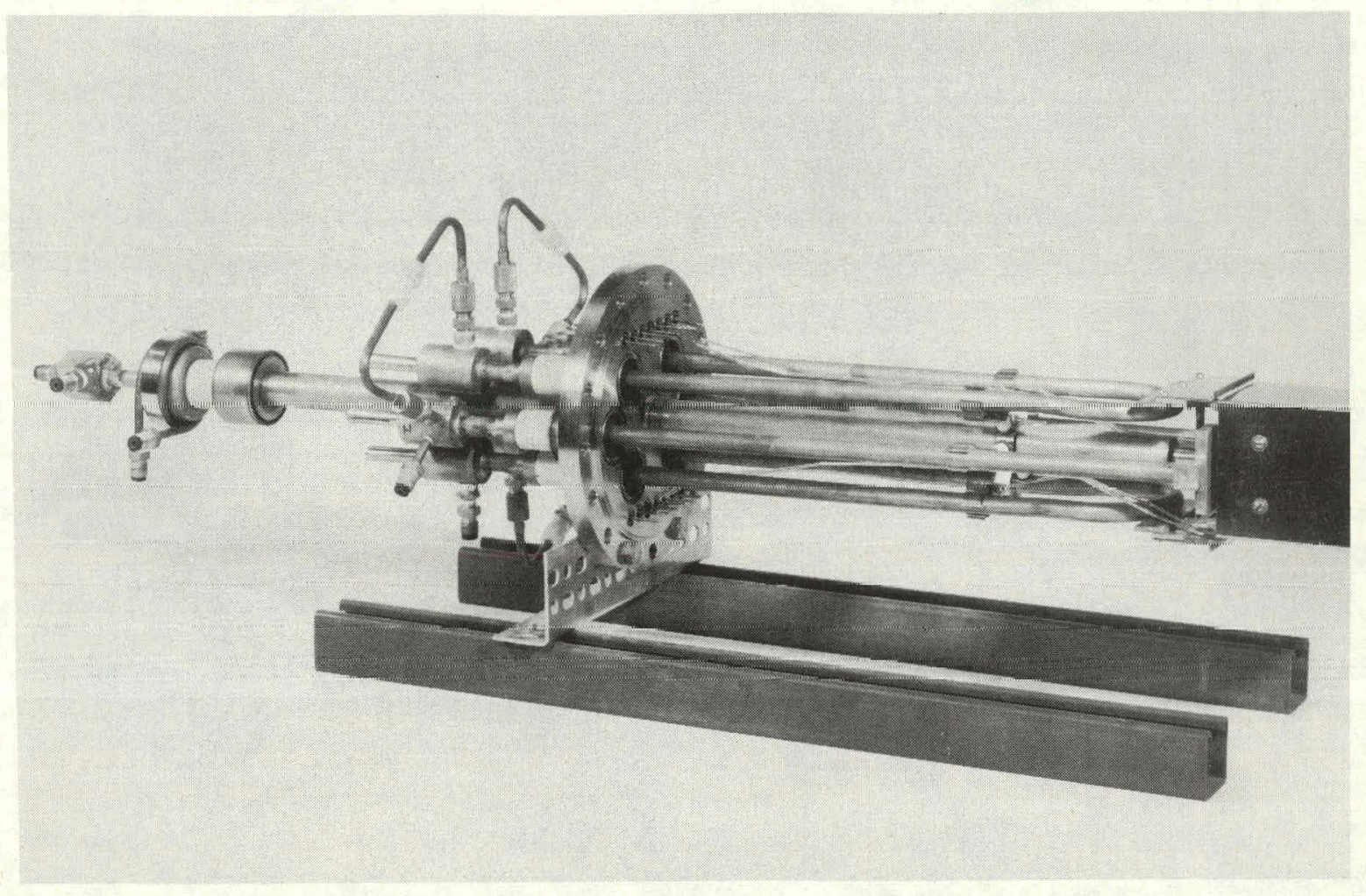

Fig. 4. Target assembly. 
of rise for a given component was characteristic of that component, and was small in magnitude when the target was cold.

To confirm the observations with respect to deuterium in the gas phase during bombardment of the cold target, the target was heated to $180^{\circ} \mathrm{C}$ after bombardment at $22^{\circ} \mathrm{C}$. It was immediately cooled with liquid nitrogen and the deuterium in the gas phase was followed during bombardment. The rate of deuterium evolution was then recorded as the temperature of the target was increased to $18^{\circ} \mathrm{C}$.

\section{Results and Discussion}

The deuterium concentration in the gas phase during bombardment of the

$22^{\circ} \mathrm{C}$ stainless steel target with $13-\mathrm{keV}$ deuterons is shown in Fig. 5(a). The beam current was $3.8 \mu \mathrm{A}$. Bombardment was terminated at $12 \mathrm{~min}$, after which the concentration of deuterium in the gas phase decayed exponentially with time as the target chamber was evacuated by the molybdenum pump Mo-3. At $22 \mathrm{~min}$, the target temperature was increased by indirectly heating the target with the two tungsten heaters shown in Fig. 3. The deuterium in the gas phase immediately increased as it was desorbed from the heater wires or evolved from the target. By the time the target had reached $120^{\circ} \mathrm{C}$, the evolution of deuterium was essentially complete. The rate of evolution was then approximately equal to the rate of evacuation from the target chamber. The partial pressure of deuterium in the target chamber was reduced to the initial concentration at 34 min.

The exponential rise in the deuterium concentration at $22^{\circ} \mathrm{C}$ during the first 12 min may be contrasted with the same period during bombardment with the target at $120^{\circ} \mathrm{K}$, as shown in Fig. $5(\mathrm{~b})$. With the target at $120^{\circ} \mathrm{K}$, the rise in the partial pressure of deuterium is not detectable. After the beam was switched off at $12 \mathrm{~min}$ and the liquid nitrogen coolant turned off at $18 \mathrm{~min}$, it was found that the target temperatures could go as high as $250^{\circ} \mathrm{K}$ before evolution of deuterium from the stainless steel target could be detected. This result implies that the diffusion rates for deuterium in stainless steel are vanishingly small at temperatures less than $250^{\circ} \mathrm{K}$.

Increases in relative magnitude of the mass numbers $2,12,14$, and 28 during bombardment of the 304 stainless steel target at $297^{\circ} \mathrm{K}$ and $120^{\circ} \mathrm{K}$ are given in Fig. 6 .

Figure 6(a) shows the mass -2 component. This component is assumed to be molecular hydrogen and not atomic deuterium. Atomic species of either hydrogen or deuterium were never observed with the mass spectrometer, at least partly because of the low cross section for the production of protons or deuterons by electronic ionization under high-vacuum conditions. 61

In Fig. 6(a) the bars indicating the base spectra were obtained before bombardment with the target at $120^{\circ} \mathrm{K}$ and $297^{\circ} \mathrm{K}$, and were due to residual hydrogen. The increase above the indicated base due to bombardment of the target is also shown.

The hydrogen base recorded by the mass spectrometer without bombardment is lcss by more than a factor of two when the target is at liquid nitrogen temperature. This reduction in base hydrogen level at liquid nitrogen temperatures might be partially 

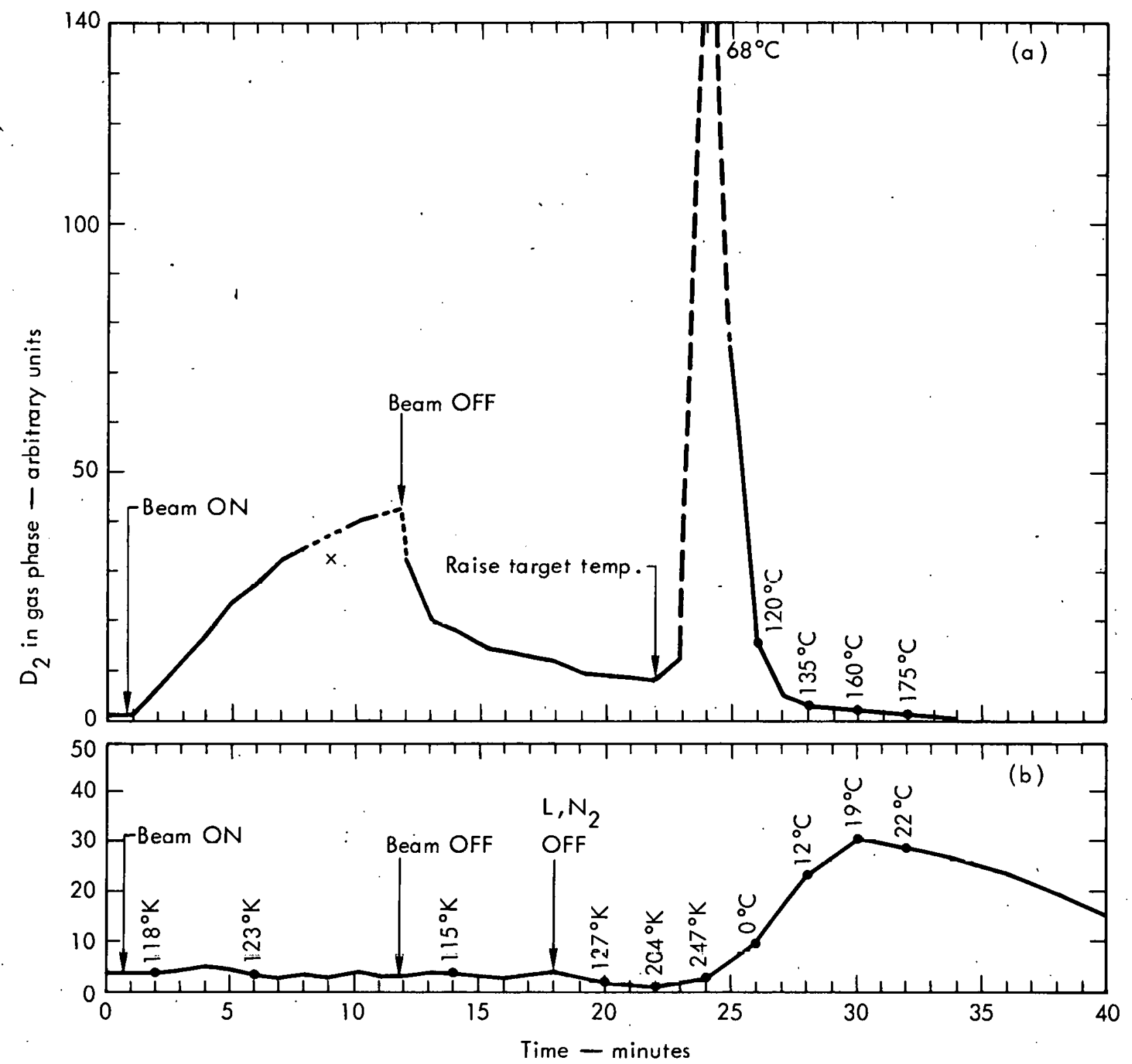

Fig. 5. 12-keV, $\mathrm{D}_{1}^{+}$bombardment of 304 stainless steel; (a) at $22^{\circ} \mathrm{C}$, and (b) at $120^{\circ} \mathrm{K}$. 


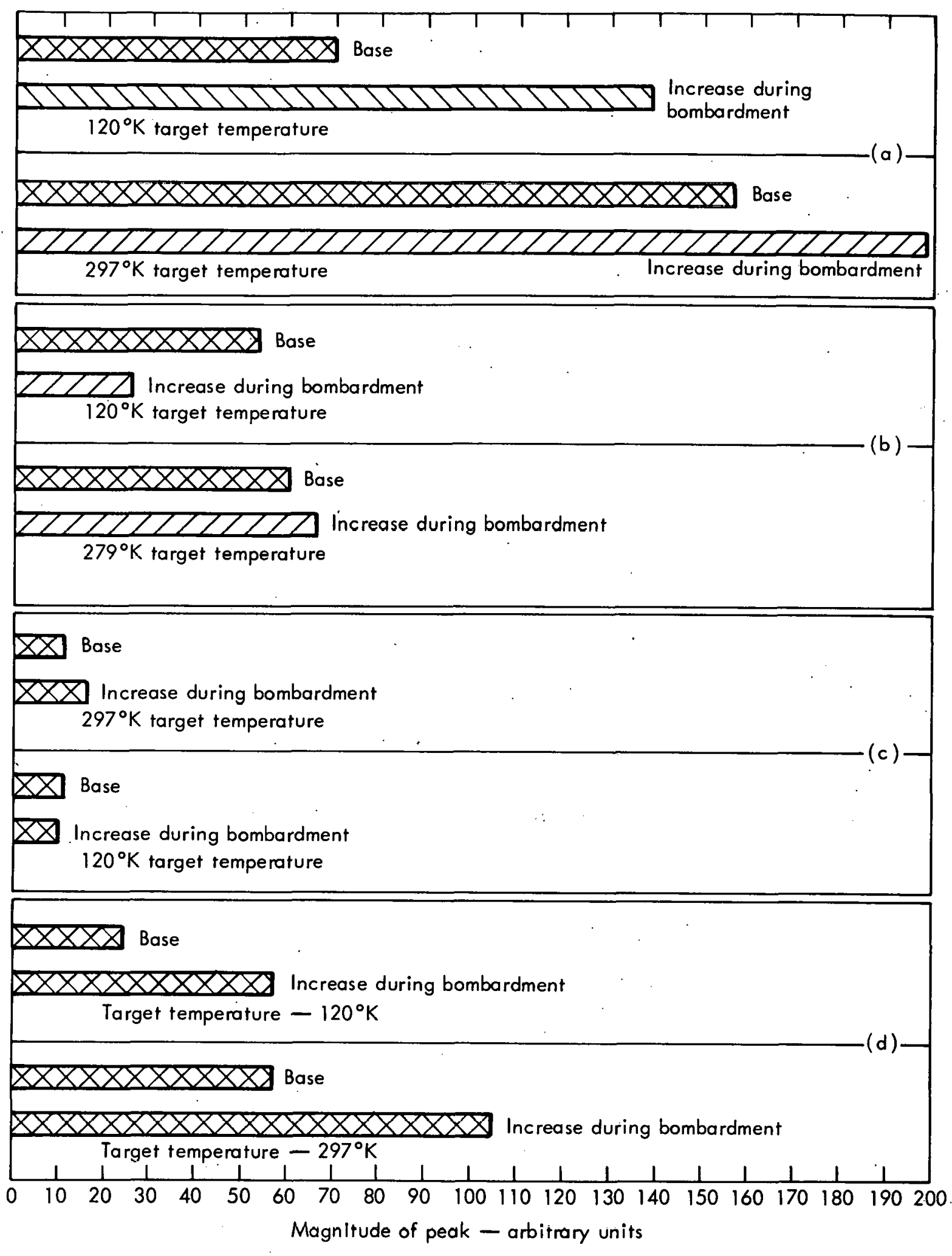

Fig. 6. $\mathrm{H}_{2}$ in gas phase before bombardment with $13-\mathrm{keV} \mathrm{D}_{1}^{+}$, and the increase in $\mathrm{H}_{2}$ concentration during bombardment at $120^{\circ} \mathrm{K}$ and $297^{\circ} \mathrm{K}$ of 304 stainless steel target; (a) mass-2 peak, (b) mass-12 peak, (c) mass-14 peak, and (d) mass -28 peak. 
ascribed to the adsorption of a complex component which dissociates into hydrogen within the mass spectrometer or on the ionization gauge filaments.

The hydrogen increase during bombardment is larger at high temperature than for the $120^{\circ} \mathrm{K}$ target. Again it is not known whether the differences between the bombardment-induced evolution of hydrogen with the high-and low-temperature targets is due to desorption of hydrogen from the target or desorption of a gas containing hydrogen. Based upon the associated rise in other mass numbers, it is certain that gases containing hydrogen are desorbed by the beam. However, it is certain from these data on hydrogen that less hydrogen is evolved from targets during bombardment if the target is maintained at liquid nitrogen temperature.

With respect to the similar measurements on the mass -12 peak, as illustrated in Fig. 6(b), it is first obvious that this does not represent free carbon desorbed from the target under any conditions, but must be a measure of the carbon fraction from dissociation of hydrocarbons. The base spectrum, or the magnitude of the mass -12 peak with no beam, is practically unchanged by lowering the target temperatures from $297^{\circ} \mathrm{K}$ to $120^{\circ} \mathrm{K}$. This is believed to indicate that this base is almost completely associated with contamination within the mass spectrometer. The increase shown during bombardment is a measure of the hydrocarbon evolution from the target. There is a significant gain in lowering the target temperature if the objective is to prevent the desorption of hydrocarbons by the incident beam of deuterons.

Figure 6(c) illustrates the result for the mass-14 peak which is usually associated with nitrogen. This base does not change with a reduction in target temperature, indicating either that nitrogen is not adsorbed by the cold target or that the nitrogen is associated with mass spectrometric contamination or the residual gas background in the system. There is an increase in the mass-14 peak during bombardment which is approximately a third larger if the target is at room temperature rather than liquid nitrogen temperature. The nitrogen evolved from the target is probably chemisorbed on the target.

The mass -28 peak, associated with carbon monoxide and nitrogen, is shown in Fig. 6(d). The large low-temperature or $120^{\circ} \mathrm{K}$ evolution under bombardment can be attributed to $\mathrm{CO}$ and might be the result of dissociation of some heavier molecule. The reduction in the base peak without bombardment indicates increased adsorption at $120^{\circ} \mathrm{K}$ and implies a heavier molecule, while the large increase under bombardment comparcd to the increase observed for the mass-14 peak implies the desorbed product cannot be nitrogen. The magnitude of the increase in the carbon peak (12) which generally should be associated with the heavier hydrocarbon molecule indicates that the mass -2.8 peak is probably associated with $\mathrm{CO}$ in this case.

Some of the difficulty in association of the increase in mass peak during bombardment with the mass peak magnitude before bombardment is illustrated in Table 1. 
Table 1. Ratio of increase in mass peak magnitude to mass peak before bombardment.

\begin{tabular}{|c|c|c|c|c|}
\hline & \multicolumn{4}{|c|}{ Mass number } \\
\hline & 2 & 12 & 1,4 & 28 \\
\hline $297^{\circ} \mathrm{K}$ & 1.28 & 1.1 & 1.33 & 1.84 \\
\hline $120^{\circ} \mathrm{K}$ & 2 & 0.47 & 0.83 & 2.38 \\
\hline
\end{tabular}

In an attempt to identify the species adsorbed at low temperatures on the stainless steel substrate, one can calculate the ratio of the base peak magnitude at $120^{\circ} \mathrm{K}$ to that at $297^{\circ} \mathrm{K}$ for the mass peaks as follows:

$\begin{array}{llccc}\text { Mass No.: } & 2 & 12 & 14 & 28 \\ \text { Ratio: } & 0.43 & 0.88 & 1.0 & 0.42\end{array}$

A correlation is found between hydrogen and the mass peak 28 .

The results presented in Fig. 5 were confirmed by again monitoring the $\mathrm{m} / \mathrm{e}=4$ peak during bombardment of the stainless steel target at $22^{\circ} \mathrm{C}$ and at $120^{\circ} \mathrm{K}$. These data are given in Fig. 7. The results are essentially the same as those discussed in connection with Fig. 5. The small' rise in the deuterium peak after the liquid nitrogen coolant was removed is probably not significant as the concentration of deuterium will depend on the rate of heating the target compared to the rate of evacuation of the target chamber, which was assumed constant. However, the evidence for evolution of deuterium from the target at temperatures as low as $160^{\circ} \mathrm{K}$ is conclusive and is suggestive of surface desorption of deuterium or some deuterated gas at this temperature.

$\underline{\mathrm{D}}_{1}^{+}$Bombardment of Mo Films Deposited on 304 Stainless Steel Before and After $\mathrm{H}_{2}$ Saturation

Molybdenum was sublimed onto the target while the target was cooled with liquid nitrogen. While cold, it was bombarded with the beam of deuterons, and the deuterium in the gas phase was recorded. The Mo film temperature was increased to $22^{\circ} \mathrm{C}$ and the deuterium peak was again recorded during bombardment. A complete mass spectrum was obtained during the low-temperature and the room-temperature bombardments.

The Mo film was aged for $24 \mathrm{hr}$ while cooled to about $16^{\circ} \mathrm{C}$. The bombardment was repeated at the end of this period, and the rise in the deuterium as well as other components was recorded.

After aging the film another $24 \mathrm{hr}$ the film was saturated with hydrogen from an external source. The saturated film was bombarded while both the deuterium rise and the rise in the partial pressure of the other components were observed. 


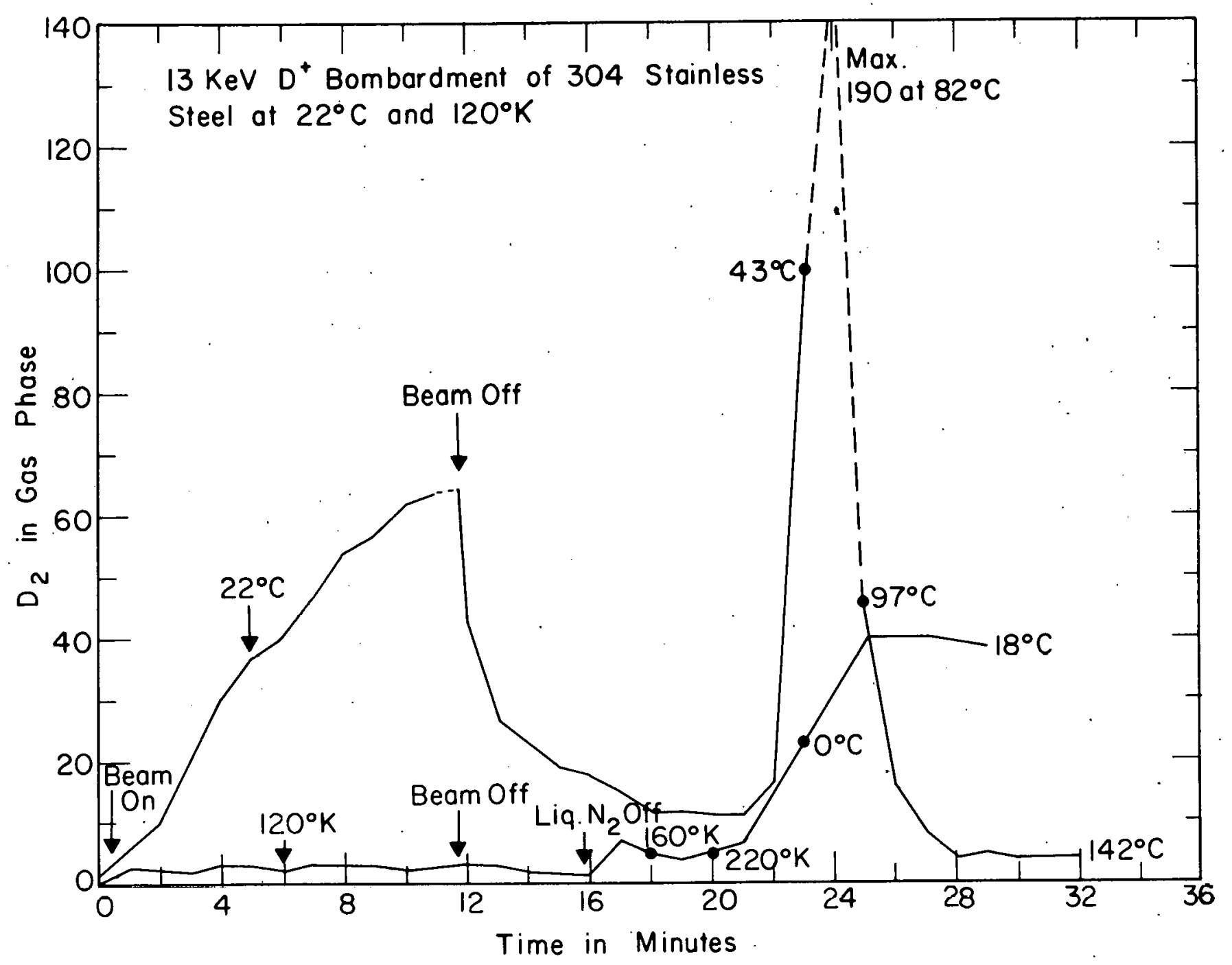

Fig. 7. $\mathrm{D}_{2}$ in gas phase during bombardment of 304 stainless steel with a $13-\mathrm{keV} \mathrm{D}_{1}^{+}$ beam for target temperatures of $22^{\circ} \mathrm{C}$ and $120^{\circ} \mathrm{K}$. 
A fresh Mo film was then deposited on the room-temperature target. The Mo sublimation filament failed during this deposition due to excessive temperature. The new film was then saturated with hydrogen and bombarded. The deuterium rise and the rise in other partial pressures were monitored during bombardment. The saturated ' film was heated to $212^{\circ} \mathrm{C}$ and the deuterium increase was recorded as the beam im pinged on the target. The target was heated for $12 \mathrm{hr}$ at $197^{\circ} \mathrm{C}$ and again bombarded while hot. The experiment with this target was terminated by cooling to $50^{\circ} \mathrm{C}$ and recording deuterium rise under bombardment at this intermediate temperature.

\section{$\underline{\text { Results and Discussion }}$}

\section{Bombarding Before $\mathrm{H}_{2}$ Saturation}

The increase in the gas-phase hydrogen during bombardment is shown in Fig. 8. The evolution of hydrogen was found to be much less for the Mo film than in the comparable case of stainless steel at the same low temperature.

The increase in other mass components during the bombardment of liquidnitrogen-cooled Mo is shown in Table 2. The large increase in the mass -17 peak with

Table 2. Increase in other mass components during bombardment.

\begin{tabular}{lcccccccccc}
\hline & \multicolumn{1}{c}{ Mass number } \\
\cline { 2 - 10 } & 12 & 13 & 14 & 15 & 16 & 17 & 18 & 20 & 28 & 44 \\
\hline $\begin{array}{c}\text { Base at } 120^{\circ} \mathrm{K} \\
\begin{array}{c}\text { Increase under } \\
\text { bombardment }\end{array}\end{array}$ & 10.2 & 1.5 & 1.2 & 2.1 & 6 & 8.4 & 25.2 & 1.3 & 4.8 & 4.5 \\
\hline
\end{tabular}

respect to the increase in the mass-18 (normally about 1:3 for $\mathrm{H}_{2} \mathrm{O}$ ) peak might be attributed to the formation of deuterated hydrocarbons such as methane which normally has the 15 and 16 peaks.

The mass -20 peak appears anomalous from two aspects. First, this peak cannot be associated with doubly charged argon, for the primary peak at mass 40 is insignificant. Secondly, this peak decreased under bombardment. Regardless of the identity of the component responsible for the mass -20 peak, it is probably necessary to assume that the anomalous decrease under bombardment was due to zero drift of the mass spectrometer amplifier. To be consistent, all increases less than 0.6 must be discarded from Table 2. Thus it can be affirmed only that the increases in mass numbers $14,20,28$, and 44 are immeasurably small during bombardment of a liquidnitrogen-cooled Mo film.

The ratios of mass peak increase during bombardment to the mass peak before bombardment are as follows: 


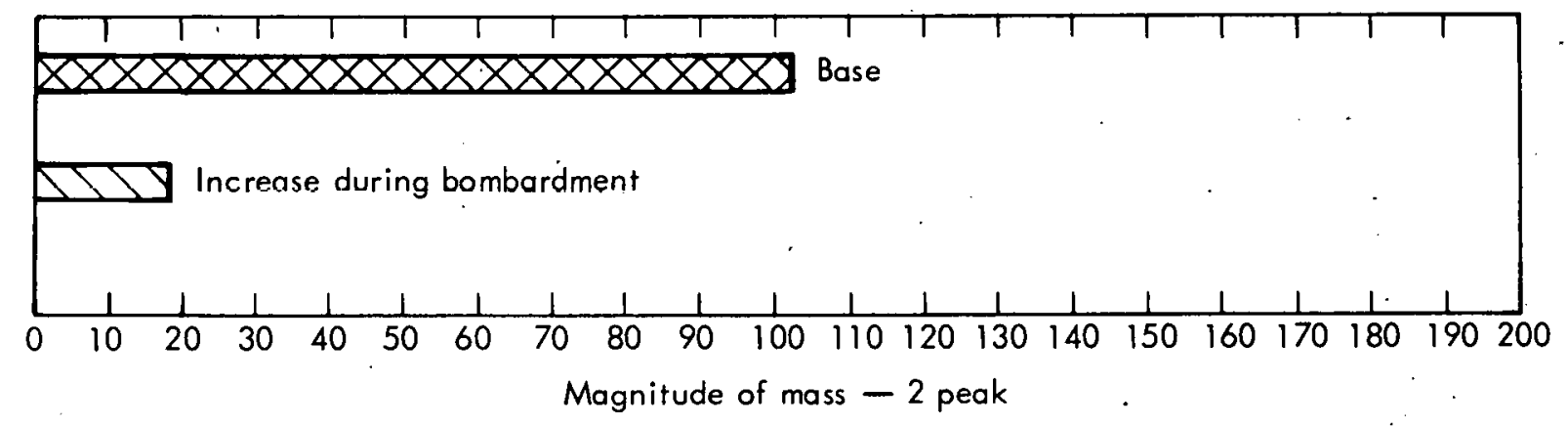

Fig. 8. $\mathrm{H}_{2}$ increase during bombardment for Mo-covered target at $120^{\circ} \mathrm{K}$. 


$\begin{array}{lcccccc}\text { Mass No.: } & 12 & 13 & 15 & 16 & 17 & 18 \\ \text { Ratio: } & 0.59 & 1 & 0.43 & 0.40 & 0.14 & 0.08\end{array}$

A possible association between the 12,15 , and 16 increases is suggested.

The largest of all the mass numbers in terms of absolute magnitude during bombardment occurs for hydrogen by about one order of magnitude. .It is also the largest in magnitude prior to bombardment.

The relative amounts of deuterium in the gas phase during bombardment of the Mo film at $22^{\circ} \mathrm{C}$ are given in Fig. $9(\mathrm{a})$. For easier comparison, the ordinate of Fig. 9 (a) has been made the same as those in Figs. 5 and 7 . The fresh Mo film at room temperature is apparently as effective in capturing the deuteron beam as is stainless steel at $120^{\circ} \mathrm{K}$. After the film was aged at $16^{\circ} \mathrm{C}$ in the vacuum for $24 \mathrm{hr}$, it was again bombarded at $22^{\circ} \mathrm{C}$. The deuterium was not removed from the film prior to bombardment. As Fig. 9(a) shows, the aged film was not as effective in terminating the beam. A significant rise in the gas-phase deuterium concentration had occurred by the end of $11 \mathrm{~min}$ of bombardment, but the film remained more effective than the stainless steel surface.

As it was impossible to confine the Mo vapor solely to the target area, part of the remarkable result for the fresh Mo film might be ascribed to pumping of the evolved gas by the Mo-covered surfaces surrounding the target. But if it is assumed that these surfaces would also pump hydrogen as well as deuterium, it can be argued that these surfaces are of minor influence on the measurements, at least insofar as the deuterium concentration in the gas phase is concerned, for the partial pressure of hydrogen increases during bombardment even for a $120^{\circ} \mathrm{K}$ Mo film target. It would seem that if deuterium were present in the gas phase, it too should also increase in partial pressure. The conclusion is that the deuterium does not evolve from the target of Mo until large quantities have been injected into the target by the high-energy beam.

When the beam of deutrons was incident on the $120^{\circ} \mathrm{K}$ Mo film, the deuterium increase in the gas phase, if any, was found to be below the sensitivity limit of the mass spectrometer. The beam of deuterons was buried within bulk of the target, as no deuterium was found in the gas phase after $21 \mathrm{~min}$ of continuous bombardment with a $3.6-\mu \mathrm{A}$ beam at $13 \mathrm{keV}$. The total pressure rise within the target chamber was less than $10^{-9}$ Torr during the bombardment of this low-temperature Mo film. The flux to the surface was about $3.6 \mu \mathrm{A} / \mathrm{cm}^{2}$ or $2.1 \times 10^{13}$ ions $/ \mathrm{cm}^{2}-\mathrm{sec}$. This flux on the target for 21 min placed $2.7 \times 10^{16}$ ions $/ \mathrm{cm}^{2}$ on the surface or about $10^{16}$ molecules $/ \mathrm{cm}^{2}$. The integrated coverage over this period is significantly in excess of a monolayer. It may be ascertained that all this deuterium cannot reside on the target surface without some appearing in the gas phase. This argument supports the view that the deuterium must be retained within the bulk of the target.

The aged Mo film was bombarded at $19^{\circ} \mathrm{C}$. The resulting increases in selected mass peaks other than deuterium, which was shown in Fig. 9(a), are given in Table 3 . 


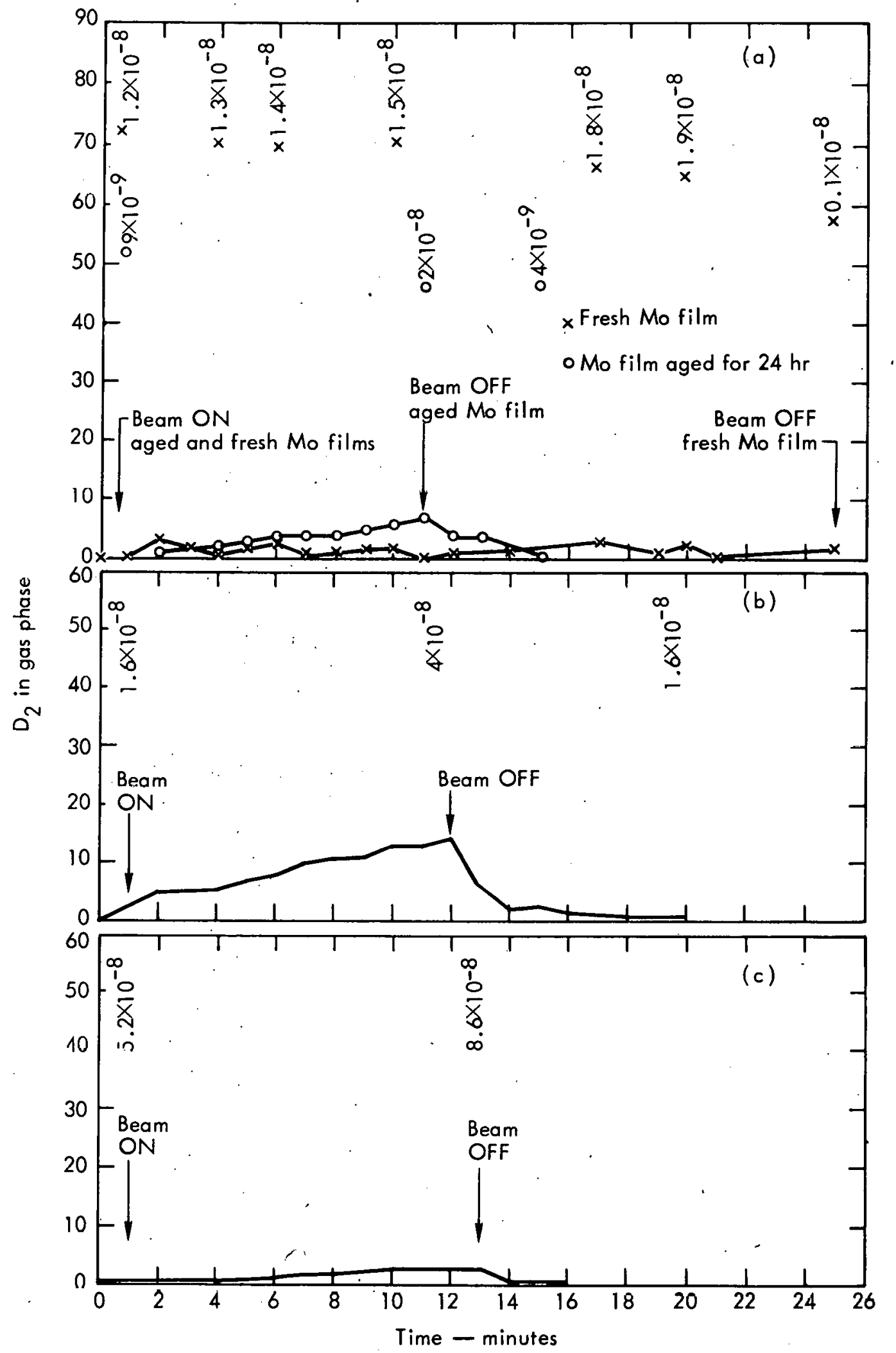

Fig. 9. 13-keV D ${ }_{1}^{+}$bombardment of Mo film on stainless steel, $\mathrm{D}_{2}$ in gas phase: (a) at $22^{\circ} \mathrm{C}$; (b) at $17^{\circ} \mathrm{C}$, Mo film aged $48 \mathrm{hr}$ and saturated with $\mathrm{H}_{2}$; and (c) at $15^{\circ} \mathrm{C}$, fresh Mo film saturated with $\mathrm{H}_{2}$. 
Table 3. Increase in mass peaks other than deuterium resulting from bombardment.

\begin{tabular}{lccccccccccc}
\hline & \multicolumn{10}{c}{ Mass number } \\
\cline { 2 - 11 } & 2 & 12 & 13 & 14 & 15 & 16 & 17 & 18 & 20 & 28 & 44 \\
\hline Base & 84 & 6 & 1.5 & 1.5 & 3.9 & 5.4 & 7.5 & 21 & 0.9 & 3.6 & 0.9 \\
$\begin{array}{l}\text { During } \\
\text { bombardment }\end{array}$ & 144 & 19.5 & 5.7 & 5.7 & 17.1 & 22.5 & 9 & 23.4 & 0.9 & 12.3 & 9.6 \\
$\begin{array}{c}\text { Increase due to } \\
\text { bombardment }\end{array}$ & 60 & 13.5 & 4.2 & 4.2 & 13.2 & 17.1 & 1.5 & 2.4 & 0 & 8.7 & 8.7 \\
\hline
\end{tabular}

The ratios of mass peak increase during bombardment to the mass peak before bombardment are as follows:

$\begin{array}{lcccccccccc}\text { Mass No.: } & 2 & 12 & 13 & 14 & 15 & 16 & 17 & 18 & 28 & 44 \\ \text { Ratio: } & 0.715 & 2.25 & 2.7 & 2.7 & 3.4 & 3.16 & 0.2 & 0.114 & 2.42 & 9.66\end{array}$

The dirty condition of the aged Mo surface is emphasized by the ratios exceeding unity for all components except hydrogen and water vapor.

\section{Bombarding After $\mathrm{H}_{2}$ Saturation}

After the film was aged another $24 \mathrm{hr}$, for a total of $48 \mathrm{hr}$, it was saturated with hydrogen by diffusion of hydrogen into the target chamber with a palladium thimble. The hydrogen pressure reached $10^{-6}$ Torr. The purpose of saturating with hydrogen was to eliminate deuterium adsorption on any clean, active surfaces. Figure 9 (b) shows the result of bombarding this saturated surface at $17^{\circ} \mathrm{C}$ with deu- terons. Since the surfaces of the Mo films were now inactive and nonadsorptive, at least with respect to hydrogen and deuterium, the reduction in the gas-phase dueterium during hombardment, compared with that illustrated in Fig. 5(a), is interpreted as a bulk property of the Mo. The bulk property of importance here is thought to be the low diffusion rate for deuterium in Mo at room temperature.

That the surface was saturated with hydrogen was confirmed by the large evolution of hydrogen during the deuteron bombardment as well as a very large residual hydrogen pressure as shown in Fig. 10. Other evolved components are also in high concentration, as shown in Table 4, reflecting the dirty condition of the Mo film.

Table 4. Increases in mass peaks resulting from bombardment.

\begin{tabular}{lcccccccccccccc}
\hline & \multicolumn{10}{c}{ Mass number } \\
\cline { 2 - 11 } & 2 & 12 & 13 & 14 & 15 & 16 & 17 & 18 & 19 & 20 & 2.8 & 44 \\
\hline $\begin{array}{l}\text { Base } \\
\begin{array}{c}\text { During } \\
\text { bombardment }\end{array}\end{array}$ & 144 & 9.6 & 2.4 & 2.4 & 6 & 10.8 & 9.6 & 28.5 & 0.6 & 0.9 & 9.9 & 3 \\
$\begin{array}{l}\text { Increase due to } \\
\text { bombardment }\end{array}$ & 90 & 22.5 & 6 & 6.9 & 15.6 & 24.9 & 4.2 & 6.3 & 0.3 & 0.3 & 17.1 & 19.5 \\
\hline
\end{tabular}




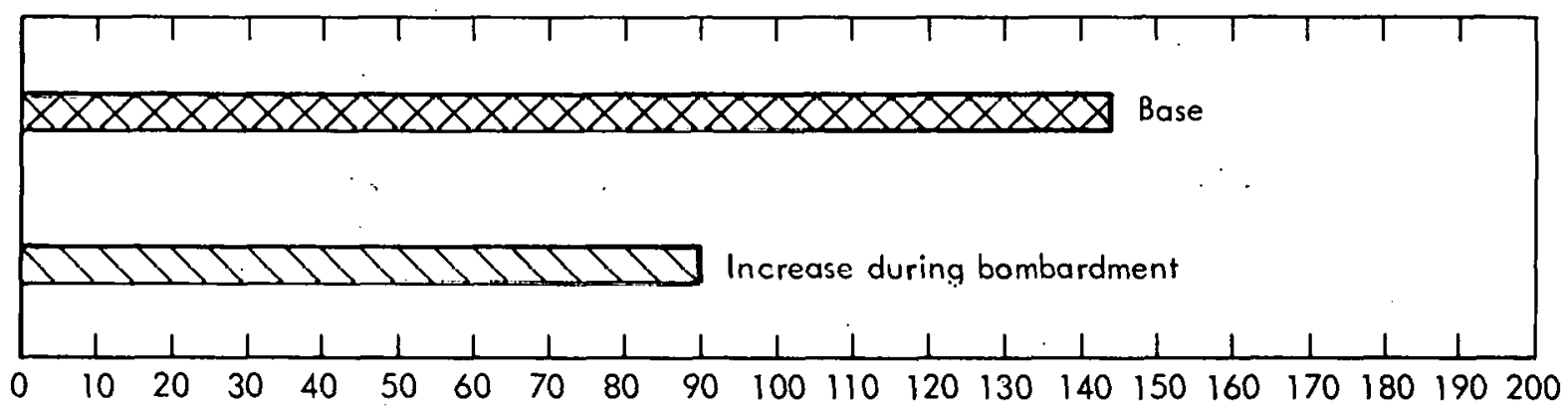

Fig. 10. $\mathrm{H}_{2}$ increase during bombardment of 48-hr-old Mo film saturated with $\mathrm{H}_{2}$ at $290^{\circ} \mathrm{K}$. 
The ratios of increase in magnitude of mass peak to the magnitude of the mass peak before bombardment for the aged Mo film saturated with hydrogen are as follows:

$\begin{array}{lcccccccccccc}\text { Mass No.: } & 2 & 12 & 13 & 14 & 15 & 16 & 17 & 18 & 19 & 20 & 28 & 44 \\ \text { Ratio: } & 0.625 & 2.35 & 2.5 & 2.87 & 2.6 & 2.3 & 0.437 & 0.22 & 0.5 & 0.33 & 1.73 & 6.5\end{array}$

There appears to be a correlation between mass numbers $12,13,14,15,16$, and perhaps 28 , and the increase under bombardment of a species present in the residual gas within the system. This correlation indicates that this species is probably also present on the target surface. Hydrogen, water vapor and $\mathrm{CO}_{2}$ are not correlated with any other mass numbers, so hydrogen and $\mathrm{CO}_{2}$ may be present on the target as hydrogen and $\mathrm{CO}_{2}$. The ratio for water vapor is so small as to suggest that the water vapor is primarily a residual in the mass spectrometer.

A fresh Mo film was then deposited on the target. The coverage obtained was probably quite good, as the filament failed due to excessive current. Hydrogen was admitted to saturate the film and the film was bombarded after the target chamber had been repumped to $5.2 \times 10^{-8}$ Torr. The concentration of deuterium in the gas phase during the bombardment is given in Fig. 9(c). As Fig. 9(c) shows, the rise in the deuterium concentration was just within the sensitivity limits of the mass spectrometer for this fresh film saturated with hydrogen.

The other evolved components were in very high concentration, indicating that the target had been seriously contaminated by the failure of the Mo filament and the excessive temperature coincident with its fusion. The hydrogen component was expected to be high because the system had been saturated with hydrogen. The pressure during this bombardment was high, $8.4 \times 10^{-8}$, increasing toward the end of the bombardment to $8.9 \times 10^{-8}$. Table 5 indicates these increases in individual components corresponding to the large pressure rise during bombardment.

Table 5. Increases in mass peaks corresponding to large pressure rise during bombardment.

\begin{tabular}{lccccccccccc}
\hline & \multicolumn{10}{c}{ Mass number } \\
\cline { 2 - 11 } & 2 & 12 & 13 & 14 & 15 & 16 & 17 & 18 & 20 & 28 & 44 \\
\hline $\begin{array}{l}\text { Base } \\
\begin{array}{l}\text { During } \\
\text { bombardment }\end{array}\end{array}$ & 138 & 52 & 7.5 & 18.6 & 13.3 & 40 & 46 & 120 & 2 & 55 & 12.3 \\
$\begin{array}{c}\text { Increase due to } \\
\text { bombardment }\end{array}$ & 78 & 104 & 29 & 42 & 71 & 110 & 67 & 159 & 2 & 113 & 40 \\
\hline
\end{tabular}

The ratio of increase in the magnitude of a peak during bombardment to the peak height before bombardment are listed as follows:

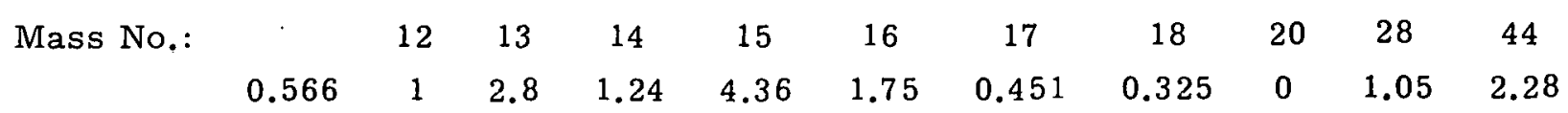


The effect of target temperature above room temperature on the evolution of deuterium during deuteron bombardment of Mo is shown in Fig. 11. The target was heated to temperatures in excess of $212^{\circ} \mathrm{C}$ between measurements to remove the sorbed deuterium.

While the target was at $212^{\circ} \mathrm{C}$, the target chamber pressure was $1.8 \times 10^{-7}$ Torr before bombardment and $2.5 \times 10^{-7}$ Torr during bombardment. The high pressure coupled with the presence of tungsten heaters for indirectly heating the target made measurement of the relative amounts of deuterium in the gas phase unreliable because large quantities of deuterium were converted to deuterated hydrogen on the heater surface.

These measurements completed our study of the gas evolution from 304 stainless steel during deuteron bombardment and the evolution from.Mo films deposited on this -stainlesis steel.

\section{Copper Target}

Bombardment of $\mathrm{Cu}$ with $15-\mathrm{keV}$ Deuterons

The failure of the Mo sublimation filament provided an opportunity to effect several improvements in the apparatus. The source was disassembled and adjusted to allow increasing the bombarding energy to $15 \mathrm{keV}$. In the target chamber, the Mo evapurator was replaced and a copper target was installed. A new bakeable mass spectrometer (General Electric Model PA-514*) was installed to increase the partial pressure sensitivity. After these changes the system was evacuated and the target chamber and mass spectrometer were baked at $200^{\circ} \mathrm{C}$ until the pressure was about $10^{-7}$ Torr.

Complete spectra (mass numbers 2-44) were obtained with the $\mathrm{Cu}$ target at $23^{\circ} \mathrm{C}$, before and during bombardment of the target with a beam of $15-\mathrm{keV}$ deuterons. The deuterium peak was followed during a second bombardment with 15-keV deuterons at a target temperature of $24^{\circ} \mathrm{C}$. With the new mass spectrometer it was possible to follow the deuterium peak during bombardment from the first few seconds to several minutes.

The Cu target was cooled to $83^{\circ} \mathrm{K}$. The target was bombarded while cold with a $5-\mu \mathrm{A}$ beam of $15-\mathrm{keV}$ deuterons for a period of $10 \mathrm{~min}$. The deuterium peak was then followed as the target temperature was slowly increased from $83^{\circ} \mathrm{K}$ to $15^{\circ} \mathrm{C}$. After the target had been at $23^{\circ} \mathrm{C}$ for about $15 \mathrm{hr}$ a complete spectrum was recorded with no beam on the target. The evolution of deuterium was not detectable as the target temperature was increased to $113^{\circ} \mathrm{C}$.

After the $\mathrm{Cu}$ target attained a temperature of $135^{\circ} \mathrm{C}$, a complete spectrum was obtained at a pressure of $1.8 \times 10^{-7}$ Torr, with no beam on the target and compared

\footnotetext{
*Reference to a company. or product name does not imply approval or recommendation of the product by the University of California or the U.S. Atomic Energy Commission to the exclusion of others that may be suitable.
} 


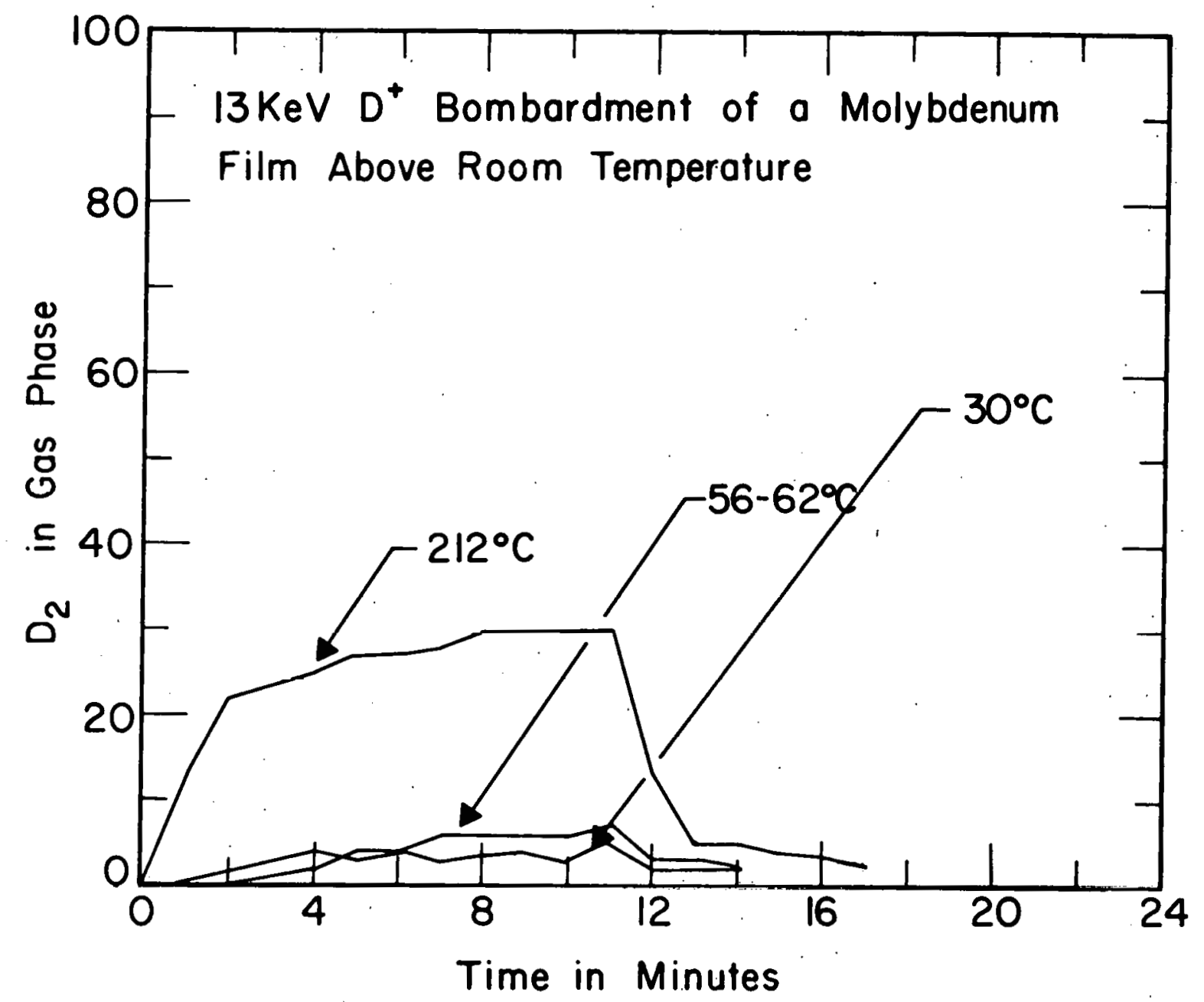

Fig. 11. $13-\mathrm{keV} \mathrm{D}_{1}^{+}$bombarding Mo film above room temperature, $\mathrm{D}_{2}$ in gas phase,
for $30^{\circ} \mathrm{C}, 56-62^{\circ} \mathrm{C}$. 
with a similar spectrum after the Mo pumps had been reduced to their lowest possible pressure. The hot target was bombarded with $6 \mu \mathrm{A}$ of $15-\mathrm{keV}$ deuterons and the deuterium increase was monitored. While the beam was incident on the hot $\mathrm{Cu}$ target, a complete mass spectrum was obtained.

The target was then cooled to $83^{\circ} \mathrm{K}$ and a mass spectrum again was recorded at a pressure in the target chamber of $1.3 \times 10^{-8}$ Torr. The target was bombarded and a slight increase in gas phase deuterium was noted on a sensitivity scale one order of magnitude greater than that used for the previous. bombardment of the cold Cu target. A complete spectrum was also obtained during this bombardment. The cold target was allowed to come to room temperature and the rate of deuterium evolution was monitored simultaneously. The target was pumped at room temperature overnight.

We then thought it advisable, before evaporating Mo on the $\mathrm{Cu}$ target, to repeat the measurements. This time the temperature was held at $15^{\circ} \mathrm{C}$ rather than $23^{\circ} \mathrm{C}$ dur ing the first part of the procedure by water-cooling the target. Before obtaining a spectrum at $15^{\circ} \mathrm{C}$, the target was heated to $139^{\circ} \mathrm{C}$ and a spectrum was obtained at this higher temperature. After obtaining a spectrum at $15^{\circ} \mathrm{C}$ the deuterium in the gas phase was monitored during bombardment. Before bombardment the pressure was 4.2 $\times 10^{-8}$ Torr while during the bombardment the pressure increased to $1.2 \times 10^{-7}$ Torr. The deuterium rise was rapid and large.

The target was then heated to $157^{\circ} \mathrm{C}$ to remove all deuterium. A complete spectrum was obtained at this high temperature before again cooling the target to $83^{\circ} \mathrm{K}$.

To attain the ultimate vacuum, the deuterium in the gas phase was recorded during the period of cooling and as the Mo evaporated in the pumps. Before recording the deuterium. rise under bombardment of the cold $\mathrm{Cu}$ target, a complete mass spectrum was obtained. The rate of evolution of deuterium was also monitored as the target temperature, after the bombardment, was increased to $108^{\circ} \mathrm{C}$. The system was then allowed to stand idle for a period of four days under vacuum.

\section{Results}

Since the mass spectrometer used in this and subsequent experiments was different from that used previously, great care must be exercised in comparing the magnitude of signals obtained for various mass peaks with those already listed.

After the $\mathrm{Cu}$ target had been baked and cooled to $23^{\circ} \mathrm{C}$, a reference spectrum with no beam was obtained. This is listed by mass peak below. The magnitude of the peak is listed in terms of $10^{-9} \mathrm{~A}$ as a full scale of 10 , or alternatively in terms of $10^{-10} \mathrm{~A}$.

$\begin{array}{lcccccccccccccc}\text { Mass No.: } & 2 & 3 . & 4 & 12 & 13 & 14 & 15 & 16 & 17 & 18 & 19 & 20 & 28 & 44 \\ \begin{array}{l}\text { Peak } \\ \text { magnitude: }\end{array} & 320 & 0.1 & 0.02 & 2.8 & 0.16 & 1.1 & 1.3 & 6.4 & 16 & 63 & 0.69 & 0.57 & 2 & 2\end{array}$

There appeared to be vast amounts of hydrogen, water vapor, and carbon monoxide, if the low (2-4) and the high (12-44) mass spectrum ranges are comparable. 
Organic material was present as a residual contamination. The deuterium concentration was low.

During bombardment with $5.4 \mu \mathrm{A}$ of $15 \mathrm{keV}$ deuterons, the pressure increased from $9 \times 10^{-8}$ to $2.2 \times 10^{-7}$ Torr. The $\mathrm{Cu}$ target temperature was $23^{\circ} \mathrm{C}$. The magnitudes of the spectra during bombardment are as follows:

$\begin{array}{ccccccccccccccc}\text { Mass No.: } & 2 & 3 & 4 & 12 & 13 & 14 & 15 & 16 & 17 & 18 & 19 & 20 & 28 & 44 \\ \begin{array}{c}\text { Peak mag- } \\ \text { nitude: }\end{array} & 450 & 5.2 & 4.6 & 7.7 & 1.5 & 4.2 & 11.3 & 25 & 20 & 73 & 1.3 & 0.9 & 52 & 6.4\end{array}$

The difference in peak magnitude or the increase due to bombardment for each mass peak is as follows:

$\begin{array}{lcccccccccccccc}\text { Mass No.: } & 2 & 3 & 4 & 12 & 13 & 14 & 15 & 16 & 17 & 18 & 19 & 20 & 28 & 44 \\ \begin{array}{c}\text { Increase due to } \\ \text { bombardment: }\end{array} & 130 & 5.1 & 4.6 & 4.9 & 1.3 & 3.1 & 10 & 18.6 & 4 & 10 & 0.6 & 0.33 & 32 & 4.4\end{array}$

The deuterium increase during bombardment is shown in Fig. 12. In Fig. 12 the ordinate scale is the mass spectrometer current in units of $10^{-10} \mathrm{~A}$, while the smallest division is $10^{-11} \mathrm{~A}$. The zero of the ordinate is the zero current on the scale when the mass spectrometer was displaced from the deuterium peak.

The $\mathrm{Cu}$ target was cooled with liquid nitrogen to $83^{\circ} \mathrm{K}$. As the target was bombarded with $5 \mu \mathrm{A}$ of deuterons at $15-\mathrm{keV}$ energy, the deuterium level was recorded. These results are not displayed since it was found that the deuterium rise was not detectable during a continuous bombardment of $10 \mathrm{~min}$. After effectively loading the $\mathrm{Cu}$ target at low temperatures by prolonged bombardment, the target was slowly heated without bombardment to $15^{\circ} \mathrm{C}$ in an attempt to find the temperature at which deuterium evolution became rapid. The rate of evolution became sufficiently high between $210^{\circ} \mathrm{K}$ and $220^{\circ} \mathrm{K}$ to initiate a slow increase in the concentration of deuterium in the gas phase. There was a gradual increase in the partial pressure of deuterium over a period of 5 min until a temperature of $12^{\circ} \mathrm{C}$ was attained. The rate of evolution was then less. than the rate of removal of the deuterium from the target chamber, and the partial pressure of deuterium slowly decreased. These temperatures are only significant as they form the limits between which deuterium diffusion from $\mathrm{Cu}$ is slow but appreciable. Above the $12^{\circ} \mathrm{C}$ limit, diffusion from $\mathrm{Cu}$ can be considered rapid and below $200^{\circ} \mathrm{K}$ the diffusion rates can be considered small.

After the $\mathrm{Cu}$ target had been at $23^{\circ} \mathrm{C}$ for $15 \mathrm{hr}$, the following spectrum was recorded at a pressiure of $1 \times 10^{-7}$ Torr with no beam incident on the $\mathrm{Cu}$ target:

$\begin{array}{lcccccccccccccc}\text { Mass No.: } & 2 & 3 & 4 & 12 & 13 & 14 & 15 & 16 & 17 & 18 & 19 & 20 & 28 & 44 \\ \begin{array}{l}\text { Peak } \\ \text { magnitude: }\end{array} & 103 & 13 & 12 & 4.4 & 0.2 & 2 & 1.2 & 9.4 & 20 & 75 & 2.5 & 0.7 & 45 & 4.4\end{array}$

When this target was heated to $113^{\circ} \mathrm{C}$, the deuterium in the gas phase decreased as the temperature increased, indicating either that pumping at $23^{\circ} \mathrm{C}$ for prolonged periods 


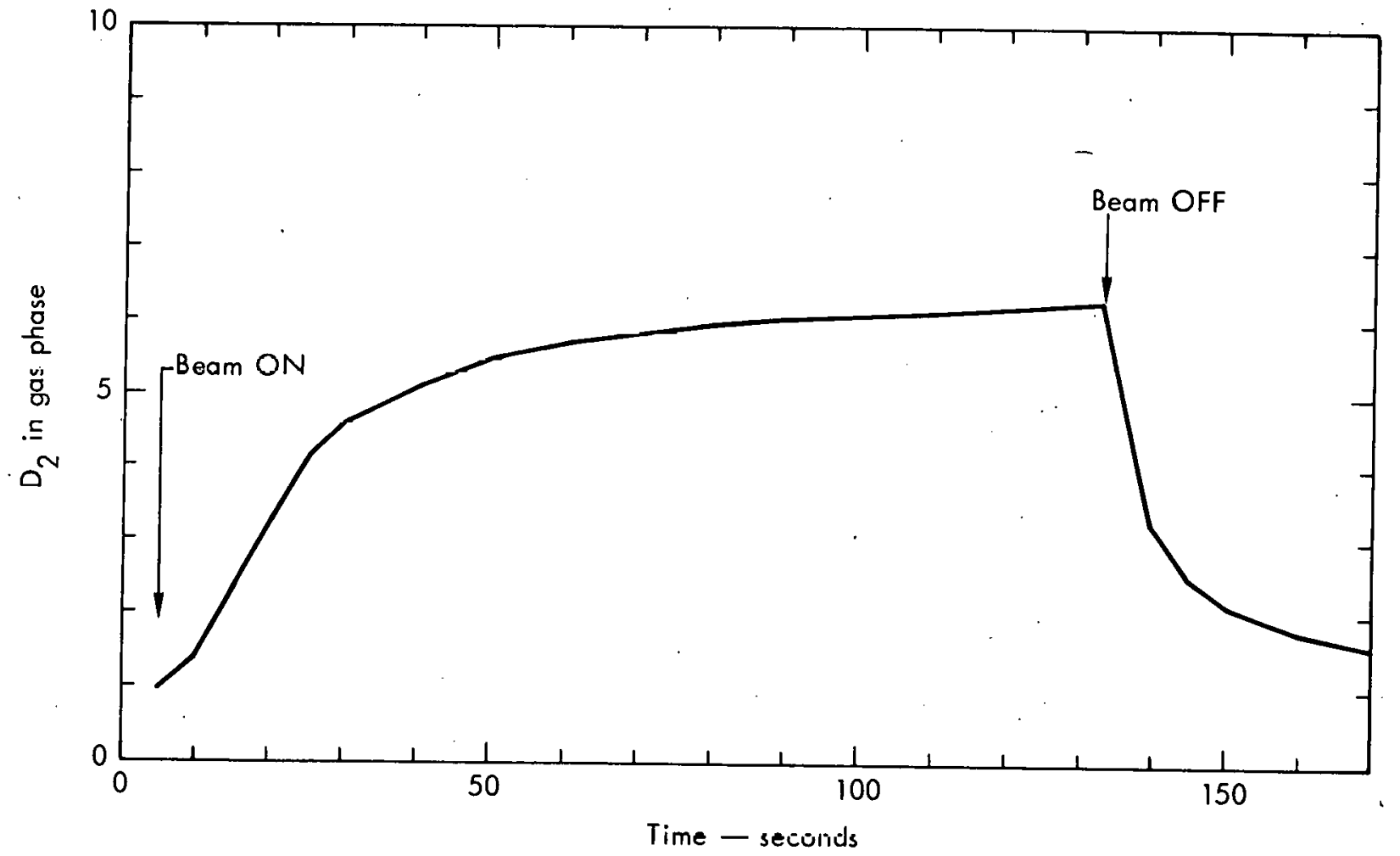

Fig. 12. 15-keV D $\mathrm{D}_{1}^{+}, 5.1-\mu \mathrm{A}$ beam, bombarding $\mathrm{Cu}$ target at $24^{\circ} \mathrm{C}, \mathrm{D}_{2}$ in gas phase. 
will exhaust the deuterium from $\mathrm{Cu}$ or that all the deuterium had been removed when the target was heated to $15^{\circ} \mathrm{C}$.

The $\mathrm{Cu}$ target temperature was then increased to $135^{\circ} \mathrm{C}$, and at a pressure of $1.8 \times 10^{-7}$ Torr the following reference spectrum was recorded with no beam on the target:

\begin{tabular}{|c|c|c|c|c|c|c|c|c|c|c|c|c|c|}
\hline lass No.: & 2 & 3 & 4 & 12 & 13 & 14 & 15 & 16 & 17 & 18 & 19 & 20 & 28 \\
\hline nitude: & 130 & 14 & 0.08 & 8.3 & 4 & 2.6 & 2.2 & 15 & 29 & 113 & 3.5 & 0.7 & 97 \\
\hline
\end{tabular}

After the evaporation of Mo in the pumps the target chamber pressure fell to $1.2 \times 10^{-7}$ Torr, although the $\mathrm{Cu}$ target temperature was increased to $146^{\circ} \mathrm{C}$. The renewed gettering surfaces in the pumps produced the following spectrum in the target chamber with no bombardment:

$\begin{array}{lcccccccccccccc}\text { Mass No:: } & 2 & 3 & 4 & 12 & 13 & 14 & 15 & 16 & 17 & 18 & 1.9 & 20 & 28 & 44 \\ \begin{array}{l}\text { Peak } \\ \text { Magnitude: }\end{array} & 87 & 1.3 & 0.05 & 5.9 & 0.4 & 1.2 & 2.9 & 14 & 26 & 97 & 2.1 & 0.7 & 62 & 3.1\end{array}$

The mass -28 and the mass -2 components show the largest reduction in magnitude, but all peaks are reduced indicating that a considerable proportion of the contamination in the target chamber is introduced from the pump side of the orifice into the target chamber. There is the possibility that these reductions are also due to higher pumping speed in the pumps for those components degassing from the walls of the target chamber. This evidence does not appear to be conclusive with respect to the source of the gaseous contamination.

Figure 13(a) shows the deuterium increase; on the same scale as Fig. 12, when a $6-\mu \mathrm{A}$ beam of $15-\mathrm{keV}$ deuterons are incident on the $\mathrm{Cu}$ target at $15^{\circ} \mathrm{C}$. The pressure prior to switching on the beam was $1.2 \times 10^{-7}$ Torr and at the end of the bombardment period, just prior to switching off the beam, was $2.6 \times 10^{-7}$ Torr. The reason for the lower magnitude of the deuterium peak in Fig. 13(a) compared with Fig. 12 might be found in terms of the high $\mathrm{HD}$ concentration, as illustrated in the following spectrum taken with the beam on the hot $\mathrm{Cu}$ target. The pressure was $2.3 \times 10^{-7}$ Torr. The measured temperature of the target was $156^{\circ} \mathrm{C}$. The beam was sputtering large amounts of hydrogen and $\mathrm{CO}$ from the target as well as methane and $\mathrm{CO}_{2}$.

$\begin{array}{lcccccccccccccc}\text { Mass No.: } & 2 & 3 & 4 & 12 & 13 & 14 & 15 & 16 & 17 & 18 & 19 & 20 & 28 & 44 \\ \begin{array}{l}\text { Peak } \\ \text { magnitude: }\end{array} & 170 & 6 & 3.5 & 13 & 1.5 & 3.5 & 13 & 34 & 31 & 114 & 5 & 1.5 & 130 & 10\end{array}$

The target was cooled to $83^{\circ} \mathrm{K}$ and a reference spectrum was obtained at a target chamber pressure of $1.3 \times 10^{-8}$ Torr.

$\begin{array}{lcccccccccccccc}\text { Mass No.: } & 2 & 3 & 4 & 12 & 13 & 14 & 15 & 16 & 17 & 18 & 19 & 20 & 28 & 44 \\ \begin{array}{l}\text { Peak } \\ \text { magnitude: }\end{array} & 18.5 & 0.4 & 0.04 & 1 & 0.2 & 0.4 & 1.5 & 3.0 & 2.6 & 8.3 & 0.8 & 0.4 & 8.6 & 0.08\end{array}$




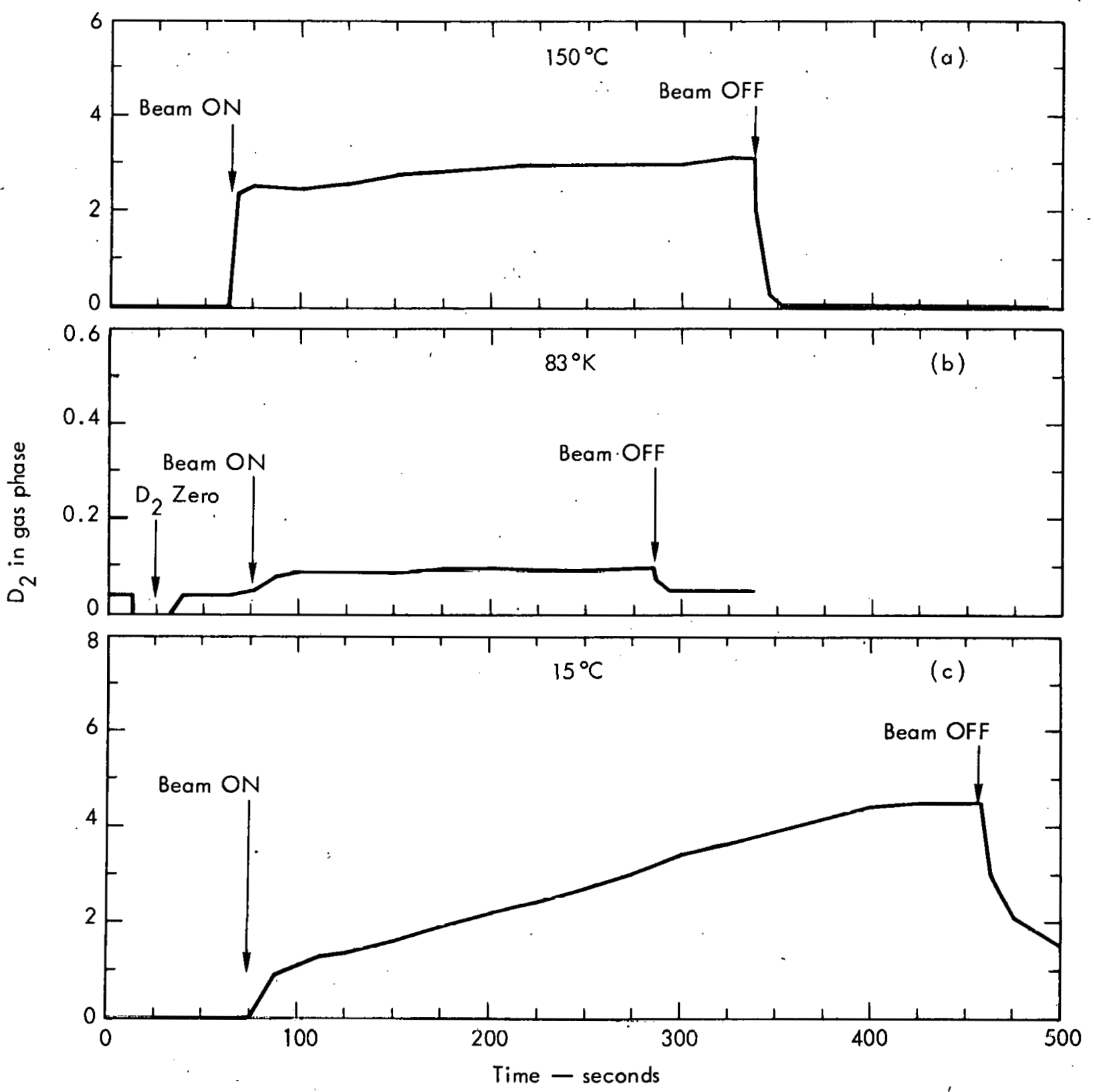

Fig. 13. 15-keV $\mathrm{D}_{1}^{+}$bombarding $\mathrm{Cu}$ target, $\mathrm{D}_{2}$ in gas phase; (a) $6-\mu \mathrm{A}$ beam, at: $150^{\circ} \mathrm{C}$, (b) $6-\mu \mathrm{A}$ beam, at $83^{\circ} \mathrm{K}$, and (c) $5.5-\mu \mathrm{A}$ beam, at $15^{\circ} \mathrm{C}$. 
Figure 13(b) shows the deuterium in gas phase during the bombardment of the $83^{\circ} \mathrm{K} \mathrm{Cu}$ target. The scale in Fig. $13(\mathrm{~b})$ is a factor of ten more sensitive than that used in Figs. 12 and $13(\mathrm{a})$ and is the most sensitive available with the mass spectrometer. The pressure prior to bombardment was $1.2 \times 10^{-8}$ Torr, during bombardment $4 \times 10^{-8}$ Torr and within $25 \mathrm{sec}$ after bombardment $1.6 \times 10^{-8}$. Torr. The beam intensity was $6 \mu \mathrm{A}$ and the beam energy was $15 \mathrm{keV}$. The small increase in the deuterium concentration during bombardment may be due to a reflected component from the surface, a desorption from the surface, or a small additional deuterium flow coaxial with the beam which does not strike the walls so it can be pumped in the Mo pumps.

The increase in total pressure from $1.2 \times 10^{-8}$ to $4 \times 10^{-8}$.Torr during the bombardment is distributed among the other desorbed components as indicated in the following mass spectrum recorded during the bombardment of the $83^{\circ} \mathrm{K} \mathrm{Cu}$ target. Due to the longer hombardment time required for the sweep to cover the larger mass spectrum, the pressure increased from 4 to $5 \times 10^{-8}$ Torr toward the higher mass numbers.

$\begin{array}{lcccccccccccccc}\text { Mass No.: } & 2 & 3 & 4 & 12 & 13 & 14 & 15 & 16 & 17 & 18 & 19 & 20 & 28 & 44 \\ \begin{array}{c}\text { Peak } \\ \text { magnitude: }\end{array} & 86 & 1.27 & 0.08 & 2.5 & 0.7 & 1.6 & 6.3 & 10.7 & 2.6 & 7.7 & 0.8 & 0.4 & 27 & 1.32\end{array}$

The increase in each mass peak due to bombardment of the $83^{\circ} \mathrm{K} \mathrm{Cu}$ target is as follows:

$\begin{array}{lllllllllllllll}\text { Mass Nn.: } & 2 & 3 & 4 & 12 & 13 & 14 & 15 & 16 & 17 & 18 & 19 & 20 & 28 & 44\end{array}$

Increase due to

$\begin{array}{lllllllllllllll}\text { bombardment: } \quad & 67.5 & 0.87 & 0.04 & 1.5 & 0.5 & 1.2 & 4.8 & 7.7 & 0 & 0.5 & 0 & 0 & 18.4 & 1.24\end{array}$

The largest increases appear in mass numbers $2,15,16$, and 28 , indicating the evolution of hydrogen, methane, and CO.

It was found that the residual deuterium of magnitude 0.04 with the beam switched off was due to the operation of the source. This indicated that the deuterium background was due to the method used in switching in which the deuteron beam was deflected into the wall of the neutralizer chamber by switching on a magnetic field. The deuteron beam strikes the wall and increases the local deuterium partial pressure. This room-temperature deuterium flows through the pumping system as a thermal molecular beam and enters the target chamber without striking the walls. There is no simple way to pump this thermal beam. Valves were found to be unsuitable as beam switching elements because of the pressure increase associated with their operation.

As the target temperature was increased slowly to $131^{\circ} \mathrm{C}$, the deuterium started to desorb from the target almost immediately. It appeared that the highest rate of deuterium desorption occurred above $0^{\circ} \mathrm{C}$, but because the rate of heating was uncontrolled the data were not satisfactory.

A mass spectrum was recorded at $131^{\circ} \mathrm{C}$ with no beam on the target. The pressure was $6.5 \times 10^{-8}$ Torr. 


$\begin{array}{lccccccccccccccc}\text { Mass No.: } & 2 & 3 & 4 & 12 & 13 & 14 & 15 & 16 & 17 & 18 & 1.9 & 20 & 28 & 44 \\ \begin{array}{l}\text { Peak } \\ \text { magnitude: }\end{array} & 56 & 0.7 & 0.03 & 3.25 & 0.2 & 0.62 & 1.8 & 6.9 & 12 & 46 & 0.9 & 0.5 & 32 & 1.8\end{array}$

The temperature was reduced to $15^{\circ} \mathrm{C}$ and a reference spectrum was obtained at a pressure of $4.4 \times 10^{-8}$ Torr.

$\begin{array}{lllllllllllllll}\text { Mass No.: } & 2 & 3 & 4 & 12 & 13 & 14 & 15 & 16 & 17 & 18 & 19 & 20 & 28 & 44\end{array}$

Peak

magnitude: $\quad \begin{array}{llllllllllllll}29.5 & 0.33 & 0.03 & 1.9 & 0.16 & 0.44 & 1.2 & 5.0 & 10 & 39 & 0.5 & 0.4 & 17 & 1.7\end{array}$

The deuterium in the gas phase was then monitored as a function of time during the period of bombardment with $5.5 \mu \mathrm{A}$ of $15-\mathrm{keV}$ deuterons. The pressure at the beginning of the bombardment was $4.2 \times 10^{-8}$ Torr and increased during bombardment to $1.2 \times 10^{-7}$ Torr. Figure 13 (c) illustrates the data obtained. The concentration of deuterium in the gas phase increases almost linearly with time and in this respect differs from the bombardment at a target temperature of $24^{\circ} \mathrm{C}$, as shown in Fig. 12 . It is apparent that the rate at which deuterium evolves from a $\mathrm{Cu}$ target is less if the target is water-cooled.

The $\mathrm{Cu}$ target was then heated to $157^{\circ} \mathrm{C}$ to remove all deuterium and a reference mass spectrum was taken to ascertain the vacuum conditions at this high temperature. The pressure was $1.8 \times 10^{-7}$ Torr.

$\begin{array}{lcccccccccccccc}\text { Mass No.: } & 2 & 3 & 4 & 12 & 13 & 14 & 15 & 16 & 17 & 18 & 19 & 20 & 28 & 44 \\ \begin{array}{l}\text { Peak } \\ \text { magnitude: }\end{array} & 130 & 1.1 & 0.04 & 5 & 0.2 & 1.1 & 2.2 & 11.4 & 29 & 105 & - & - & 75 & 3.3\end{array}$

It is evident that the higher temperature has resulted in a marked increase in the water-vapor $\mathrm{CO}$ and hydrogen desorbed either from the target or from the walls of the target chamber.

The deuterium level was recorded as the target was cooled to liquid nitrogen, temperatures. No reduction in the residual deuterium was noted during the cooling period of $13 \mathrm{~min}$ due to cooling the $\mathrm{Cu}$ target, but a sharp reduction was obtained by evaporating Mo in the pumps. This indicated again that the deuterium in the source was beaming into the target chamber and this contamination, although at a very low level, could be reduced by pumping the deuterium on fresh Mo films.

As the target temperature reached $83^{\circ} \mathrm{K}$, a reference spectrum was obtained prior to bombardment. The pressure was $1.8 \times 10^{-8}$ Torr within the target chamber.

$\begin{array}{ccccccccccccccc}\text { Mass No.: } & 2 & 3 & 4 & 12 & 13 & 14 & 15 & 16 & 17 & 18 & 19 & 20 & 28 & 44 \\ \begin{array}{c}\text { Peak mag- } \\ \text { nitude: }\end{array} & 30 & 0.3 & 0.03 & 9 & 0.13 & 0.33 & 0.88 & 2.2 & 2 & 9 & 0.2 & 0.31 & 11.7 & 0.21\end{array}$

Before the deuterium concentration change due to bombardment was recorded, the pressure was $1.8 \times 10^{-8}$. During the bombardment the pressure increased to 5.3 $\times 10^{-8}$. The beam current was $5.3 \mu \mathrm{A}$. The increase during bombardment was less than that shown in Fig. $13(\mathrm{~b})$, and is given as a function of time in Fig. 14. 


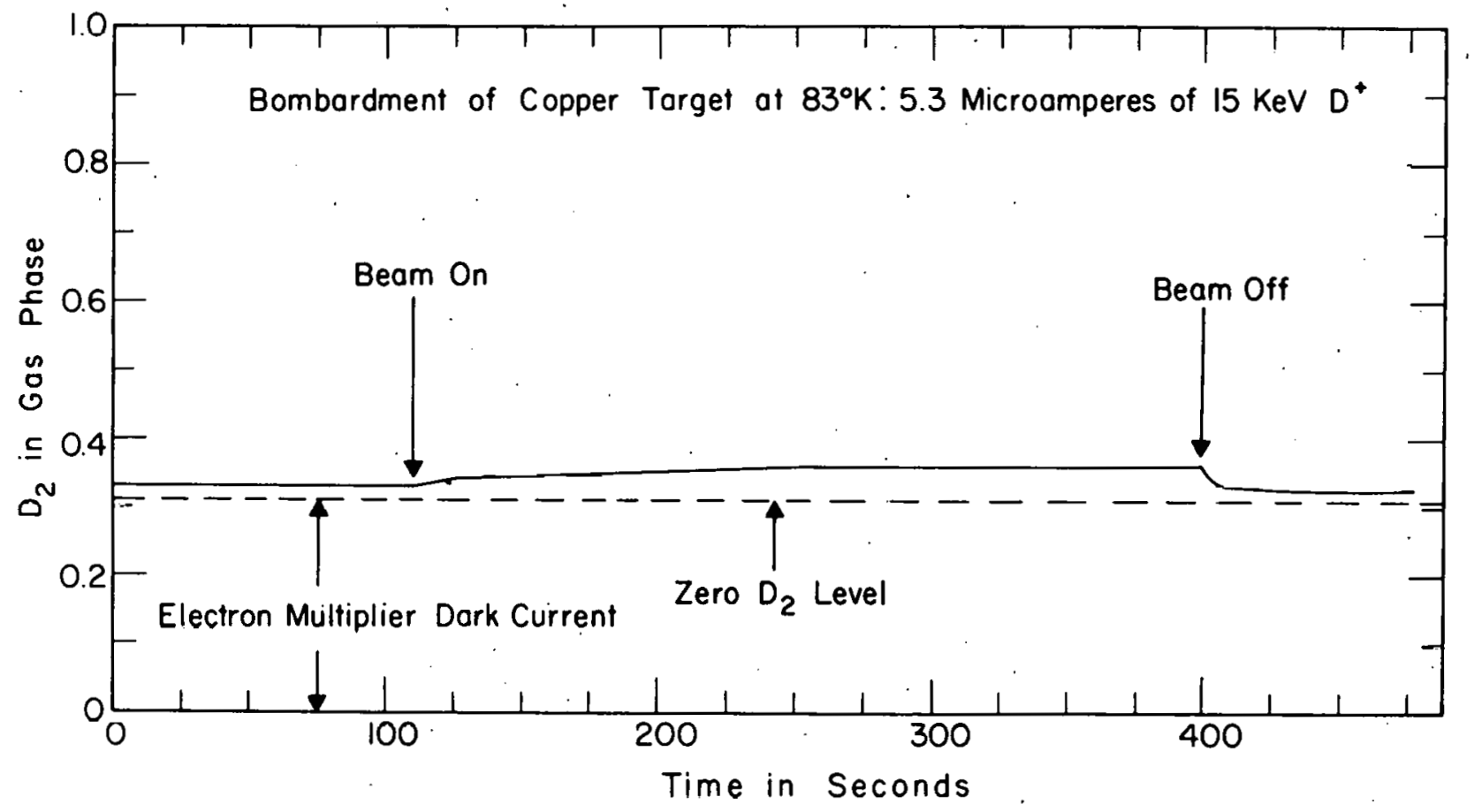

Fig. 14. $15-\mathrm{keV} \mathrm{D}+5.5-\mu \mathrm{A}$ beam, bombarding $\mathrm{Cu}$ target at $83^{\circ} \mathrm{K}, \mathrm{D}_{2}$ in gas phase. 
As the target was heated to $108^{\circ} \mathrm{C}$, the deuterium evolution into the gas phase was recorded. Again most of the deuterium was desorbed or had diffused from the $\mathrm{Cu}$ target before the temperature of the target reached $30^{\circ} \mathrm{C}$.

A summary of the data on the bombardment of $\mathrm{Cu}$ is given in Fig. 15 .

\section{Bombardment of Mo Films Deposited on $\mathrm{Cu}$}

The next procedure is concerned with evaporation of a Mo film on a $\mathrm{Cu}$ target. Since the first experiment showed that the deuterium in the gas phase under bombardment was very sensitive to the existence of a Mo film on the stainless steel target, the deuterium in the gas phase was monitored during sublimation of the Mo film and while the beam was subsequently incident on the target. By this technique the sublimation power and time required to establish a detectable Mo film on the $\mathrm{Cu}$ target was easily determined, although the target was not visually observable.

Prior to evaporating Mo on the target, it was necessary to establish a base condition for the mass spectrometer. To this end, Mo was deposited in the pumps, the beam was adjusted on the $\mathrm{Cu}$ target, and the rise in deuterium was followed. A complete spectrum was also obtained for the case where no beam was incident on the target.

A prolonged period of outgassing of the Mo sublimation filament was necessary before the pressure within the target chamber could be reduced to less than $5 \times 10^{-7}$ Torr so the mass spectrometer could be used. The deuterium level in the target chamber was checked as the target cooled following outgassing of the Mo. Molybdenum was then sublimed on the target until the deuterium in the gas phase during bombardment was greatly reduced. For comparison with the initial gas condition and to detect any effect of the evaporated Mo film on the residual partial pressures, a complete spectrum was obtained with no beam incident on the target with the target at $16^{\circ} \mathrm{C}$.

A spectrum was also obtained immediately after evaporation of Mo in the pumps to determine the effect of the lowest residual pressure within the pumps on the partial pressures within the target chamber.

The higher masses were also recorded as the temperature of the Mo covered $\mathrm{Cu}$ surface was reduced to liquid nitrogen temperature. After the target reached $83^{\circ} \mathrm{K}$, the $\mathrm{H}_{2}$, $\mathrm{HD}$ and $\mathrm{D}_{2}$ partial pressures were recorded with no beam on the target.

The cold Mo film was bombarded with $15-\mathrm{keV}$ deuterons at a beam current of $5.4 \mu \mathrm{A}$. Essentially no increase in the deuterium in the gas phase was found during the 1-min bombardment. However, a large amount of hydrogen evolved during the bombardment as was shown by a subsequent 50-sec bombardment. A fresh film of Mo was sublimed on the liquid-nitrogen-cooled target. During deposition, the target temperature increased to $0^{\circ} \mathrm{C}$. The increase in hydrogen partial pressure during bombardment of this fresh film after it had cooled to $90^{\circ} \mathrm{K}$ was much less. Cooling required about 3 min. Another fresh Mo film was deposited, and the increase in partial pressure of 


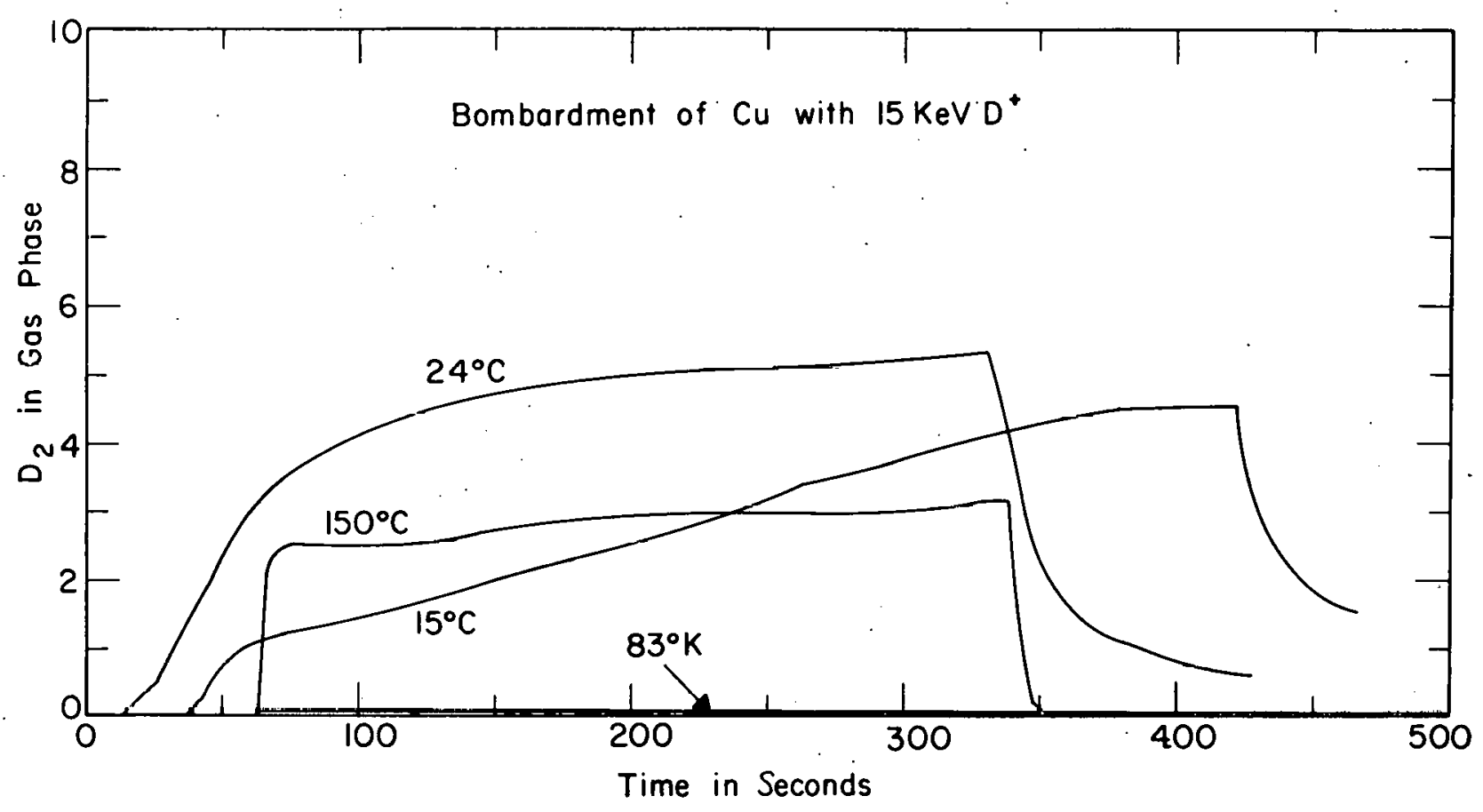

Fig. 15. Composite of Figs. 21 and 13(a), (b), and (c). 
hydrogen during bombardment further reduced. The increase in the HD partial pressure was just detectable on the most sensitive scale during bombardment of this lowtemperature film. The liquid nitrogen cooling was then removed from the target, and the film was warmed to room temperature.

After about $20 \mathrm{hr}$ at room temperature, the target was water-cooled to $17^{\circ} \mathrm{C}$. The complete residual gas spectrum was obtained with no beam on the target and with a residual pressure in the target chamber of $6 \times 10^{-8}$ Torr. This spectrum provided the reference spectrum for the subsequent determination of the gas evolved from the aged Mo film under bombardment.

Bombardment of the water-cooled, aged Mo film produced an appreciable rise in the deuterium in the gas phase and a total pressure rise from $6.3 \times 10^{-8}$ to 1.2 $\times 10^{-7}$ Torr during bombardment. The pressure decreased to $6.4 \times 10^{-8}$ Torr within 5 min after the bombardment. This rise indicated large quantities of $\mathrm{D}_{2}$ on the Mo surface. The $\mathrm{H}_{2}$ and IID increase was equally spectacular. It was also confirmed here that a part of the HD production in the system containing both hydrogen and deuterium was due to the operation of the ionization gauge filaments. The higher mass spectrum, was also recorded during this bombardment for comparison with the reference spectrum before bombardment.

A fresh Mo film was deposited on the water-cooled target. A very high $\mathrm{D}_{2}$ peak was observed as the target was heated. Bombardment of the fresh film at $18^{\circ} \mathrm{C}$ produced a large $D_{2}$ pcak, but the rate of rise was reduced over the aged film.

Another Mo film was evaporated onto the target and a large $\mathrm{H}_{2}$ peak was also produced during the subsequent bombardment. The increase in the spectrum of higher masses was also measured during bombardment at $18^{\circ} \mathrm{C}$.

An attempt was made to measure the secondary-electron emission coefficient (under deuteron bombardment) for clean and contaminated films. It was found that the target geometry was completely unsuitable for an absolute measurement, but a relative measurement could be made. It was shown that outgassing an ionization gauge near the $90^{\circ} \mathrm{K}$ Mo films would increase the emission coefficient. Reducing the pressure in the target chamber by lowering the pressure in the Mo pumps would decrease the emission. Evaporating fresh Mn films on the target would greatly decrease the emission coefficient.

The bombardment of $\mathrm{Cu}$ and 304 stainless steel, and the Mo films on each of these substrates, suggested that the deuterium diffusion rates within the target material determine the concentration of deuterium in the gas phase. For this reason, it was predicted that a metallic target with a low hydrogen or deuterium diffusion rate, such as tungsten, would effectively contain the deuterium beam.

\section{$\underline{\text { Results }}$}

Before evaporating Mo on the Cu target, we obtained a reference spectrum. The pressure was $4 \times 10^{-8}$ Torr. 
$\begin{array}{lllllllllllllll}\text { Mass No.: } & 2 & 3 & 4 & 12 & 13 & 14 & 15 & 16 & 17 & 18 & 19 & 20 & 28 & 44\end{array}$

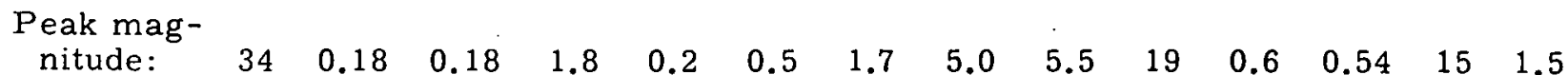

Although the deuterium level was followed as the target was cooled after the evaporator was outgassed, the results confirmed the previous observation that the deuterium level was independent of the target temperature unless a high-energy beam of deuterons was incident on the target. The only increase in deuterium level observed during the no-beam cooling of the target was solely due to a concurrent increase in the deuterium level in the Mo adsorption pumps.

Molybdenum was evaporated on the water-cooled $\mathrm{Cu}$ target after the prolonged outgassing of the evaporating filament. After each evaporation, the maximum $\mathrm{D}_{2}$ increase in the gas phase under bombardment was noted to ascertain the optimal power input for deposition of a detectable Mo film.

$\begin{array}{lcrrrr}\text { Evaporation No. } & 1 & 2 & 3 & 4 & 5 \\ \begin{array}{l}\text { Power (watt.s) } \\ \begin{array}{c}\text { D } 2 \text { level under } \\ \text { bombardment }\end{array}\end{array} & 1.7 & 360 & 360 & 380 & 400 \\ & 1.7 & 1.4 & 1.0 & 0.7 & 0.42\end{array}$

It was concluded that 400 watts applied to the Mo evaporator for 1 min would provide a satisfactory film on the target.

The reference spectrum, after evaporation of Mo on the water-cooled $\mathrm{Cu}$ target, was recorded at a target temperature of $16^{\circ} \mathrm{C}$ and a total pressure of $1.3 \times 10^{-8}$ Torr. $\begin{array}{lllllllllllllll}\text { Mass No.: } & 2 & 3 & 4 & 12 & 13 & 14 & 15 & 16 & 17 & 18 & 19 & 20 & 28 & 44\end{array}$ $\begin{array}{lllllllllllllll}\text { Peak } & \\ \text { magnitude: } & 56 & 0.63 & 0.03 & 0.35 & 0.17 & 0.44 & 1.4 & 2.4 & 3.7 & 11.9 & 0.6 & 0.6 & 3.1 & 0.16\end{array}$

After evaporation of fresh Mo in the pumps, the pressure within the target chamber was $1.5 \times 10^{-8} \mathrm{Torr}$, and the following mass spectrum taken at $16^{\circ} \mathrm{C}$ :

$\begin{array}{lcccccccccccccc}\begin{array}{l}\text { Mass No.: } \\ \text { reak }\end{array} & 2 & 3 & 4 & 12 & 13 & 14 & 15 & 16 & 17 & 18 & 19 & 20 & 28 & 44 \\ \quad \text { magnitude: } & - & - & - & 0.33 & 0.18 & 0.44 & 1.4 & 2.7 & 3.8 & 11.9 & 0.60 & 0.62 & 2.6 & 0.14\end{array}$

The decrease in pump pressure associated with evaporation of Mo in the pumps did not change the higher mass peak magnitude with the possible exception of a small reduction in the carbon monoxide, as indicated by mass number 28.

As the temperature of the Mo covered $\mathrm{Cu}$ target approached liquid nitrogen temperatures, the total pressure approached $1.3 \times 10^{-8} \mathrm{Torr}$. Between $95^{\circ} \mathrm{K}$ and $83^{\circ} \mathrm{K}$, the following reference spectrum was obtained:

$\begin{array}{lcccccccccccccc}\text { Mass No.: } & 2 & 3 & 4 & 12 & 13 & 14 & 15 & 16 & 17 & 18 & 19 & 20 & 28 & 44 \\ \begin{array}{c}\text { Peak mag- } \\ \text { nitude: }\end{array} & 71 & 1.15 & 0.03 & 0.26 & 0.05 & 0.16 & 1.4 & 2.6 & 3.3 & 11.9 & 0.6 & 0.4 & 2.4 & 0.1\end{array}$


The decrease in temperature seems to decrease the magnitude of the 21,13 , and 14 peaks which probably indicates the adsorption of a hydrocarbon. It is to be noted that the hydrogen and HD components have increased-probably due to saturation of the aged film over the levels associated with freshly deposited Mo film.

When the $83^{\circ} \mathrm{K}$ Mo film was bombarded with $5.4 \mu \mathrm{A}$ of $15-\mathrm{keV}$ deuterons for a period of $1 \mathrm{~min}$, the very slight partial pressure rise of deuterium in the gas phase was identical to that shown in Fig. 14 where $\mathrm{Cu}$ was the target material. Immediately subsequent to this 1-min bombardment, the mass spectrometer was shifted to the hydrogen peak and the Mo film was bombarded with deuterons for $50 \mathrm{sec}$ after fresh Mo had been evaporated in the pumps. The relative concentration of hydrogen within the target chamber during the evaporation of Mo within the pumps and during the subsequent bombardment is shown in Fig. 16. The beam of $15-\mathrm{keV}$ deuterons started the bombardment with a current of $5.5 \mu \mathrm{A}$, but increased during the bombardment to $6.1 \mu \mathrm{A}$. The ordinate is in units of $10^{-10} \mathrm{~A}$ of electron-multiplier/signal so that the $100 \mathrm{mark}$ indicates $10^{-8} \mathrm{~A}$.

The high concentration of hydrogen within the chamber prior to the bombardment and during the Mo evaporation assumes that the surface of the target was well covered with hydrogen and explains the immediate desorption of hydrogen when the beam struck the target.

The Mo film on the target was apparently dirty as it had been cooled after deposition. To ascertain the magnitude of the hydrogen evolved for a relatively clean Mo film at $83^{\circ} \mathrm{K}$, two fresh Mo films were deposited over the old while the target was cooled with liquid nitrogen. The target did not remain at liquid nitrogen temperature during the film deposition due to the radiation incident on the target from the incandes cent Mo evaporator. The target temperature increased to $0^{\circ} \mathrm{C}$ during each evaporation, but cooled to $90^{\circ} \mathrm{K}$ within $3 \mathrm{~min}$ after deposition ceased. This 3 -min cooling period allowed time for some contamination of the target.

The increase in partial pressure of hydrogen due to bombardment after each deposition of Mo on the liquid-nitrogen-cooled $\mathrm{Cu}$ target is shown in Fig. 17. The pressure during the first bombardment was $5.8 \times 10^{-9}$ Torr, and during the second $4.9 \times 10^{-9}$ Torr. The scale of Fig. 16 is the same as that of Fig. 15. The reduction in the quantity of hydrogen desorbed is evident. Since as in Fig. 15 the hydrogen concentration reached large values just prior to bombardments and during the evaporation of the Mo films, the difference between the results of Figs. 15 and 16 are due only to the time interval hefore bombardment and the additional quantity. of Mo on the target. The lower residual pressure after evaporation of the fresh Mo films indicates that surfaces are pumping within the target chamber and have not been saturated, for example, the residual pressure before the bombardment of the second fresh film was $3.7 \times 10^{-9}$ Torr. There is the ambiguity in this experiment with hydrogen that results in an interpretation of the data either as desorption of hydrogen under bombardment and subsequent pumping by surrounding active surfaces, or as the absence of desorption due to the relatively clean target surfaces. The interpretation favored is that the small apparent 


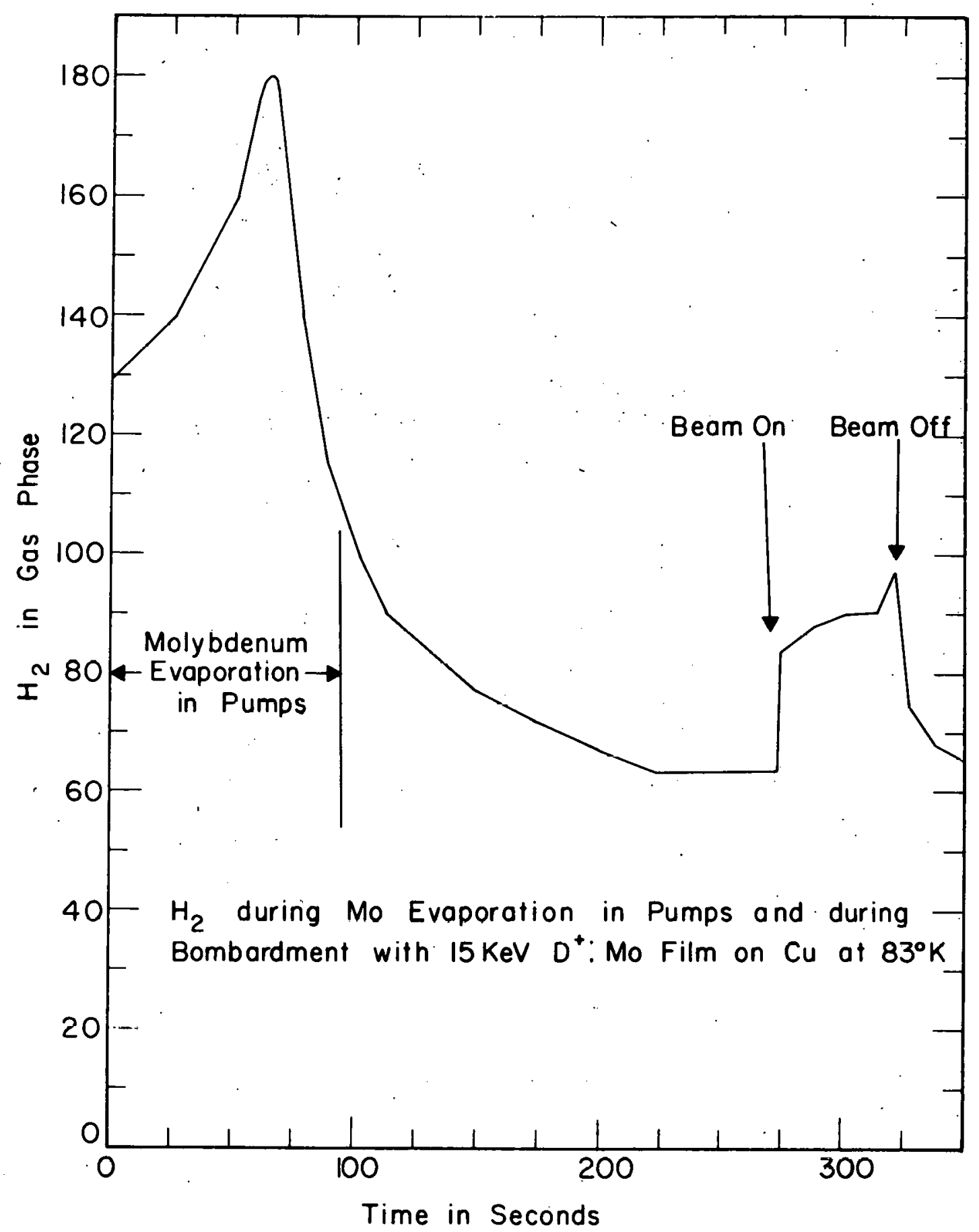

Fig. 16. $\mathrm{H}_{2}$ in gas phase during Mo evaporation in pumps and during bombardment with $15-\mathrm{keV} \cdot \mathrm{D}_{1}^{+}$for a Mo film on $\mathrm{Cu}$ at $83^{\circ} \mathrm{K}$. 


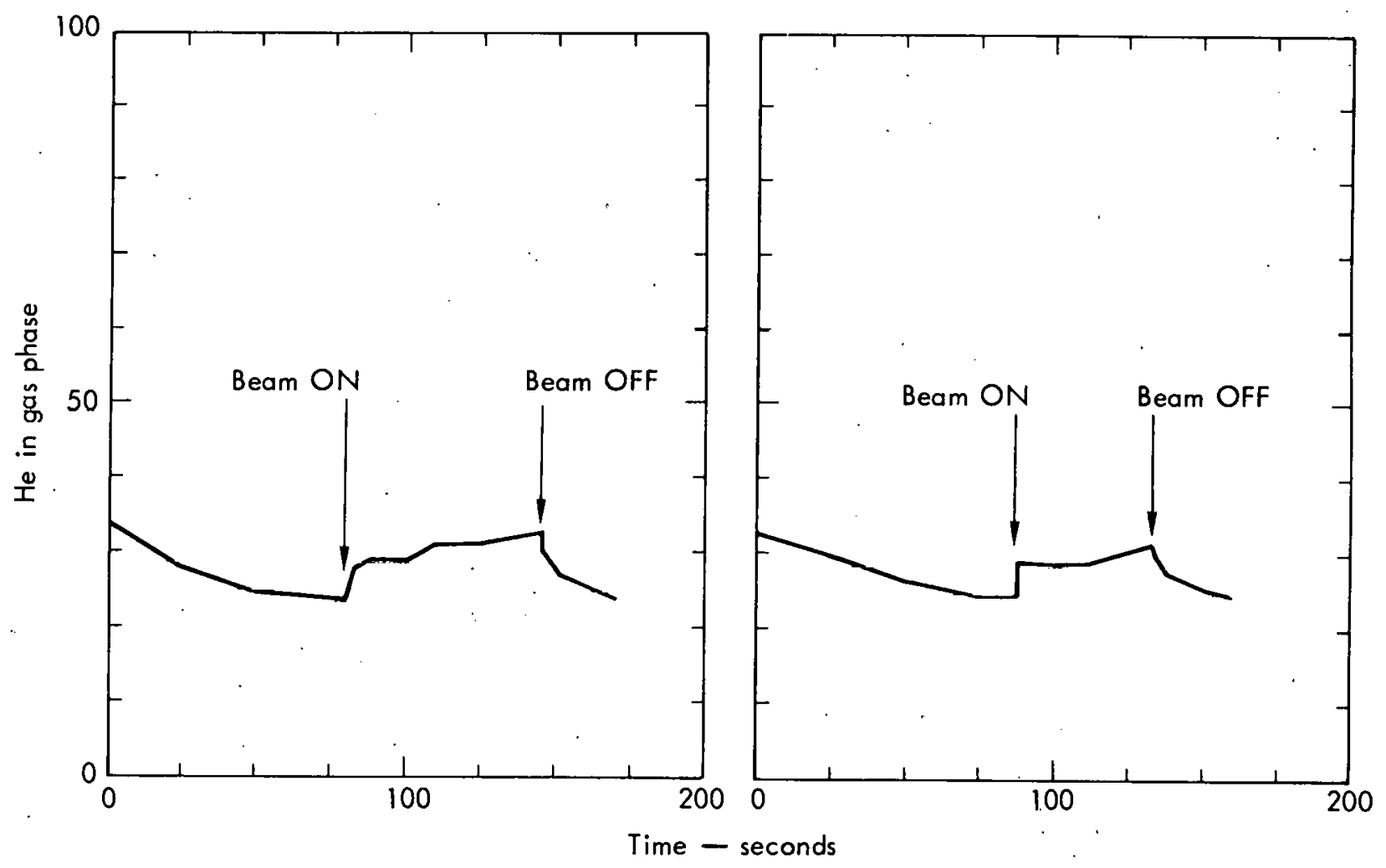

Fig. 17. $\mathrm{H}_{2}$ in gas phase during bombardment with $15-\mathrm{keV} \mathrm{D}_{1}^{+}$for two consecutive Mo films on $\mathrm{Cu}$ at $83^{\circ} \mathrm{K}$. 
hydrogen desorption observed is due to the relatively clean target. The reason for preferring this interpretation is that the measured temperature of the shield around the target was greater than $70^{\circ} \mathrm{C}$ during the bombardment. It is likely that this high temperature would make these surfaces relatively inefficient as hydrogen adsorbers even though covered with a fresh Mo film. That the deuterium level was also low during this bombardment can be inferred from the fact that the increase in the HD level was just detectable on the most sensitive scale.

The film was slowly rewarmed to room temperature where it was aged for $20 \mathrm{hr}$ before water-cooling was applied and the temperature reduced to $17^{\circ} \mathrm{C}$. The pressure in the target chamber was $6 \times 10^{-8}$ Torr when the following reference spectrum was obtained with no beam incident on the target:

$\begin{array}{lcccccccccccccc}\text { Mass No.: } & 2 & 3 & 4 & 12 & 13 & 14 & 15 & 16 & 17 & 18 & 19 & 20 & 28 & 44 \\ \begin{array}{l}\text { Peak } \\ \text { magnitude: }\end{array} & 59 & 1.05 & 0.04 & 2.3 & 0.17 & 0.42 & 1.0 & 5.7 & 18 & 73 & 0.9 & 0.6 & 29 & 2.7\end{array}$

This spectrum provides the reference spectrum for subsequent measurement on the aged Mo film under bombardment.

Figure 17 is the result of bombarding the aged film with $6 \mu \mathrm{A}$ of $15-\mathrm{keV}$ deuterons.

The temperature of the target was $17^{\circ} \mathrm{C}$. The pressure prior to bombardment was $6.3 \times 10^{-8}$ Torr and during bombardment $1.2 \times 10^{-7}$ Torr. The pressure decreased to $6.4 \times 10^{-8}$ Torr within $5 \mathrm{~min}$ after the bombardment was terminated. The comparison of Fig. 13(c) for the bombardment of a copper target at $15^{\circ} \mathrm{C}$ and Fig. 18 for the aged Mo film at $17^{\circ} \mathrm{C}$ shows a marked difference in the two target materials. The Mo appears to evolve gas at a higher initial rate.

The hydrogen increase under an immediately. subsequent bombardment is given in Fig. 19.

The distinguishing feature of the hydrogen desorption under bombardment as shown in Fig. 18 is the fast risetime compared with that for deuterium, as illustrated in Fig. 17. The magnitude of the hydrogen increase is about one order greater than the deuterium rise.

Figure 20 shows the HD desorption as a function of time. The magnitude of this desorption is about the same as the deuterium desorption. Conversion to HD on the ionization gauge elements accounts for only $5 \%$ of the HD observed, so it is concluded that the conversion to $\mathrm{HD}$ occurs largely on the surface of the target and is dependent on the deuterium concentration on the target surface.

The aged Mo film on the $\mathrm{Cu}$ target was bombarded with $6 \mu \mathrm{A}$ of $15-\mathrm{keV}$ deuterons for a period of about $500 \mathrm{sec}$. The complete high-mass spectrum, from 12-44, was rerecorded during this time. The target temperature was $18^{\circ} \mathrm{C}$. The pressure was $1 \times 10^{-7}$ Torr. All the mass numbers generally increased in signal during bombardment except water vapor (17 and 18). The largest increases were in the $13,14,15,16$, and 44 peaks which approximately doubled in magnitude. The aged Mo film was quite dirty. 


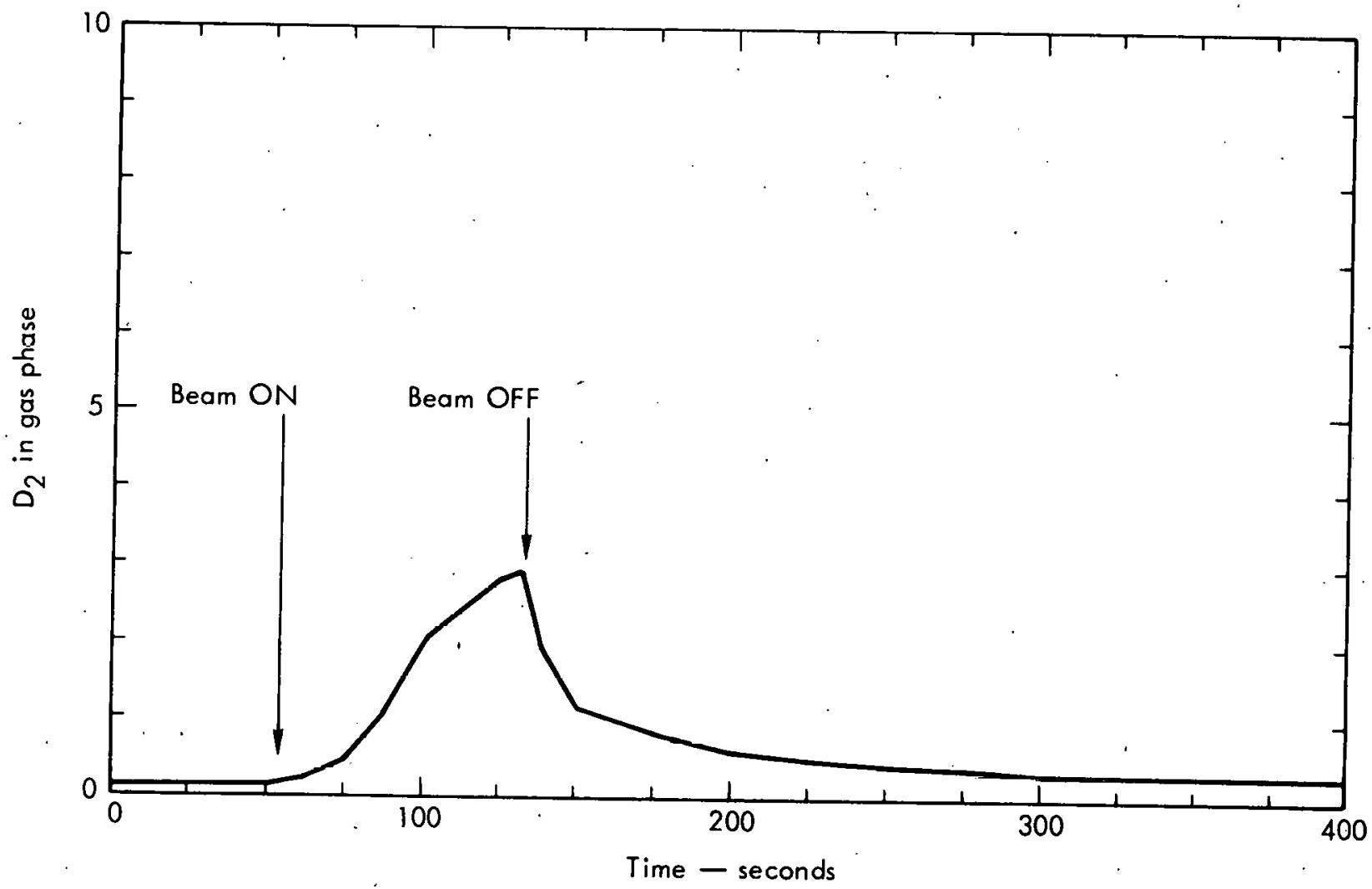

Fig. 18. $\mathrm{D}_{2}$ in gas phase during bombardment of aged $\mathrm{M} \circ$ film on $\mathrm{Cu}$ at $17{ }^{\circ} \mathrm{C}$ with a $6-\mu \mathrm{A}$ beam of $15-\mathrm{keV} \mathrm{D}_{1}^{+}$. 


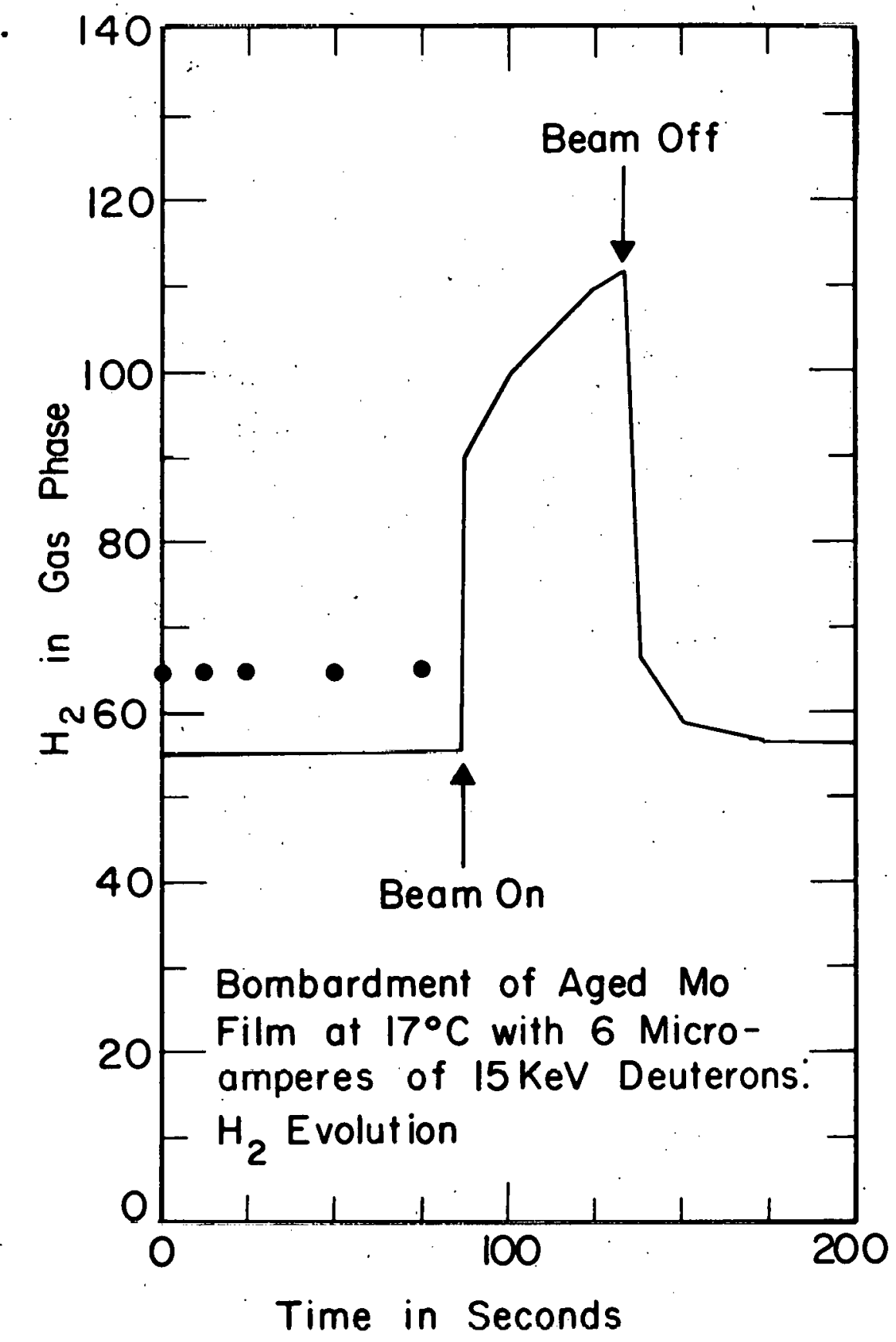

Fig. 19. $\mathrm{H}_{2}$ in gas phase during bombardment of aged Mo film on $\mathrm{Cu}$ at $17^{\circ} \mathrm{C}$ with a $6-\mu \mathrm{A}$ beam of $15-\mathrm{keV} \mathrm{D}_{1}^{+}$. 


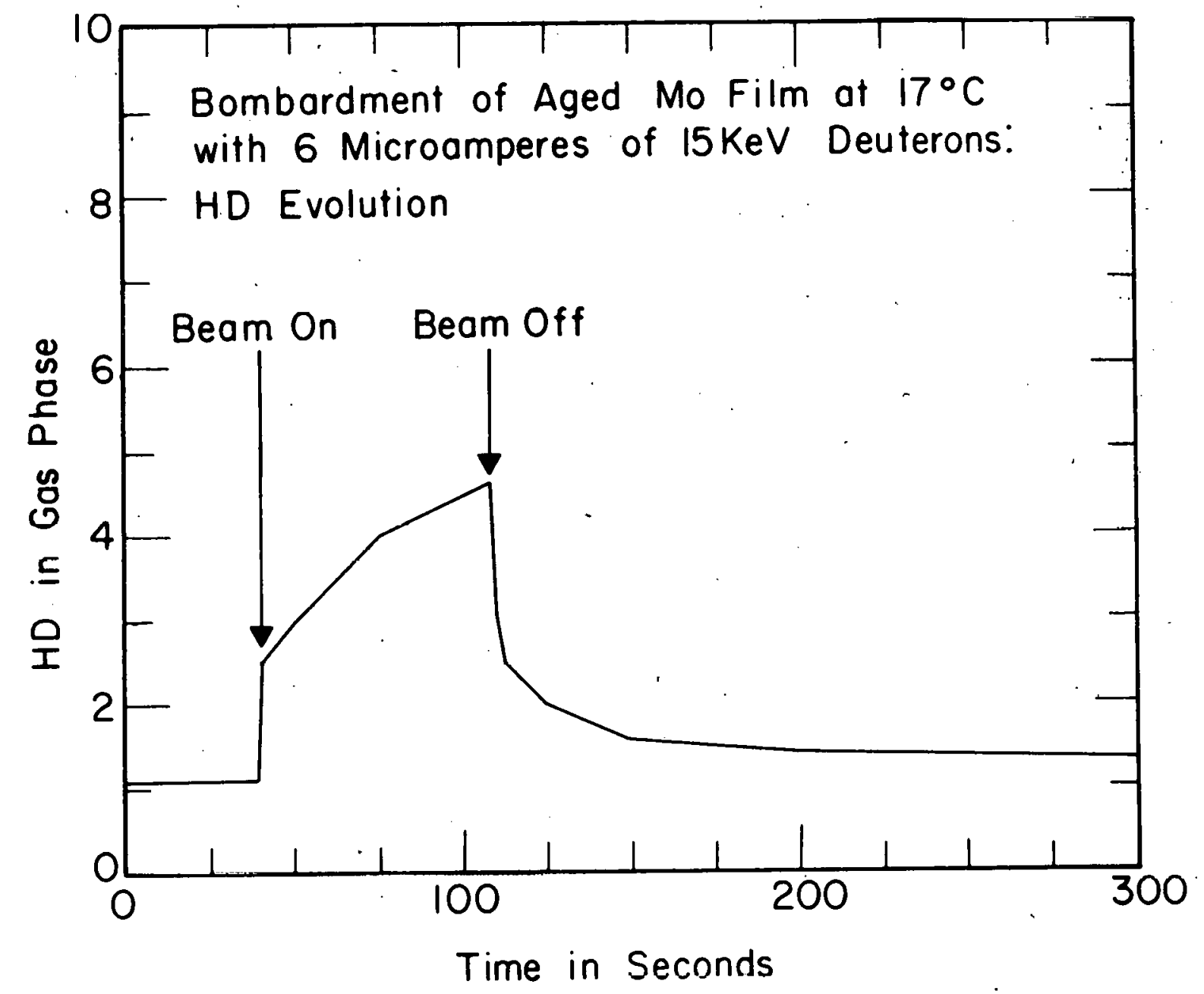

Fig. 20. $\mathrm{HD}$ in gas phase during bombardment of aged Mo film at $17^{\circ} \mathrm{C}$ with a $6-\mu \mathrm{A}$ beam of $15-\mathrm{keV} \mathrm{D} \mathrm{D}_{1}^{+}$. 
A fresh Mo film was deposited on the water-cooled target. The pressure in the target chamber decreased to $1.5 \times 10^{-8}$ Torr. With the target cooled to $18^{\circ} \mathrm{C}$, the deuterium increase under bombardment is shown in Fig. 21. The pressure increased to $2.6 \times 10^{-8}$ Torr during the bombardment. It was found that the rate of rise was reduced over the case of the aged film.

Figure 22 illustrates the difference between the $\mathrm{D}_{2}$ evolution from aged Mo films of Fig. 18 and the fresh films of Fig. 21.

After evaporation of another fresh Mo film the pressure was $1.3 \times 10^{-8}$ Torr which increased to $2.6 \times 10^{-8}$ during the subsequent deuteron bombardment. During the bombardment the hydrogen component was recorded, and is shown in Fig. 23.

The increase in the spectrum of higher masses due to bombardment at $18^{\circ} \mathrm{C}$ was also measured (see Table 6). The pressure increased during bombardment from $1.3 \times 10^{-8}$ Torr to $2.5 \times 10^{-8}$ Torr.

The largest increase is associated with the 15 and 16 mass numbers and would seem to be methane.

For the summary of the results on secondary electron emission, refer to the section on Procedure.

Table 6. Increase in spectrum of higher masses after bombardment.

\begin{tabular}{lcccccccccccc}
\hline & \multicolumn{10}{c}{ Mass number } \\
\cline { 2 - 11 } & 12 & 13 & 14 & 15 & 16 & 17 & 18 & 19 & 20 & 28 & 44 \\
\hline With beam & 0.3 & 0.3 & 0.7 & 3.1 & 4.5 & 2.1 & 6.5 & 0.45 & 0.42 & 2.7 & 0.19 \\
$\begin{array}{l}\text { Without beam } \\
\begin{array}{c}\text { Change due to } \\
\text { beam }\end{array}\end{array}$ & 0.19 & 0.98 & 0.2 & 0.7 & 1.4 & 1.8 & 6.0 & 0.25 & 0.30 & 2.3 & 0.08 \\
& 0.11 & 0.22 & 0.5 & 2.4 & 3.1 & 0.3 & 0.5 & 0.20 & 0.12 & 0.4 & 0.11 \\
\hline
\end{tabular}

\section{Tungsten Target}

Bombardment of W with 15-keV Deuterons

After the tungsten target was installed, the target chamber was baked for $24 \mathrm{hr}$ at $200^{\circ} \mathrm{C}$. On cooling to $19^{\circ} \mathrm{C}$, a reference mass spectrum was obtained with no deuteron beam incident on the target. For comparison, this was followed by a complete bombardment spectrum at a target temperature of $19^{\circ} \mathrm{C}$. A detailed record of deuterium in the gas phase was obtained during the bombardment period.

The target was cooled to $110^{\circ} \mathrm{K}$ and a low-temperature reference mass spectrum was recorded. The relative deuterium concentration in the gas phase as well as a complete mass spectrum were obtained during beam bombardment. The deuterium concentration was recorded as the target slowly reached room temperature.

The deuterium evolution was recorded as the target was heated to $300^{\circ} \mathrm{C}$. A reference spectrum was obtained for the hot $W$ target and the deuterium increase noted during bombardment. For comparison with the reference spectrum, a bombardment spectrum for the higher masses was obtained. 


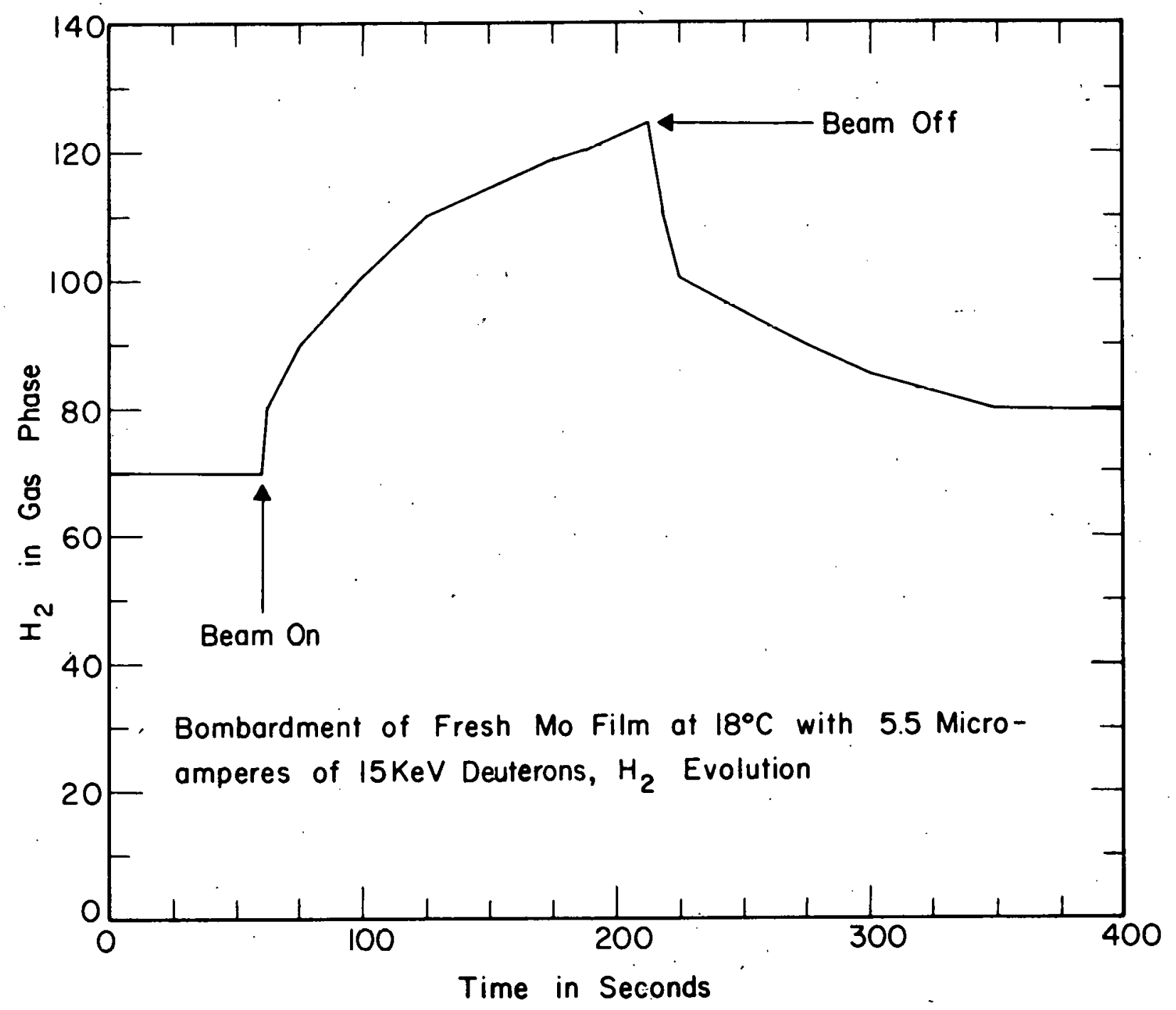

Fig. 21. $\mathrm{H}_{2}$ in gas phase during bombardment of fresh $\mathrm{Mo}$ film on $\mathrm{Cu}$ at $18^{\circ} \mathrm{C}$ with a $5.5-\mu \mathrm{A}$ beam of $15-\mathrm{keV}-\mathrm{D}_{1}^{+}$. 


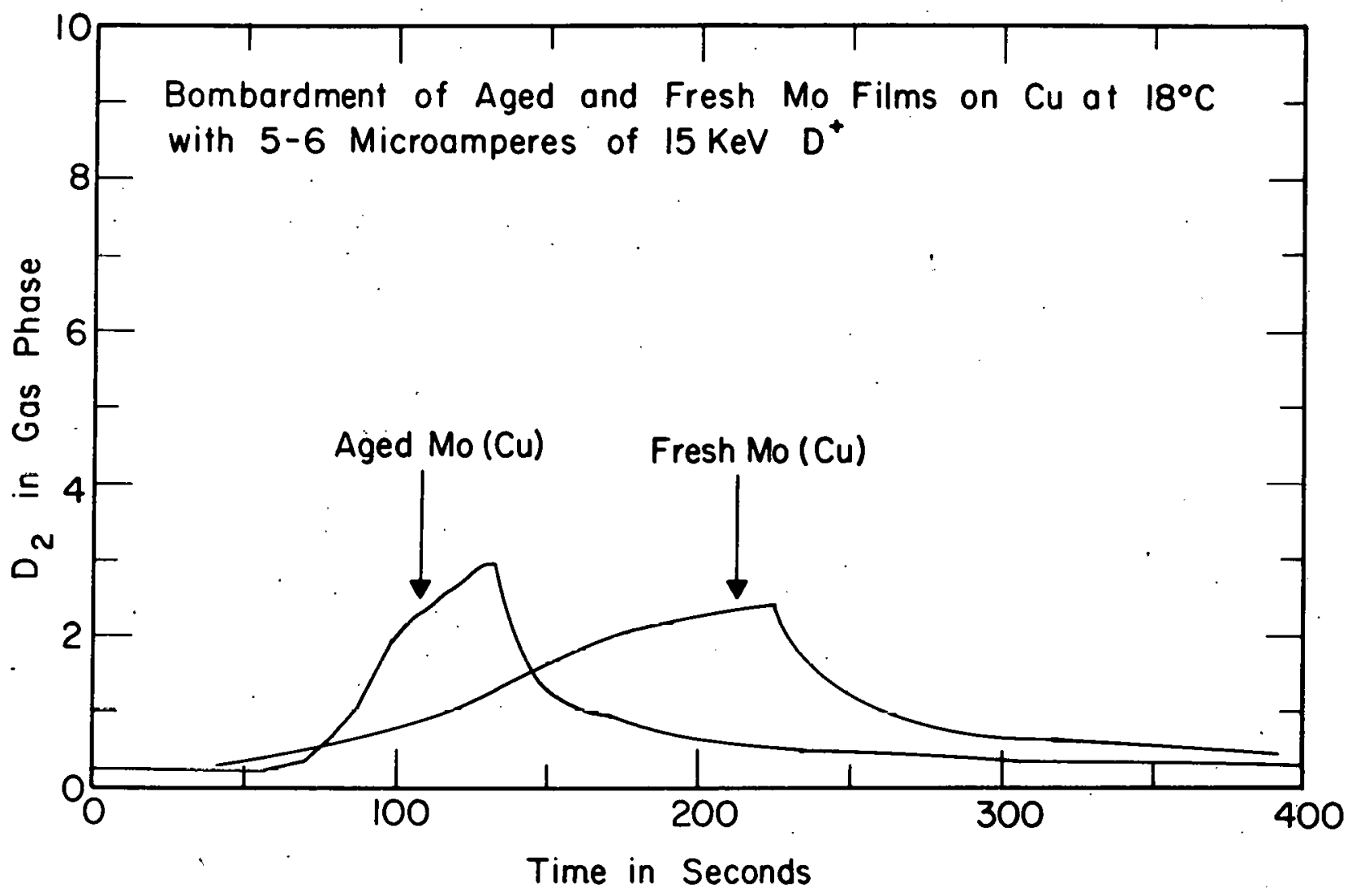

Fig. 22. Composite of Figs. 18 and 21, bombardment of ag'ed and fresh Mo films on $\mathrm{Cu}$ at $18^{\circ} \mathrm{C}$ with $5-6 \mu \mathrm{A}$ of $15-\mathrm{keV} \mathrm{D}^{+}$. 


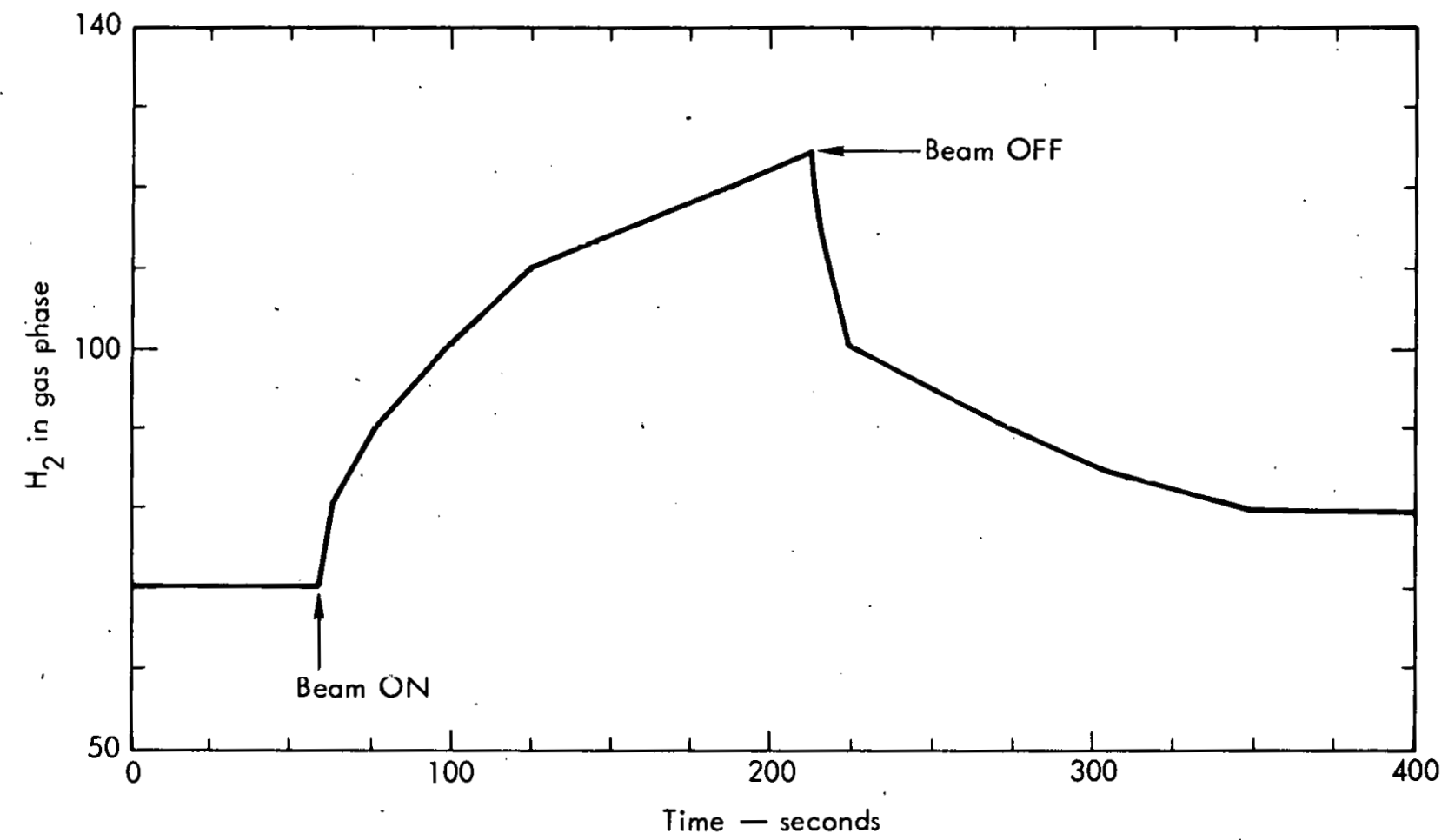

Fig. 23. 5.5- $\mu \mathrm{A}$ beam of $15-\mathrm{keV} \mathrm{D}_{1}^{+}$on fresh Mo film on $\mathrm{Cu}$ at $18^{\circ} \mathrm{C}, \mathrm{H}_{2}$ in gas phase. 
The $\mathrm{W}$ target was then water-cooled to $16^{\circ} \mathrm{C}$ and a reference spectrum was recorded. Under bombardment, the increase with time of $\mathrm{D}_{2}, \mathrm{HD}, \mathrm{H}_{2}$ and mass number 12 were recorded for the $16^{\circ} \mathrm{C}$ W target. A high mass reference spectrum was compared with a high mass bombardment spectrum.

The target was again cooled to near $100^{\circ} \mathrm{K}$ and a reference spectrum was obtained. The increase with time of $\mathrm{D}_{2}, \mathrm{HD}$ and $\mathrm{H}_{2}$ under bombarding conditions were recorded before a high mass bombardment spectrum was obtained for comparison with the reference spectrum. This last high-mass survey of increases during bombardment of the cold $\mathrm{W}$ was made for mass numbers 12 and 16. A comparison of bombardment spectra were made with the ionization gauge on and off.

After the target was heated to about $300^{\circ} \mathrm{C}$ for $60 \mathrm{hr}$, a reference spectrum was run at $22^{\circ} \mathrm{C}$ at a pressure of $4.5 \times 10^{-8}$ Torr.

\section{$\underline{\text { Results }}$}

After the target chamber was baked for $24 \mathrm{hr}$ at $200^{\circ} \mathrm{C}$, it was cooled to $19^{\circ} \mathrm{C}$. The pressure within the target chamber was $6.3 \times 10^{-8}$ Torr. A reference spectrum was obtained with no beam incident on the target.

$\begin{array}{lcccccccccccccc}\text { Mass No.: } & 2 & 3 & 4 & 12 & 13 & 14 & 15 & 16 & 17 & 18 & 19 & 20 & 28 & 44 \\ \begin{array}{l}\text { Peak } \\ \text { magnitude: }\end{array} & 113 & 0.18 & 0.03 & 3.5 & 0.5 & 1.3 & 3.4 & 10.5 & 27.5 & 105 & 0.4 & 1.2 & 25 & 2\end{array}$

This reference spectrum indicates that the target chamber is contaminated with water vapor, carbon monoxide and hydrogen, and some hydrocarbons. The system was not rebaked as would have been desirable.

The $\mathrm{W}$ target at a temperature of $19^{\circ} \mathrm{C}$ was bombarded with $5.7 \mu \mathrm{A}$ of $15-\mathrm{keV}$ deuterons. The pressure before bombardment was $6.3 \times 10^{-8}$. Torr and during the bombardment $2 \times 10^{-7}$ Torr. The mass spectrum obtained from this bombardment was as follows:

$\begin{array}{lcccccccccccccc}\begin{array}{l}\text { Mass No.: } \\ \text { Peak }\end{array} & 2 & 3 & 4 & 12 & 13 & 14 & 15 & 16 & 17 & 18 & 19 & 20 & 28 & 44 \\ \quad \text { magnitude: } & 160 & 0.9 & 0.08 & 13 & 1.8 & 4.2 & 14 & 37 & 27 & 102 & - & - & 71 & 13\end{array}$

The target shows every evidence of extreme contamination, except that the mass spectrum shows very little deuterium.

To confirm the initial burial of almost the entire beam in a $19^{\circ} \mathrm{C} \mathrm{W}$ target, the mass spectrometer was set on the mass -4 peak and the target was again bombarded with $5.7 \mu \mathrm{A}$ of $15-\mathrm{keV}$ deuterons. The result of this bombardment of room-temperature $W$ is shown in Fig. 24.

While the increase in the deuterium in the gas phase is larger than the increase associated with any of the liquid-nitrogen-cooled targets, it is smaller than the fresh Mo film target of Fig. 20 and more than a factor of two smaller than the result for the Cu target of Fig. 13(c). 


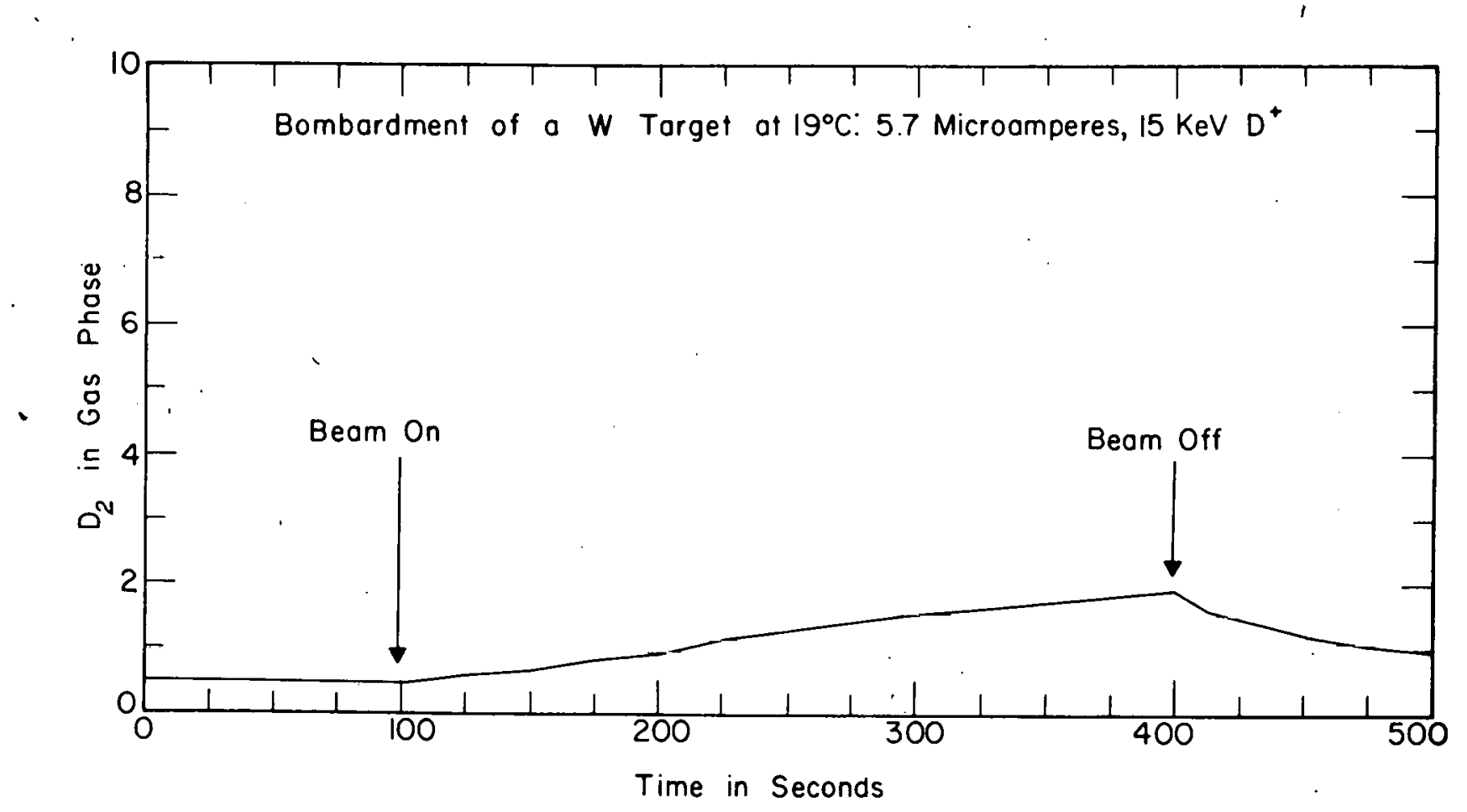

Fig. 24. 5.7- $\mu \mathrm{A}$ beam of $15-\mathrm{keV} \mathrm{D}_{1}^{+}$on $\mathrm{W}$ target at $19^{\circ} \mathrm{C}, \mathrm{D}_{2}$ in gas phase. 
When the $\mathrm{W}$ target was cooled to $110^{\circ} \mathrm{K}$, the following reference spectrum was obtained. The pressure was $7 \times 10^{-9}$ Torr:

$\begin{array}{lcccccccccccccc}\text { Mass No.: } & 2 & 3 & 4 & 12 & 13 & 14 & 15 & 16 & 17 & 18 & 19 & 20 & 28 & 44 \\ \begin{array}{c}\text { Peak } \\ \text { magnitude: }\end{array} & 22 & 0.1 & 0.02 & 1.4 & 0.4 & 0.9 & 3.7 & 6.3 & 3 & 10 & 0.2 & 0.5 & 14 & 0.1\end{array}$

The largest residual component appears to be carbon monoxide. This also seems to be an extreme reduction both in pressure and in partial pressures by simply cooling the target, and may suggest that $\mathrm{W}$ has some very special and unusual adsorptive properties at low temperatures.

The bombardment of the cold $\mathrm{W}$ target with 5.5 to $6.0 \mu \mathrm{A}$ of deuterons over a . period of $34 \mathrm{~min}$ is shown in Fig. 25. The initial pressure was $1 \times 10^{-8}$ prior to bombardment. During bombardment, the pressure increased to $6 \times 10^{-8}$ Torr. The increase in the concentration of deuterium in the target chamber is essentially not detectable on the most sensitive mass spectrometer scale. The pressure increased in the Mo pumps during the prolonged bombardment and was reduced by an evaporation of Mo at the 30-min mark. The slight increase in deuterium when the beam was turned on appears as a constant displacement, and is probably due to streaming of deuterium molecules from the high-pressure ion source. This is the most remarkable example of beam burial obscrved during the course of these experiments. The capacity of the $\mathrm{W}$ target at $110^{\circ} \mathrm{K}$ was not determined in this experiment.

But the quantity of deuterium driven into the target greatly exceeded any monolayer coverage of deuterium molecules. The complete bombardment probably placed over $10^{17}$ molecules per $\mathrm{cm}^{2}$ on the surface or in the interior of the cold $\mathrm{W}$ target.

A complete bombardment spectrum was obtained with the $W$ target at $110^{\circ} \mathrm{K}$ with $5.8 \mu \mathrm{A}$ of deuterons at $15 \mathrm{keV}$. The pressure during the bombardment was $5-6.3$ $\times 10^{-8}$ Torr.

$\begin{array}{lcccccccccccccc}\begin{array}{l}\text { Mass No.: } \\ \text { Peak }\end{array} & 2 & 3 & 4 & 12 & 13 & 14 & 15 & 16 & 17 & 18 & 19 & 20 & 28 & 44 \\ \text { magnitıde: } & 116 & 1.15 & 0.05 & 4.0 & 0.9 & 2.2 & 9.0 & 15 & 2.5 & 9.0 & 0.3 & 0.4 & 33 & 1.4\end{array}$

The increase in mass component under bombardment is largest for the most prevalent components in the system prior to bombardment; in this case, hydrogen (2) and carbon monoxide (28).

As the cold $\mathrm{W}$ target was slowly warmed to room temperature, deuterium evolution did not occur at a high rate until the target reached about $210^{\circ} \mathrm{K}$. As expected, the diffusion rate for deuterium in $\mathrm{W}$ is smaller than that in the $\mathrm{Cu}$, stainless steel or Mo.

The $\mathrm{W}$ target was then heated to $88^{\circ} \mathrm{C}$ from $20^{\circ} \mathrm{C}$ while the beam was incident on the target and the deuterium in the gas phase was recorded. This experiment was designed to determine the temperature of a discontinuity, if any, in the rate of diffusion of deuterium from the $\mathrm{W}$ target. Figure 26 shows the deuterium concentration as a function of the time of bombardment with the temperature of the target noted along 


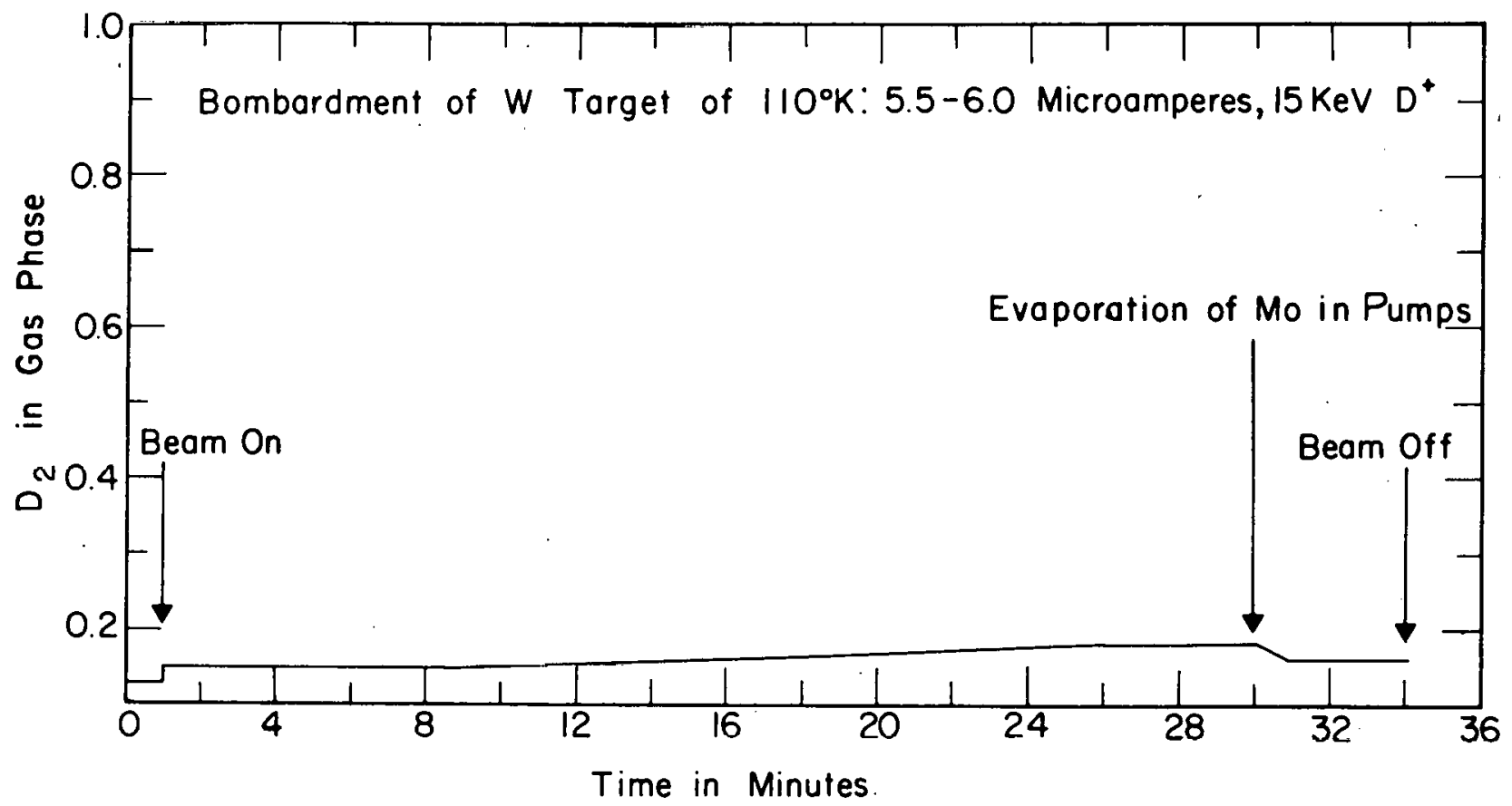

Fig. 25. 5.5-6.0 $\mu \mathrm{A}$ beam of $15-\mathrm{keV} \mathrm{D}_{1}^{+}$on $\mathrm{W}$ target at $110^{\circ} \mathrm{K}, \mathrm{D}_{2}$ in gas phase. 


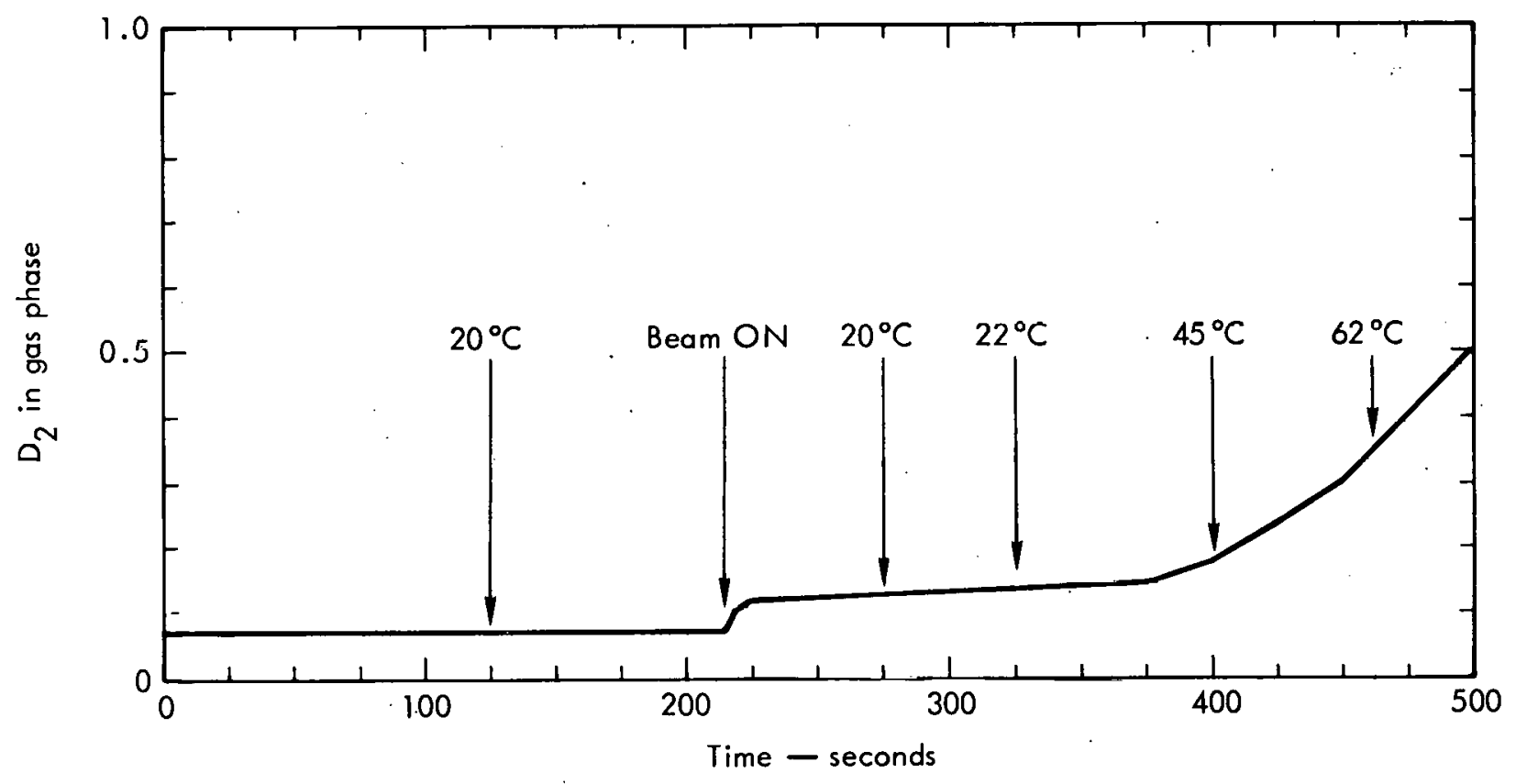

Fig. 26. $5.7-\mu \mathrm{A}$ beam of $15-\mathrm{keV}$ of $\mathrm{D}_{1}^{+}$on $\mathrm{W}$ target as target is heated from $20^{\circ} \mathrm{C}$ to $65^{\circ} \mathrm{C}, . \mathrm{D}_{2}$ in gas phase. 
the curve. No sharp discontinuity appeared, but there is an increase in rate at about $45^{\circ} \mathrm{C}$. The pressure was about $1.7 \times 10^{-7}$ Torr.

The tungsten target was heated to $302^{\circ} \mathrm{C}$ and the following reference spectrum was taken with no beam on the target. The pressure was $1.1 \times 10^{-7}$ Torr.

$\begin{array}{lllllllllllllll}\text { Mass No.: } & 2 & 3 & 4 & 12 & 13 & 14 & 15 & 16 & 17 & 18 & 19 & 20 & 28 & 44\end{array}$

Peak

$\begin{array}{lllllllllllllll}\text { magnitudc: } & 109 & 0.8 & 0.02 & 6.0 & 1 & 1.5 & 3 & 13 & 34 & 127 & - & - & 55 & 3.0\end{array}$

At these high temperatures, it would be expected that during bombardment the deuterium would immediately differ from the target to produce a high concentration of deuterium in the gas phase. But in the bombardment of the hot $\mathrm{W}$ target, the deuterium level did not reach large values. In fact, the magnitude of the mass -4 peak did not exceed 0.4 during a $50-\mathrm{sec}$ bombardment with a beam current of $5.4 \mu \mathrm{A}$. The reason for the absence of deuterium became evident when the HD peak was followed during bombardment with the target heaters on and off. It was found that in the presence of large quantities of hydrogen the deuterium evolved from the target was rapidly converted to $\mathrm{HD}$, as is shown in Fig. 27. The agent converting the deuterium to HD was shown to be the incandescent $W$ heaters by turning off the heaters. The HD concentration then decreased rapidly. The target temperature decreased only $27^{\circ}$, that is, from $330^{\circ} \mathrm{C}$ to $273^{\circ} \mathrm{C}$ while the heaters were off. It. is also of interest to note the peculiar shape of the HD versus time curve just after the $W$ heaters were turned off. The W heaters appeared to adsorb deuterated hydrogen and then create a burst of HD at a lower temperature.

While the target was at high temperature $\left(297^{\circ} \mathrm{C}\right)$, the deuteron bombardment at $6.1 \mu \mathrm{A}$ produced the following distribution:

$\begin{array}{lcccccccccccccc}\text { Mass No.: } & 2 & 3 & 4 & 12 & 13 & 14 & 15 & 16 & 17 & 18 & 19 & 20 & 28 & 44 \\ \begin{array}{l}\text { Peak } \\ \text { magnitude: }\end{array} & 200 & 4.3 & 1.6 & 20 & 2 & 6 & 16 & 42 & 40 & 140 & 3 & 0.5 & 160 & 11\end{array}$

The increase in each component due to bombardment of the hot $\mathrm{W}$ target is as follows:

$\begin{array}{lcccccccccccccc}\text { Mass No.: } & 2 & 3 & 4 & 12 & 13 & 14 & 15 & 16 & 17 & 18 & 19 & 20 & 28 & 44 \\ \begin{array}{c}\text { Peak } \\ \text { magnitude: }\end{array} & 30 & 3.5 & 1.6 & 14 & 1 & 4.5 & 13 & 29 & 6 & 13 & - & - & 105 & 8\end{array}$

The large increases are again due to hydrogen (2), methane (15 and 16), and carbon monoxide (28).

The tungsten target was water-cooled to $16^{\circ} \mathrm{C}$ and a reference spectrum was recorded with no beam. The pressure was $6 \times 10^{-8}$ Torr.

$\begin{array}{lllllllllllllll}\text { Mass No.: } & 2 & 3 & 4 & 12 & 13 & 14 & 15 & 16 & 17 & 18 & 19 & 20 & 28 & 44\end{array}$

Peak

$\begin{array}{lllllllllllllll}\text { magnitude: } & 85 & 0.7 & 0.03 & 2.1 & 0.15 & 0.45 & 1.4 & 5.75 & 16 & 62 & 0.4 & 0.4 & 14 & 1.5\end{array}$




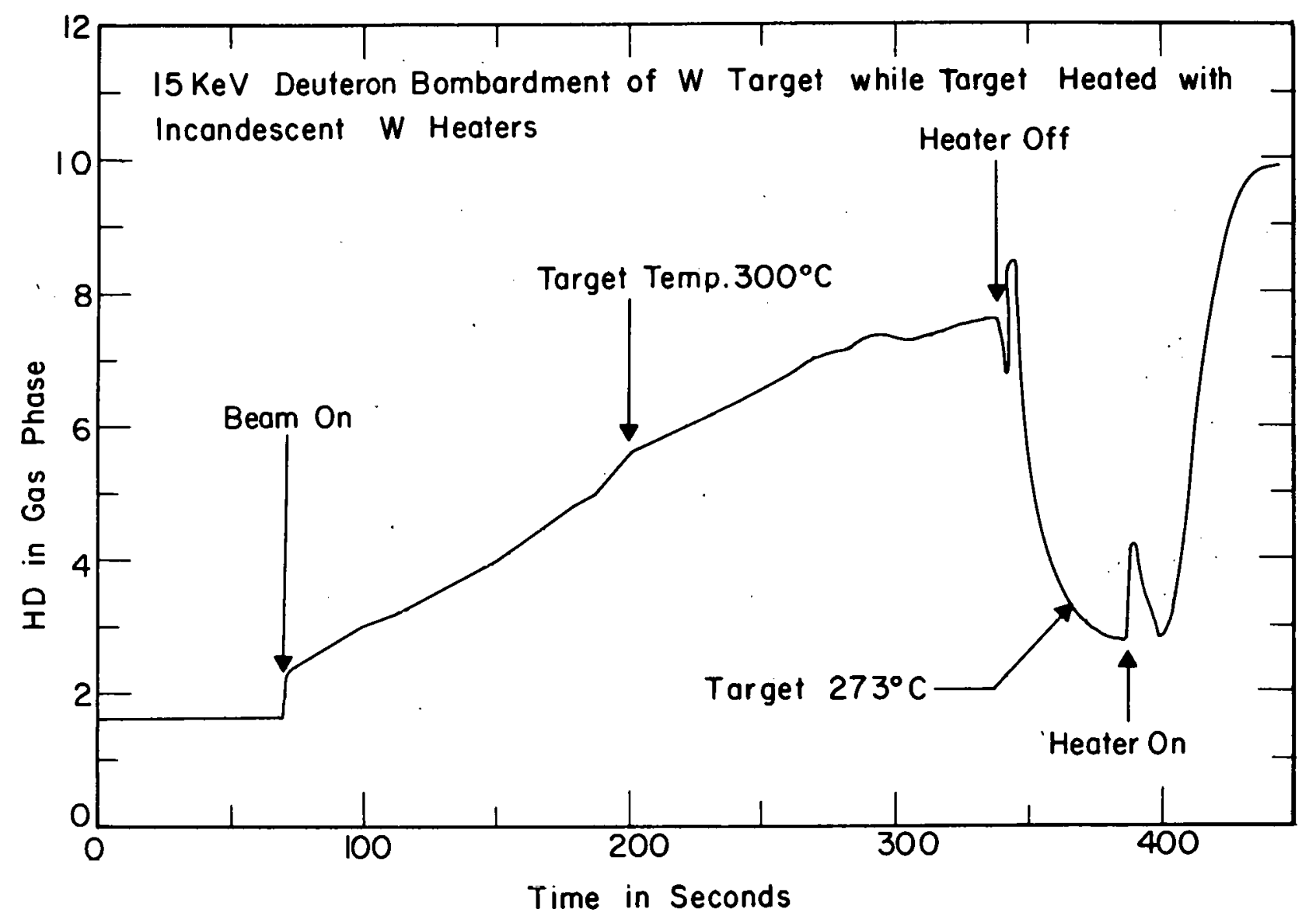

Fig. 27. 15-keV $\mathrm{D}_{1}^{+}$bombardment of $\mathrm{W}$ target while target is heated with auxiliary $\mathrm{W}$ heaters, HD in gas phase. 
It might be of some interest to list the ratio of the magnitude of the component in the reference spectrum at $300^{\circ} \mathrm{C}$ to the magnitude of the corresponding component in the reference spectrum at $16^{\circ} \mathrm{C}$.

$\begin{array}{lcccccccccccc}\text { Mass No.: } & 2 & 3 & 4 & 12 & 13 & 14 & 15 & 16 & 17 & 18 & 28 & 44 \\ \text { Ratio: } & 2.2 & 1 & 1 & 2.86 & 6.67 & 3.3 & 2.14 & 2.26 & 2.12 & 2.05 & 3.92 & 2\end{array}$

While it is not to be expected that the increase in temperature would desorb all components in the same proportion, there does seem to be a correlation between mass numbers $2,15,16,17,18$, and 44 . The deuterium level in the system is unchanged.

Under bombardment with a $5.7-\mu \mathrm{A}$ beam of $15-\mathrm{keV}$ deuterons, the increase in the deuterium level on the same scale used previously for all the work on $\mathrm{Cu}$ and $\mathrm{W}$ was 0.04 during a $75-\mathrm{sec}$ bombardment at a total initial pressure of $5.7 \times 10^{-8}$ Torr. During the bombardment the pressure increased to $1.6 \times 10^{-7}$ Torr. The target temperature was $16^{\circ} \mathrm{C}$.

During a similar bombardment, the HD increased 0.8 on the same scale with 0.1 of this due to the operation of the ionization gauge. The bombardment period was $125 \mathrm{sec}$.

The $\mathrm{H}_{2}$ increase, during a similar $150-\mathrm{sec}$ bombardment immediately after the above bombardment, was 95 on the same scale. This large increase in hydrogen indicates that the $16^{\circ} \mathrm{C}$ target was very contaminated. No such large evolution of hydrogen was observed when the hot $\mathrm{W}$ target was bombarded. Additional evidence that the target was seriously contaminated can be obtained from the total pressure increase during the bombardment. The increase was $1 \times 10^{-7}$ Torr. To confirm this conclusion, a high-mass reference spectrum (masses 12-44) was compared with a bombardment spectrum. All heavy-mass components increased during the bombardment.

The cause of the heavy target contamination was traced to a power failure, during which the system was allowed to come to forepump pressure. Although the forepump and the diffusion pumps were trapped with liquid nitrogen, serious contamination did occur.

This accidental contamination of the target provided an opportunity to investigate the effect of bombarding a seriously contaminated target which was cooled to liquidnitrogen temperatures.

The target was conled to $100^{\circ} \mathrm{K}$ and a reference spectrum was obtained at a pressure of $1.3 \times 10^{-8}$ Torr.

$\begin{array}{lcccccccccccccc}\text { Mass No.: } & 2 & 3 & 4 & 12 & 13 & 14 & 15 & 16 & 17 & 18 & 19 & 20 & 28 & 44 \\ \begin{array}{c}\text { Peak } \\ \text { magnitude: }\end{array} & 32 & 0.4 & 0.03 & 0.6 & 0.18 & 0.4 & 1.4 & 2.3 & 2.0 & 7.2 & 0.2 & 0.3 & 4.0 & 0.1\end{array}$

The $100^{\circ} \mathrm{K} \mathrm{W}$ target was now bombarded with $5.5 \mu \mathrm{A}$ of $15-\mathrm{keV}$ deuterons. The pressure increased due to bombardment from $1.2 \times 10^{-8}$ to $3.5 \times 10^{-8}$ Torr. The . mass -4 pcak - the measure of the deuterium concentration in the gas phase-increased only detectably during the bombardment. The magnitude of the increase, on the scale used above, was 0.02 and probably can largely be attributed to deuterium from the 
source. The burial of the deuterons was unaffected by the target contamination.

The mass -3 component increased by 0.8 as the pressure increased from

$1.4 \times 10^{-8}$ to $3.9 \times 10^{-8}$ Torr during the bombardment for a period of $75 \mathrm{sec}$, with the same beam.

The mass -2 component (hydrogen) increased by 80 on the same scale, as the total pressure increased from $1.9 \times 10^{-8}$ to $4 \times 10^{-8}$ Torr during an identical bombardment period. The increase in at least the very light mass components during bombardment appears unaffected by decreasing the target temperature.

There appeared to be a remarkably large quantity of hydrogen in the system.

The deuterium component in the gas phase was followed during a 500-sec deu-, teron bombardment with a beam current of $5.7 \mu \mathrm{A}$ to $6 \mu \mathrm{A}$ at $15 \mathrm{keV}$. The increase in deuterium is shown in Fig. 28 for the $W$ target and for a Mo film deposited on the W target at $23^{\circ} \mathrm{C}$. It is evident that the $\mathrm{W}$ target is slightly superior in its ability to retain deuterons.

Bombardment of Mo Films Deposited on W

The deuterium peak was followed during bombardment at $23^{\circ} \mathrm{C}$ and then a fresh Mo film was deposited on the $\mathrm{W}$ substrate. The deuterium peak was again recorded after the target had cooled to $23^{\circ} \mathrm{C}$.

The target was warmed to $90^{\circ} \mathrm{C}$ overnight and then a reference spectrum was run at a temperature of $12^{\circ} \mathrm{C}$ and a pressure of $1.2 \times 10^{-8}$ Torr. Deuterium and hydrogen increases during bombardment were obtained for the $12^{\circ}$ target.

The hydrogen peak was followed as the Mo-covered $\mathrm{W}$ target was cooled to $110^{\circ} \mathrm{K}$. Then the $\mathrm{H}_{2}$ and $\mathrm{D}_{2}$ increases were compared during bombardment. The hydrogen peak was followed during the evaporation of Mo on the liquid-nitrogen-cooled target where the effect of the bombarding deuterons on the hydrogen peak was determined. The evaporation produced a very high dark current in the mass spectrometer. The increase produced in the deuterium was recorded during bombardment for a period of 5 min. After four depositions of Mo on the liquid-nitrogen-cooled W target, the hydrogen and deuterium increases were again noted under deuteron bombardment. Increases in the $12,14,15,16,17,18$, and 28 peaks during bombardment were recorded.

An uncooled silver target was lowered into the beam and the hydrogen peak was followed while the Mo-covered target was at liquid-nitrogen temperature. Massive quantities of hydrogen were released by the bombardment of the uncooled silver target.

\section{Results}

The $\mathrm{W}$ target covered with a INo film was heated to $90^{\circ} \mathrm{C}$ for $15 \mathrm{hr}$. It was then water-cooled to $12^{\circ} \mathrm{C}$, and a reference spectrum was obtained. The pressure was $1.2 \times 10^{-8}$ Torr.

$\begin{array}{lcccccccccccccc}\text { Mass No.: } & 2 & 3 & 4 & 12 & 13 & 14 & 15 & 16 & 17 & 18 & 19 & 20 & 28 & 44 \\ \begin{array}{c}\text { Peak } \\ \text { magnitude: }\end{array} & 24 & 0.23 & 0.04 & 0.95 & 0.15 & 0.35 & 1.0 & 2.6 & 2.9 & 9.5 & 0.8 & 0.5 & 5.6 & 0.48\end{array}$




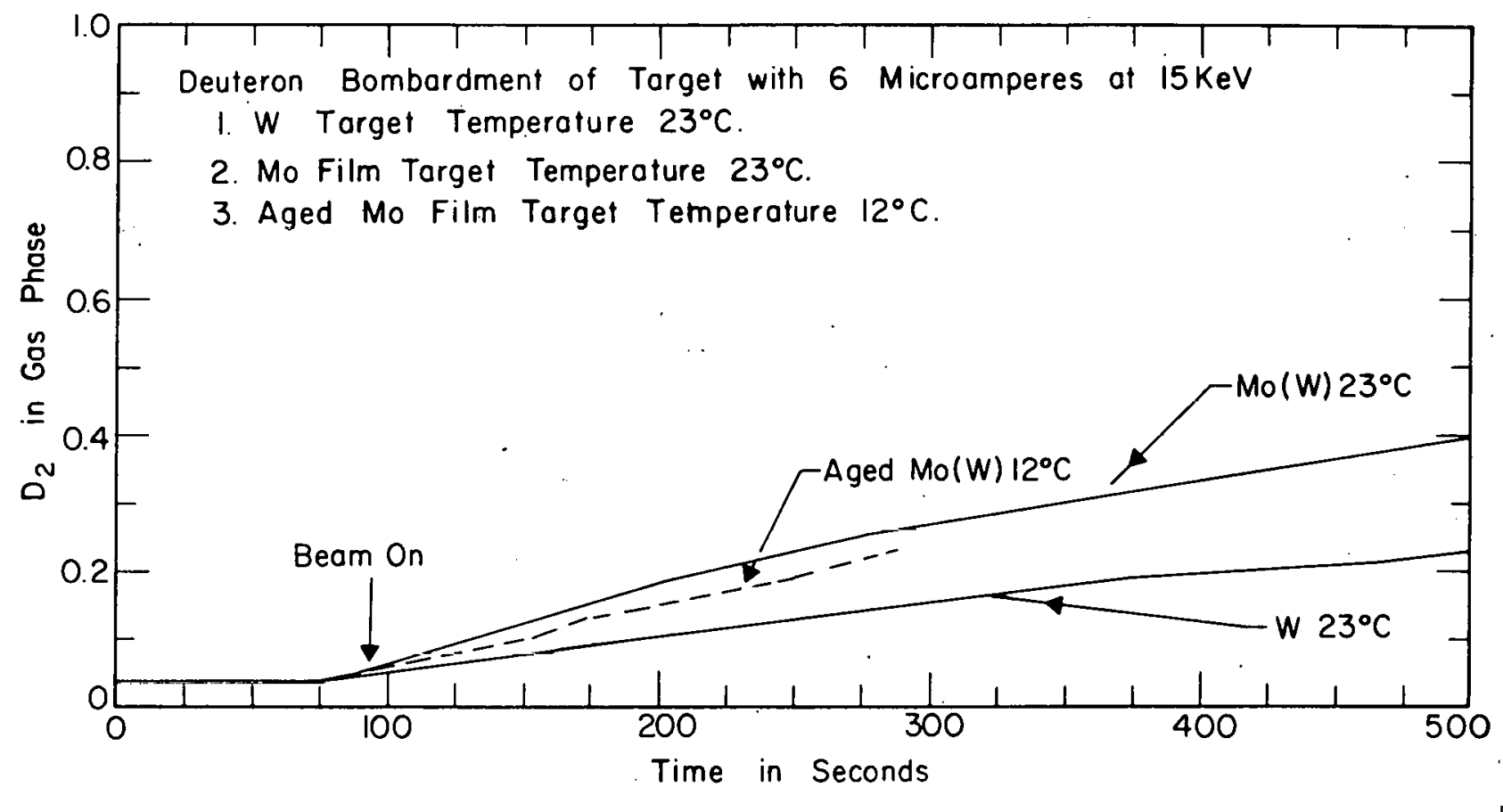

Fig. 28. $\mathrm{D}_{2}$ in gas phase for $\mathrm{W}$ target at $23^{\circ} \mathrm{C}$, Mo film on $\mathrm{W}$ target, and a Mo target during bombardment with $15-\mathrm{keV} \mathrm{D}_{1}^{+}$. 
The deuterium increase during bombardment with $6.3 \mu \mathrm{A}$ of $15-\mathrm{keV}$ deuterons on the aged Mo film on $\mathrm{W}$, Mo (W), at a target temperature of $12^{\circ} \mathrm{C}$ is shown as a dotted line on Fig. 28. The smaller slope of this curve compared to that for the fresh Mo film at $23^{\circ} \mathrm{C}$ is thought to be due to the lower temperature. The pressure increased during the $200-\mathrm{sec}$ bombardment from $1.1 \times 10^{-8}$ to $3 \times 10^{-8}$ Torr.

The hydrogen increase during bombardment of the well-baked Mo covered tungsten target at $12^{\circ} \mathrm{C}$ with $6.3 \mu \mathrm{A}$ of $15-\mathrm{keV}$ deuterons was characterized by a very rapid rise to the maximum as the beam was switched to the target. The hydrogen or mass -2 component increased by 25 on the usual scale during the $125-\mathrm{sec}$ bombardment. The record indicated that the rise to 0.8 of this maximum occurred during the first $2.5 \mathrm{sec}$ of bombardment. It is thought that the desorption of hydrogen is immeasurably fast in view of the beam conductance limitation to the mass spectrometer and the relatively slow response time of the $x-y$ recorder.

As the Mo covered target was cooled with liquid nitrogen over a 25 -min period, the hydrogen magnitude was monitored. It was found that the residual hydrogen remained constant as the total pressure decreased from $1.2 \times 10^{-8}$ to $3.6 \times 10^{-9}$ Torr during the cooling period. It was also found by intermittent gauge operation that about $20 \%$ of the residual hydrogen was produced by gauge operation.

After the target reached $110^{\circ} \mathrm{K}$, the hydrogen increase was compared to the deuterium increase during short periods of bombardment. During the deuteron bombardment with $6.6 \mu \mathrm{A}$ at $15 \mathrm{keV}$, the hydrogen increase was scaled as 20 while the deuterium increase was 0.30 . The total pressure increased from $4.6 \times 10^{-9}$ to 8.7 $\times 10^{-9}$ Torr during the bombardment.

The increase in the heavier masses was recorded for masses 12 and 16 under prolonged bombardment with the $5.5-\mu \mathrm{A}$ beam of $15-\mathrm{keV}$ deuterons. The mass -12 component was monitored during a $150-\mathrm{sec}$ bombardment; it increased slowly to a maximum change of 1.4. The rise in the mass-16 component during a 500-sec bombardment was continuously increasing until a maximum change of 7 was recorded just before beam termination. The rise appeared to approach an asymptotic limit near 7 under the prolongcd bombardment.

The complete heavy-mass spectrum was then recorded during a subsequent bombardment. The total pressure increased from $4.6 \times 10^{-8}$ to $5.4 \times 10^{-8}$ Torr during the bombardment. The beam current was $5.6 \mu \mathrm{A}$.

$\begin{array}{lllllllllllllll}\text { Mass No.: } & 2 & 3 & 4 & 12 & 13 & 14 & 15 & 16 & 17 & 18 & 19 & 20 & 28 & 44 \\ \begin{array}{l}\text { Peak } \\ \text { magnitude: }\end{array} & - & - & - & 2.8 & 0.7 & 1.5 & 6.4 & 10.2 & 2.3 & 6.7 & 0.3 & 0.3 & 22 & 0.4\end{array}$

A similar spectrum was recorded with the gauge filament off and with a beam of $5.7 \mu \mathrm{A}$.

$\begin{array}{lllllllllllllll}\text { Mass No.: } & 2 & 3 & 4 & 12 & 13 & 14 & 15 & 16 & 17 & 18 & 19 & 20 & 28 & 44 \\ \begin{array}{l}\text { Peak } \\ \text { magnitude: }\end{array} & - & - & - & 2.3 & 0.7 & 1.5 & 6.4 & 9.9 & 2.2 & 6.6 & 0.3 & 0.3 & 19 & 0.5\end{array}$


The gauge operation might produce an increase in masses 12 and 28 , but in general the gauge effect is small.

To remove the apparent contamination, the $\mathrm{W}$ target was baked at $300^{\circ} \mathrm{C}$ for $50 \mathrm{hr}$. After cooling the target to $22^{\circ} \mathrm{C}$, a reference spectrum was recorded with no beam on the target. The pressure was $4.5 \times 10^{-8}$ Torr in the target chamber.

$\begin{array}{lcccccccccccccc}\text { Mass No.: } & 2 & 3 & 4 & 12 & 13 & 14 & 15 & 16 & 17 & 18 & 19 & 20 & 28 & 44 \\ \begin{array}{c}\text { Peak } \\ \text { magnitude: }\end{array} & 225 & 0.3 & 0.03 & 1.7 & 0.25 & 0.65 & 1.8 & 4.7 & 8.5 & 27.5 & 1.6 & 0.7 & 12.3 & 0.95\end{array}$

Molybdenum was then evaporated on the liquid-nitrogen-cooled target. During evaporation the pressure increased to $4 \times 10^{-6}$ Torr in the target chamber, and $10 \mathrm{~min}$ were required to reach a low pressure of $2.1 \times 10^{-9}$ Torr after power to the evaporating filament was switched off. The pressure decreased with target temperature. At the end of this period, the bombardment with $6.5 \mu \mathrm{A}$ of $15-\mathrm{keV}$ deuterons for $50 \mathrm{sec}$ produced an increase in the hydrogen peak of 18 which is almost the same as for the $12^{\circ} \mathrm{C}$ target. The deuterium increase during a $50-\mathrm{sec}$ bombardment was 0.1 and after $5 \min 0.2$.

After four 1/2-minute evaporations of Mo on the liquid-nitrogen-cooled target, the hydrogen and deuterium increases were again noted under deuteron bombardment.

The bombardment with $6 \mu \mathrm{A}$ of deuterons at $15 \mathrm{keV}$ produced a pressure increase from $2.6 \times 10^{-9}$ to $4 \times 10^{-9}$ Torr. The hydrogen component increased by 7 and the deuterium by only 0.02 under a $50-\mathrm{sec}$ bombardment. The large reduction in the hydrogen magnitude when compared with the single fresh Mo film implies that these four evaporations for shorter times produced a cleaner Mo film. It is not certain that the very small increase in the deuterium level under this bombardment is due to the component from the target or gas diffusing from the source.

Short bombardments of about $50 \mathrm{sec}$ were completed with the mass spectrometer centered on the higher mass peaks to provide information on the initial rise for each of these peaks for a clean Mo target at low temperatures.

$\begin{array}{lccccccc}\text { Mass No.: } & 12 & 14 & 15 & 16 & 17 & 18 & 28 \\ \text { Increase: } & 0.04 & 0.02 & 0.1 & 0.17 & 0.00 & 0.00 & 0.1\end{array}$

The increase is much smaller than any observed in this experiment, and indicates that the surface is truly clean or that the contamination is adsorbed on adjacent surfaces so rapidly-that it does not reach the mass spectrometer.

It is necessary to prove that the signal obtained as a mass spectrometer spectrum was due only to target interaction with the deuteron beam and not influenced by pumping surfaces within the target chamber.

A silver foil was located within the target chamber which was used in the early part of the experiments as a calorimeter. The foil was withdrawn from the line of the beam by means of an adjustable screw protected by a bellows. During the course of these experiments with the deuteron beam, the silver foil had not been cleaned by bombardment or heating and it had been protected from the Mo vapor. It was reasoned that 
if the mass spectrometers were adjusted to monitor the hydrogen peak and the beam were incident on the cold Mo target, sudden rise in the hydrogen peak should be observed as the silver target was lowered and intercepted the beam. This rise in hydrogen should be large if the pumping surfaces in the chamber, that is, evaporated Mo and clear filament surfaces, were inactive as pumps. The rise should be small if appreciable pumping was present within the target chamber. As the silver target was lowered into the beam, an immediate and extremely large hydrogen peak was detected. The residual hydrogen was magnitude 10 at a pressure of $2.7 \times 10^{-9}$ Torr before the beam was incident on the Mo target. As the beam was incident on the cold Mo target the hydrogen peak increased to 20 , but as the silver target intercepted the $6-\mu \mathrm{A}, 15-\mathrm{keV}$ deuteron beam the hydrogen peak increased to 200 . This rise indicated that the pumping in the target chamber was not important and that the gas evolved from the cold Mo film was measurable with the mass spectrometer.

\section{Titanium Sheet Target}

Bombardment of Titanium with 15-keV Deuterons

For a $15-\mathrm{keV} \mathrm{D}^{+}$beam incident on a titanium sheet target $0.003 \mathrm{in}$. thick, the partial pressure of $\mathrm{D}_{2}$ in the gas phase was recorded during a 2-hr continuous bombardment at a flux density of $5 \mu \mathrm{A} / \mathrm{cm}^{2}$. The target temperature was $23^{\circ} \mathrm{C}$. These results are depicted in Fig. 29. There was a very slow increase in the $\mathrm{D}_{2}$ concentration in the gas phase to approximately a constant level after the first $30 \mathrm{~min}$ of bombardment. The rate of increase of $\mathrm{D}_{2}$ indicated that a large proportion of the deuteron beam was buried within the target, probably in the form of a nonstoichiometric titanium deuteride. This hypothesis was confirmed by subsequently heating the titanium target after bombardment. Almost no evolution of deuterium was found until the target temperature exceeded $400^{\circ} \mathrm{C}$. The evolution of deuterium became massive at about $500^{\circ} \mathrm{C}$. These conclusions are in accord with the radiation damage studies of Yonts and Strehlow for larger flux densities. ${ }^{62}$ It was also found as illustrated in Fig. 30 that when the titanium target was slowly increased in temperature while the deuteron beam was incident on the surface, a temperature of about $350^{\circ} \mathrm{C}$ could be attained before large quantities of deuterium appeared in the gas phase. If the beam were incident on a titanium surface at $625^{\circ} \mathrm{C}$, the evolution of deuterium would approach large values in times as short as $3 \mathrm{~min}$ as shown in Fig. 31 , the increase in other mass components due to bombardment at a target temperature of $-120^{\circ} \mathrm{C}$ was compared with the increase at a target temperature of $+330^{\circ} \mathrm{C}$. The bombardment-induced evolution of components associated with the 15, 16, and 28 mass numbers was greatly reduced at the lower temperature as indicated in Fig. 32. Figure 33 shows the effects of bombardment with $\mathrm{D}_{1}^{+}$or $\mathrm{D}_{3}^{+}$.

To summarize these results it has been shown that a deuteron flux of $3 \times 10^{13}$ ions $/ \mathrm{cm}^{2} \mathrm{sec}$ with an energy of $15 \mathrm{keV}$ is totally captured, within the preci- 
sion of the measurement, by a titanium sheet at $-120^{\circ} \mathrm{C}$. Further, it was found that at low temperatures the bombardment-induced evolution of methane and especially carbon monoxide is markedly reduced. These results are in general agreement with the published work of Simonov et al. ${ }^{59}$ 


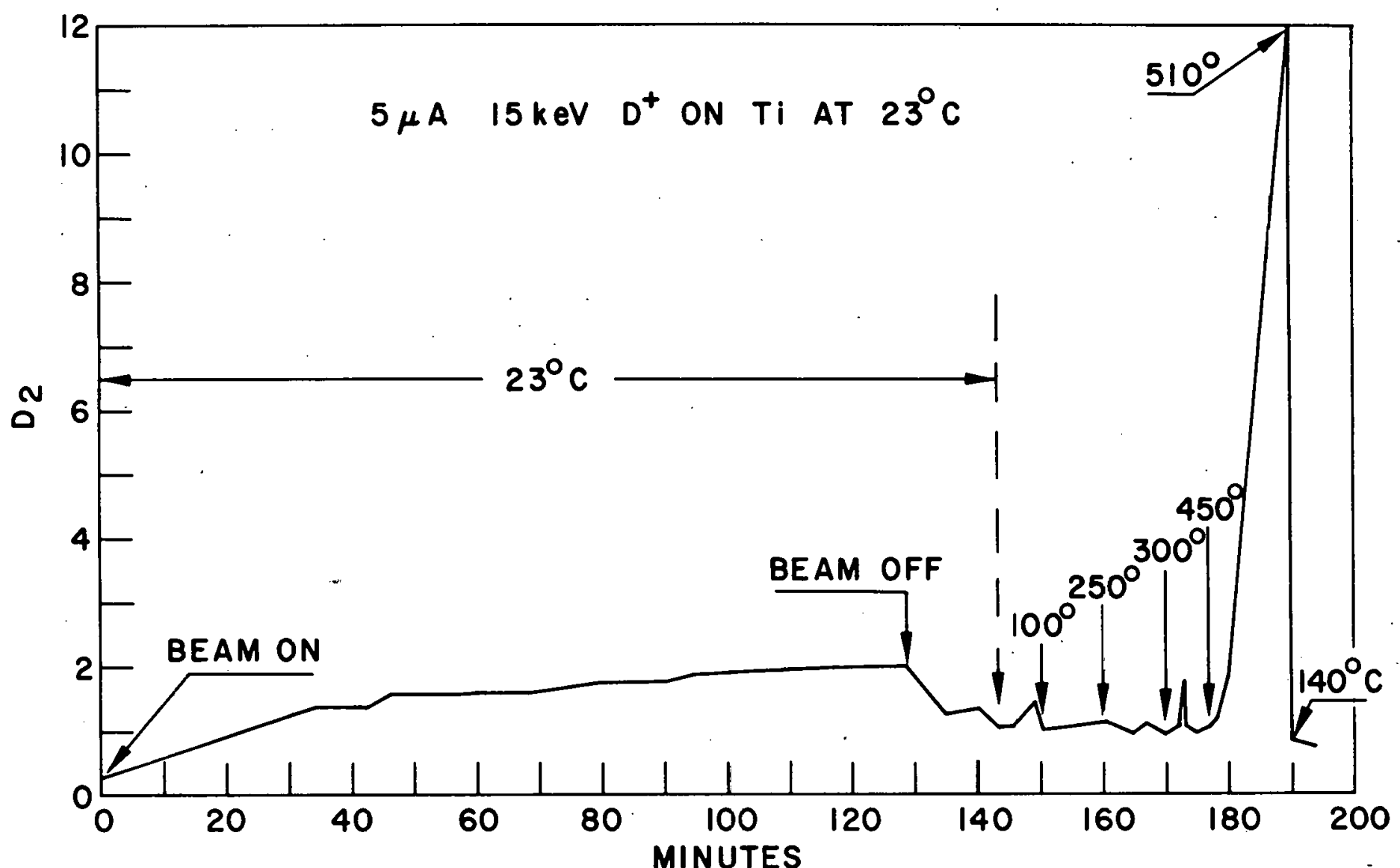

Fig. 29. $5-\mu \mathrm{A}$ beam of $15-\mathrm{keV} \mathrm{D}{ }^{+}$on $\mathrm{Ti}$ at $23^{\circ} \mathrm{C}, \mathrm{D}_{2}$ in gas phase. 


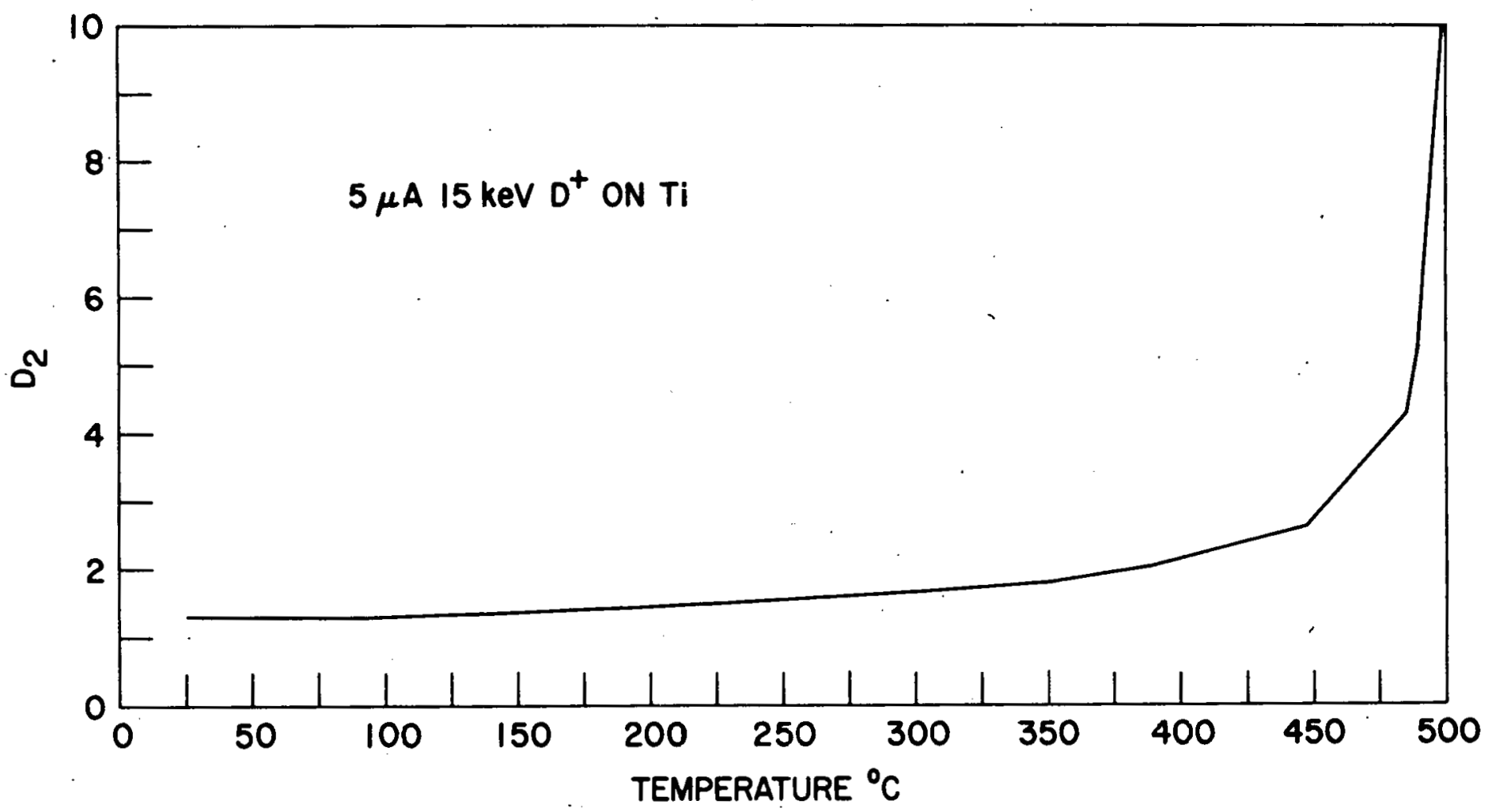

Fig. 30. 5- $\mu \mathrm{A}$ beam of $15-\mathrm{keV} \mathrm{D}{ }^{+}$on $\mathrm{Ti}, \mathrm{D}_{2}$ in gas phase, temperature from $50-500^{\circ} \mathrm{C}$. 


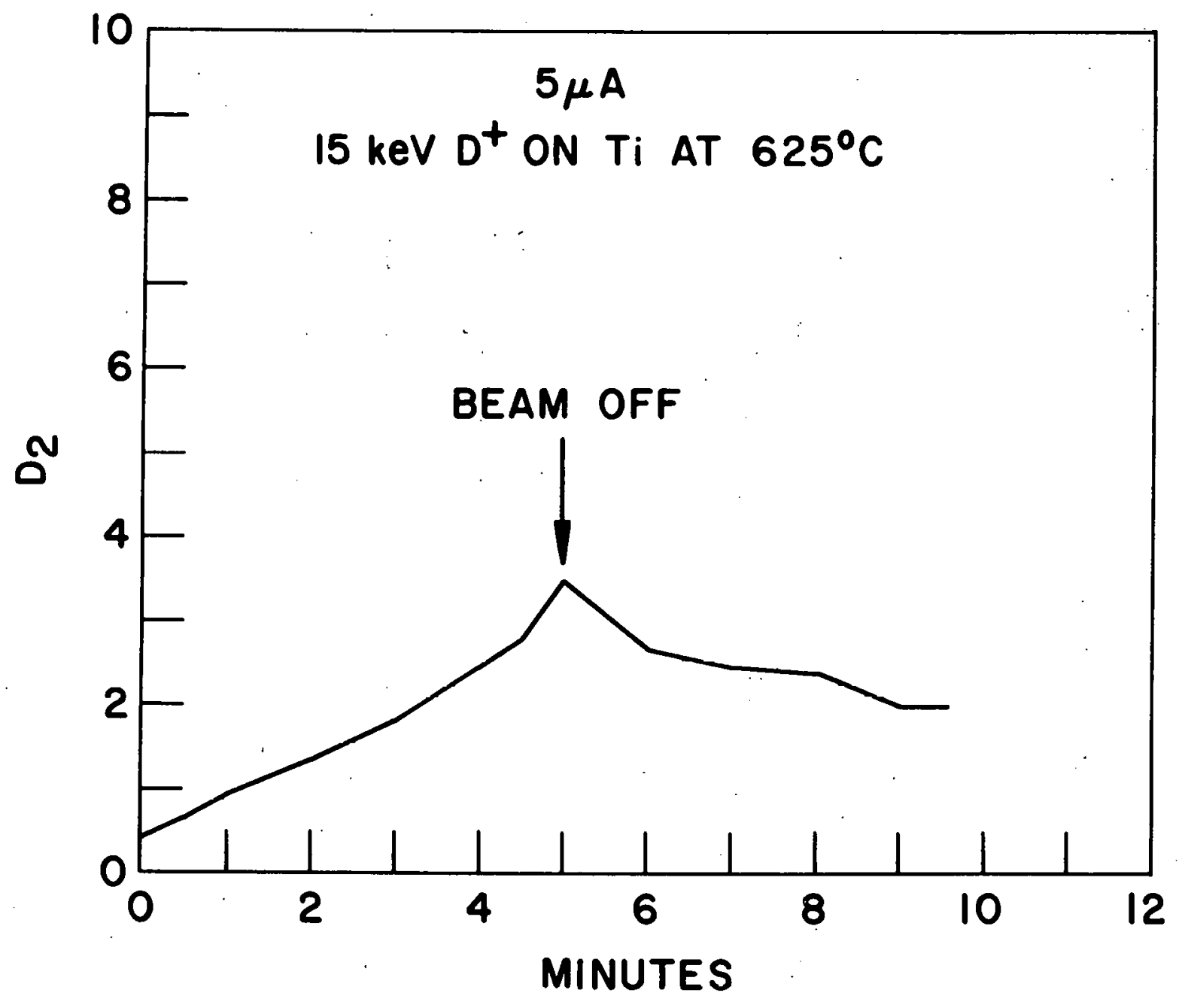

Fig. 31. 5- $4 \mathrm{~A}$ beam of $15-\mathrm{keV} \hat{\mathrm{D}}^{+}$on $\mathrm{Ti}$ at $625^{\circ} \mathrm{C}, \mathrm{D}_{2}$ in gas phase. 


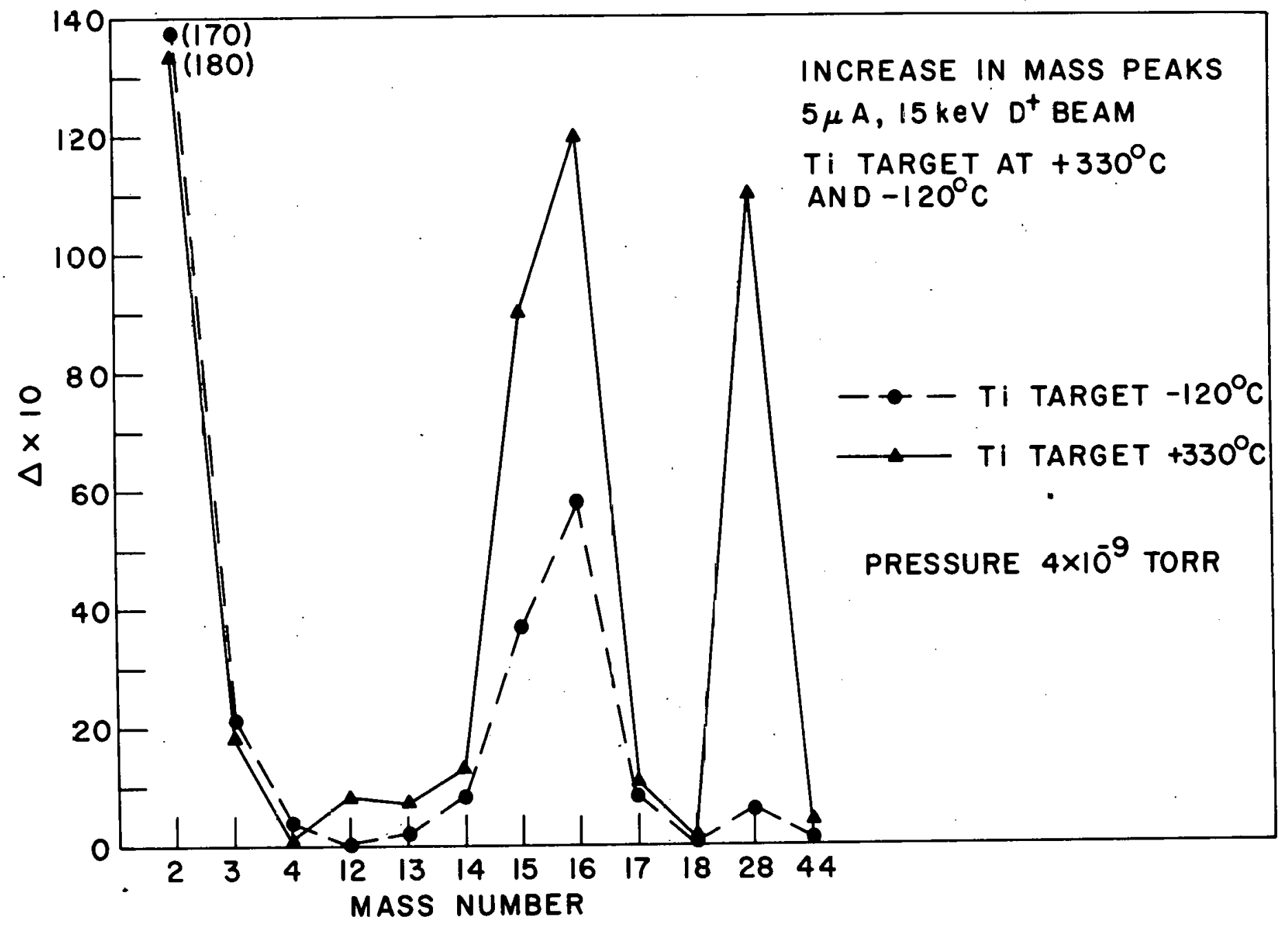
Fig. 32. Increase in mass peaks $2-44$ for $5-\mu \mathrm{A} 15-\mathrm{keV} \mathrm{D}_{1}^{+}$beam with $\mathrm{Ti}$ target at
$+330^{\circ} \mathrm{C}$ and at $-120^{\circ} \mathrm{C}$, pressure $4 \times 10^{-9} \mathrm{Torr}$. 


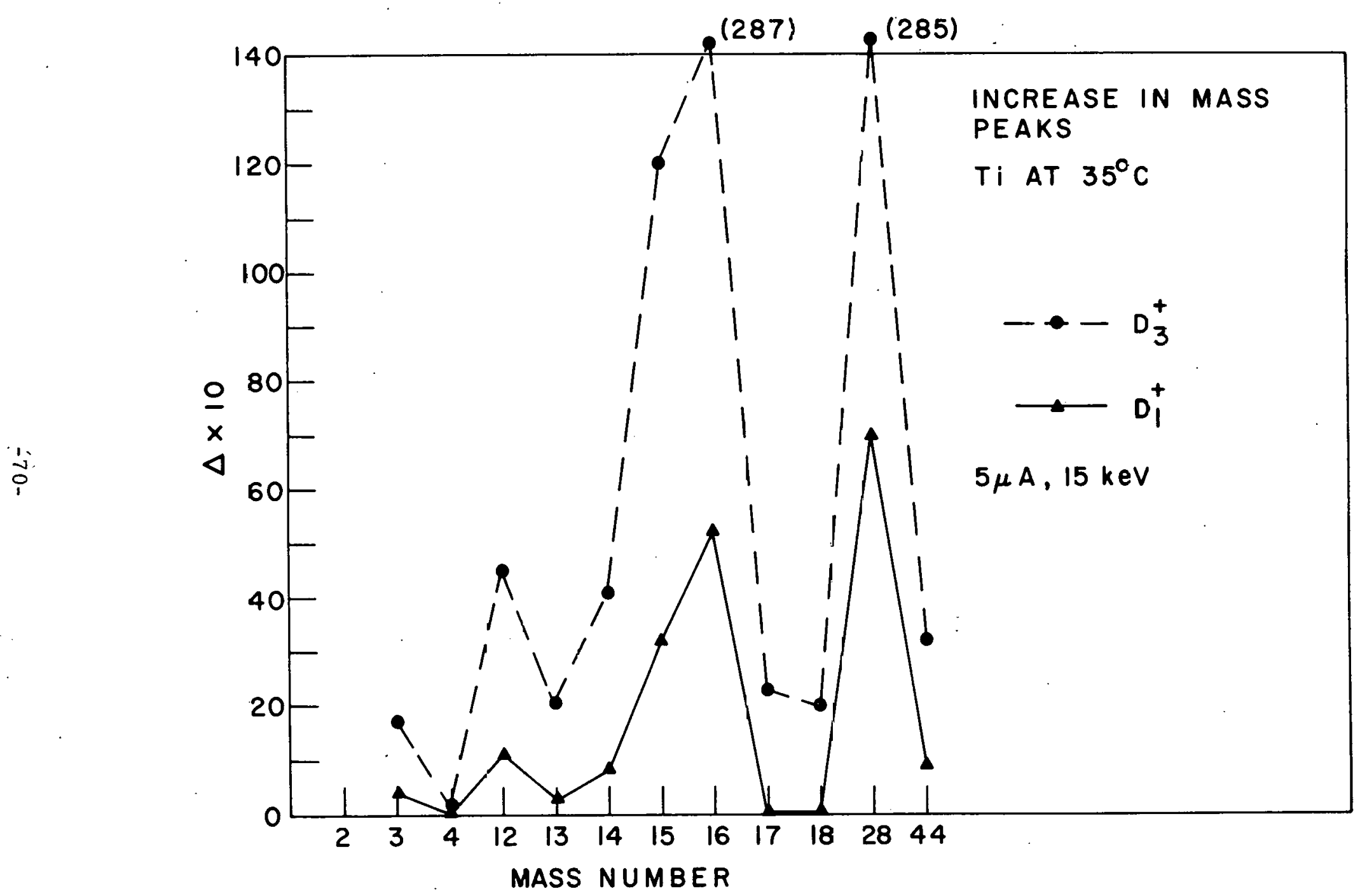
Fig. 33. Increase in mass peaks $3-44$, for $5-\mu \mathrm{A} 15-\mathrm{keV}$ beam on $\mathrm{Ti}$ at $35^{\circ} \mathrm{C}, \mathrm{D}_{3}^{+}$and
$\mathrm{D}_{1}^{+}$bombardment. 


\section{REFERENCES}

1. R. F. Post, "Impurity Radiation Losses from a High-Temperature Plasma," Danish AEC Intern. Summer Course in Plasma Physics, Riso, Roskilde, Denmark, 1960, Rept. No. 18. (Also UCRL-6130.)

2. A. H. Futch, W. Heckrotte, C. C. Damm, J. Killeen and L. E. Mish. Phys. Fluids 5, 10 (1962).

3. W. A. Perkins and R. F. Post, Phys. Fluids 6 , 1537 (1963).

4. J. F. Cranston, R. Hancox, A. F. Robson, S. Kaufman, H. T. Miles, A. A. Ware, and J. A. Wesson, in Proc. U.N. Intern. Conf. Peaceful Uses Atomic Energy, 2nd, Geneva, 1958 (United Nations, Geneva, 1958), vol. 32, p. 414.

5. A. E. Robson and R. Hancox, Inst. Elcctron. Eng. Proc. 106, Suppl. A, 47 (1959).

6. D. S. Billington and J. H. Crawford, Radiation Damage in Solids (Princeton University Press, Princeton, N. J., 1961).

7. F. Seitz, Rev. Mod. Phys. 34, 656 (1962).

8. D. S. Billington, Ed., Proc. Intern. School Physics "Enrico Fermi" XVIIl Course, Sept. 5-24, 1960, Italian Physical Society (Academic Press, New York, 1962).

9. H. S. W. Massey and E. H. S. Burhop, Electronic and Ionic Impact Phenomena (Clarendon Press, Oxford, 1952).

10. D. E. Harrison, N. S. Levy, J. P. Johnson III, and H. M. Effron, J. Appl. Phys. 39, 3742 (1968).

11. D. E. Harrison, J. Appl. Phys. 40, 3870 (1969).

12. W. L. Gay and D. E. Harrison, Jr., "Machine Calculations of Energy Transfer between a Copper Atom and Copper Crystal," to be published (1963).

13. G. K. Wehner, J. Appl. Phys. 25, 270 (1954).

14. G. K. Wehner, J. Appl. Phys. 26, 1056 (1955).

15. G. K. Wehner, in Advances in Electronics and Electron Physics, L. Marton, Ed. (Academic Press, New York, 1955), vol. 7, p. 239.

16. G. K. Wehner, Appl. Sci. Res. B5, 334 (1955).

17. G. K. Wehner, Phys. Rev. 102, 690 (1956).

18. G. K. Wehner, Phys. Rev. 108, 33 (1957).

19. G. K. Wehner, Phys. Rev. 112, 1120 (1958).

20. N. Laegreid, G. K. Wehner, and B. Mcckcl, J. Appl. Phys. 30, 374 (1959).

21. G. S. Anderson and G. K. Wehner, J. Appl. Phys. 31, 1392 (1960).

22. G. K. Wehner and D. Rosenberg, J. Appl. Phys. 31, 177 (1960).

23. N. Laegreid and G. K. Wehner, in Sixth Natl. Symp. Vacuum Technol. Trans. (Pergamon Press, New York, 1960).

24. R. V. Stuart and G. K. Wehner, in Seventh National Symp. Vacuum Technol. Trans. (Pergamon Press, New York, 1961), p. 290.

25. N. Laegreid and G. K. Wehner, J. Appl. Phys. 32, 365 (1961).

26. G. K. Wehner and D. Rosenberg, J. Appl. Phys. 32, 88'7 (1961). 
27. D. T. Goldman and A. Simon, Phys. Rev. 111, 383 (1958).

28. D. E. Harrison, Jr. and G. D. Magnuson, Phys. Rev. 122, 1421 (1961).

29. E. B. Henshke, Phys. Rev. 106, 737 (1957); 121, 1286 (1961).

30. H. Poppa, Phil. Mag. 7,1013 (1962).

31. O. C. Yonts, C. E. Normand, and D. E. Harrison, Jr., J. Appl. Phys. 31, 447 (1960).

32. N. V. Pleshivtsev, Soviet Phys. JETP 37, 878 (1960); J. Exptl. Theoret. Phys. (USSR) 37, 1233 (1959).

33. A. Weiss, L. Heldt, and W. J. Moore, J. Chem. Phys. 29, 7 (1958).

34. F. Gronlund and W. J. Moore, J. Chem. Phys. 31, 1132 (1959).

35. F. Gronlund and W. J. Moore, J. Chem. Phys. 32, 1540 (1960).

36. R. L. Hines and R. Arndt, Phys. Rev. 119, 623 (1960).

37. R. L. Hines, J. Appl. Phys, 28, 587 (1957).

38. R. S. Pease, Scuola Internationaledi Fisca "Enrico Fermi" Rendiconti, Milan, 1959, Corse 13 (1960), pp. 158-165.

39. R. C. Bradley, J. Appl. Phys. 30, 1 (1959).

40. D. B. Bills, Phys. Rev. 107, 994 (1957).

41. A. Riddoch and J. H. Leck, Roy Soc. London, Proc. 72, 467 (1958).

42. R. E. Honig, J. Appl. Phys. 29, 549 (1958).

43. R. E. Honig in Advances in Mass Spectrometry, J. D. Waldron, Ed. (Pergamon Press, New York, 1959), pp. 162-171.

44. R. C. Bradley, A. Arking, and D. S. Beers, J. Chem. Phys. 33 (1960).

45. R. C. Bradley, Phys. Rev. 117, 1204 (1960).

46. E. Ruedl and R. C. Bradley, J. Phys. Chem. Solids 23, 885 (1962).

47. E. Ruedl and R. C. Bradley, op. cit., p. 887.

48. J. H. Leck, The Bombardment of Surfaces by Positive Ions in Chemisorption,

W. E. Garner, Ed. (Academic Press, New York, 1957), pp. 162-168.

49. E. Brown and J. H. Leck, Brit. J. Appl. Phys. 6, 161 (1955). (First work on bombardment - recognized desorption of surface layers and loss of incident particle.)

50. E. Kay, "Impact Evaporation and Thin Film Growth in a Glow Discharge," in Advances in Electronics and Electron Physics, L. Marton, Ed. (Academic Press, New York, 1962), vol. 17, p. 271.

51. P. A. Redhead, J. P. Hobson, and E. V. Kornelson, "Ultrahigh Vacuum," Ibid., vol. 17, pp. 358-366.

52. J. A. Phillips, Phys. Rev. 97, 404 (1955).

33. S. K. Allison, Rev. Mod. Phys. 30, 1137 (1938).

54. S. D. Warshaw, Phys. Rev. 76, 1759 (1949).

55. W. R. Arnold, J. A. Phillips, G. A. Sawyer, E. J. Storall, Jr., and J. L. Tuck, Phys. Rev. 93, 483 (1954).

56. S. K. Allison and S. D. Warshaw, Rev. Mod. Phys. 25, 779 (1953).

57. R. L. Hines, Phys. Rev. 132, 701 (1963). 
58. J. Linhard and M. Scharff, Phys. Rev. 124, 128 (1961).

59. 'V. A. Simonov, G. F. Kleymenov, A. G. Mileshkin, and V. A. Kochnev, Nuclear Fusion 1962 Supplement - Part I, International Atomic Energy Agency, Vienna 1962, p. 325-339, AEC-tr-5589.

60. J. R. Young, J. Appl. Phys. 27, 1 (1956).

61. H. S. Massey and E. H. S. Burhop, Electronic and Lonic Impact Phenomena (Clarendon Press, Oxford, 1952), p. 247.

62. O. C. Yonts and R. A. Strehlow, J. Appl. Phys. 33, 2903 (1962).

\section{Additional References}

U. A. Arifov, Interaction of Atomic Particles with a Solid Surface (Consultants Bureau, Plenum Publ. Co., New York, 1969), (Transl. from Russian).

C. J. Beevers and D. J. Mazey, "Irradiation Damage in Mo after Energetic $\mathrm{H}^{+}$and $\mathrm{H}^{++}$Ion Bombardment," Atomic Energy Research Establishment, Harwell, Berkshirc, U. K., Rept. AERE-M-991.

H. Brooks, "Radiation Effects in Materials," J. Appl. Phys. 30, 1118 (1959). (Highenergy radiation 'damage neutrons.)

J. H. Carmichael and F. A. Trendelenburg, "Ion-Induced Re-emission of Noble Gases from a Nickel Surface," J. Appl. Phys. 29, 1570 (1958).

R. L. Cunningham, P. Haymann, C. LeConte, W. J. Moore, and J. J. Trillat, "Etching of Surfaces with 8-keV Argon Ions," J. Appl. Phys. 31, 839 (1960).

H. E. Farnsworth, R. E. Schlier, T. H. George, and R. M. Burger, "Ion BombardBombardment-Cleaning of Germanium and Titanium as Determined by LowEnergy Electron Diffraction," J. Appl. Phys. 26, 252 (1955).

E. B. Henschke, "New Collision Theory of Cathode Sputtering of Metals at Low Ion Energies," Phys. Kev. 106, 737 (1959).

R. L. Hines and R. Wallor, "Sputtering of Vitreous Silica by 20 - to 60-keV Xe ${ }^{+}$Ions," J. Appl. Phys. 32, 202 (1961).

E. Kay, "Impact Evaporation and Thin Film Growth in a Glow Discharge," in Advances in Electronics and Electron Physics, L. Marton, Ed. (Academic Press, New York, 1962), vol. 17, pp. 245-344.

S. A. Kuchai and A. M. Rodin, "Electric Absorption of a Gas by a Metal with a Vaporizing Surface," Soviet J. Atomic Energy 4, 277 (1958). (Mathematical treatment of different concentration of gases buried in surface and limits.)

P. A. Rerhea.d, J. P. Hobson, and E. V. Kornelson, "Ultrahigh Vacuum," in Advances in Electronics and Electron Physics, L. Marton, Ed. (Academic Press, New York, 1962), vol. 17, pp. 323-431.

D. P. Smith, Hydrogen in Metals (University of Chicago Press, Chicago, 1948).

O. C. Yonts and D. E. Harrison, "Surface Cleaning by Cathode Sputtering," J. Appl. Phys. 31,1583 (1960). 
LLL Internal Distribution

W. L. Barr, L-386

T. H. Batzer, L-383

J. W. Beal, L-383

D. H. Birdsall, L-387

F. H. Coensgen, L-386

C. C. Damm, L-386

J. H. Foote, L-386

T. K. Fowler, L-382

A. H. Futch, L-386

R. K. Goodman, L. -386

G. W. Hamilton, L-386

C. W. Hartman, L-387

J. R. Hiskes, L-388

E. B. Hooper, L-387

A. L. Hunt, L-386

J. S. Kane, L-401

R. W. Moir, L-386

W. E. Nexsen, Jr., L-396

J. E. Osher, L-386

G. D. Porter, L-386

R. F. Post, L-386

C. E. Taylor, $\mathrm{L}-382$

R. W. Werner, $L-383$

TID File, $I=3$

\section{External Distribution}

F. R. Scott

R. W. Bussard

K. M. Zwilsky

Division of CTR

U.S. Atomic Energy Commission

Washington, D.C.

Technical Information Center Oak Ridge, Tennessee

$\mathrm{VRM} / \mathrm{rt}$

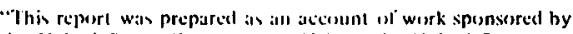

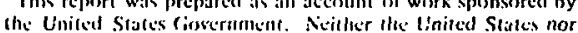

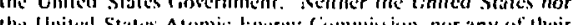

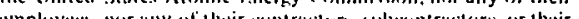

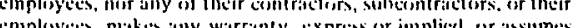

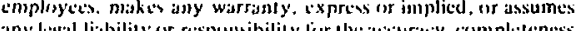
any legal liability or respons.

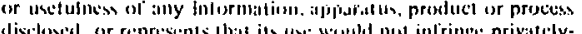
disclesed, of represents that its we woukd not inlringe privately owned rights." 